\title{
an architecture for the fourth dimension the Andorran Pavilion, Expo 2010 Shanghai
}

\author{
Katelyn Wurts, BAS
}

A thesis submitted to the Faculty of Graduate Studies and Research in partial fulfillment of the requirements for the degree of:

\section{Masters of Architecture \\ M. ARCH (Professional)}

\author{
Carleton University, Ottawa, Ontario \\ 2009-2010 \\ Katelyn Wurts (C) 2010
}




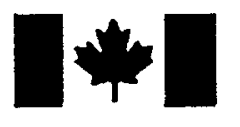

\author{
Library and Archives \\ Canada \\ Published Heritage \\ Branch \\ 395 Wellington Street \\ Ottawa ON K1A ON4 \\ Canada
}

Bibliotheque et

Archives Canada

Direction du

Patrimoine de l'édition

395, rue Wellington

Ottawa ON K1A ON4

Canada
Your file Votre référence
ISBN: $978-0-494-79580-4$
Our file Notre référence
ISBN: $978-0-494-79580-4$
NOTICE:

The author has granted a nonexclusive license allowing Library and Archives Canada to reproduce, publish, archive, preserve, conserve, communicate to the public by telecommunication or on the Internet, loan, distribute and sell theses worldwide, for commercial or noncommercial purposes, in microform, paper, electronic and/or any other formats.

The author retains copyright ownership and moral rights in this thesis. Neither the thesis nor substantial extracts from it may be printed or otherwise reproduced without the author's permission.
AVIS:

L'auteur a accordé une licence non exclusive permettant à la Bibliothèque et Archives Canada de reproduire, publier, archiver, sauvegarder, conserver, transmettre au public par télécommunication ou par l'Internet, prêter, distribuer et vendre des thèses partout dans le monde, à des fins commerciales ou autres, sur support microforme, papier, électronique et/ou autres formats.

L'auteur conserve la propriété du droit d'auteur et des droits moraux qui protège cette thèse. $\mathrm{Ni}$ la thèse ni des extraits substantiels de celle-ci ne doivent être imprimés ou autrement reproduits sans son autorisation.
In compliance with the Canadian Privacy Act some supporting forms may have been removed from this thesis.

While these forms may be included in the document page count, their removal does not represent any loss of content from the thesis.
Conformément à la loi canadienne sur la protection de la vie privée, quelques formulaires secondaires ont été enlevés de cette thèse.

Bien que ces formulaires aient inclus dans la pagination, il n'y aura aucun contenu manquant.

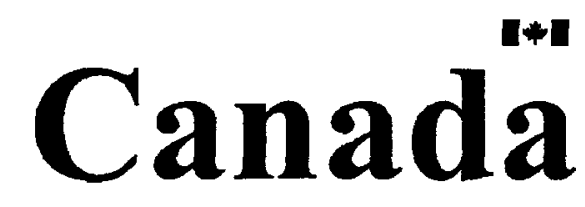




\section{Abstract}

The fourth dimension, according to mathematical theory, is a spatial expansion of the third and physical dimension. It expands the current space into a direction perpendicular to those

currently known. It is not left and right, nor forward and back, nor up and down. It is a new, undefined direction. The question is what if architecture was allowed to expand into this allusive fourth dimension? What would it reveal about the architecture and how would it be beneficial to the design? This thesis plans to explore these topics by proposing that the fourth dimension should expand on the physical world within the platform of the Internet. By designing a threedimensional physical and four-dimensional virtual pavilion for the country of Andorra in Expo 2010 Shanghai, it will be shown that the expansion into the higher dimension will reveal new architectural ideas and elements not performed or capable within the lower. 


\section{Thank You}

To my thesis advisor, Steve Fai, for his guidance and wisdom,

To Eric Malboeuf for his editing assistance,

To my family for their love and support

And most importantly to Ryan Graham, for always believing in me. 


\section{Table of Contents}

-
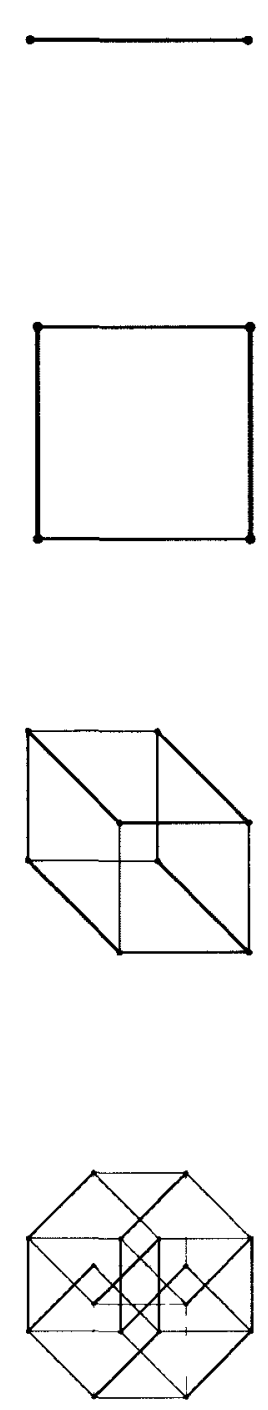

Abstract.

ii

Thank You.

List of Illustrations iii

v

\section{Introduction 1}

1 Dimensions 4

Dimensions Defined.............................................................. 4

Dimensions and Video Games............................................ 8

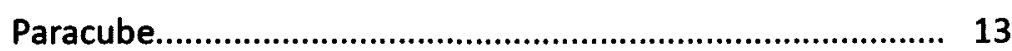

Beckman Institute Research Project.................................. 15

2 World Exhibitions 20

World Exhibition Themes...................................................... 21

Expo 2010 Shanghai - The Physical....................................... 24

Expo 2010 Shanghai - The Virtual....................................... 30

\section{The Andorran Pavilion 38}

Building Blocks of the Fourth Dimension............................... 38

APrototypeforAndorra's Pavilion in theFourth Dimension.......... 41

A Pavilion for Andorra Shanghai Expo $2010 \quad 43$

1.Andorra's Pavilion in the Third Dimension......................... 43

2.Andorra's Pavilion for theFourth Dimension...................... 51

Reflection Back Onto the Three-Dimensional........................ 56

\section{Conclusion $\quad 59$}

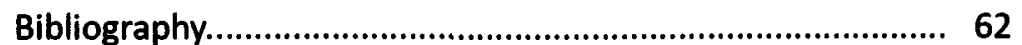

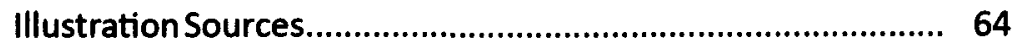

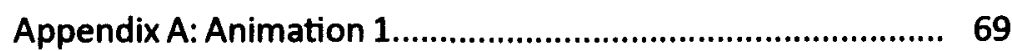

Appendix B: Animation 2 ................................................. 71

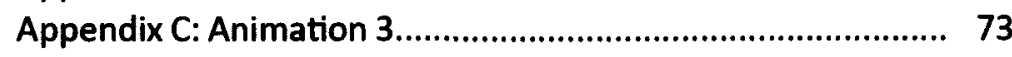

Appendix D: Animation 4.................................................... 75 


\section{List of Illustrations}
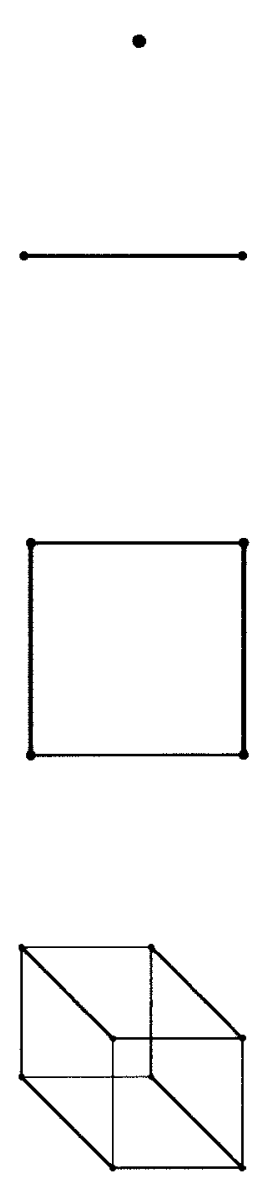

$1^{1}$ Dimensional Progression............................................................ 5

$1^{2}$ Hypercube Breakdown.................................................................... 5

$1^{3}$ Two Dimensional Interaction With the First Dimension.................. 6

$1^{4}$ Three Dimensional Theft of a Two Dimensional Object................... 7

$1^{5}$ Sphere Passing Through Flatland..................................................... 7

$1^{6}$ Super Paper Mario Storyboard........................................................ 9

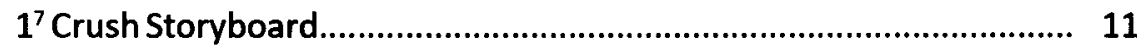

$1^{8}$ Lookley's Line Up.................................................................... 12

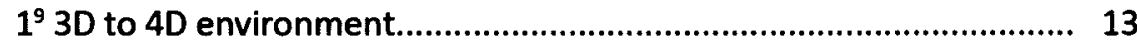

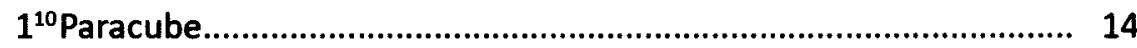

$1^{11}$ Beckman Institute Experiment..................................................... 16

$2^{1}$ German Congress Hall.......................................................... 22

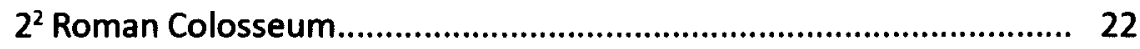

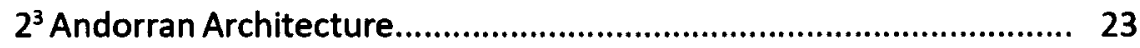

$2^{4}$ Andorran Churches...................................................................... 23

$2^{6}$ Expo 2010 Shanghai Expo Rendering........................................... 24

$2^{7}$ Expo 2010 Shanghai Expo Site.................................................... 24

$2^{7}$ Latvian Physical Pavilion Exterior................................................ 26

$2^{8}$ Latvian Physical Pavilion Interior.................................................. 26

$2^{9}$ Spanish Physical Pavilion Exterior............................................... 26

$2^{10}$ Spanish Physical Pavilion Interior............................................... 26

$2^{11}$ Slovenian Physical Pavilion Exterior.............................................. 28

$2^{12}$ Slovenian Physical Pavilion Interior............................................ 28

$2^{13}$ African Physical Pavilion Exterior................................................ 29

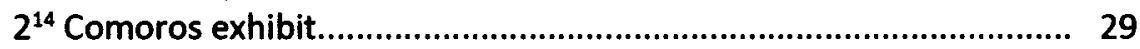

$2^{15}$ Expo Shanghai Online............................................................ 31

$2^{16}$ Expo Shanghai Online Zone C................................................... 31

$2^{17}$ Latvian Virtual Pavilion............................................................. 32

$2^{18}$ Slovenian Virtual Pavilion Layout.............................................. 34

$2^{19}$ Slovenian Virtual Pavilion.......................................................... 34

$2^{20}$ Spanish Virtual Pavilion............................................................ 34

$2^{21}$ Spanish Virtual Pavilion Entrance to Extended Virtual Space......... 35

$2^{22}$ Spanish Virtual Pavilion Extended Virtual Space............................ 35 


\section{List of Illustrations}
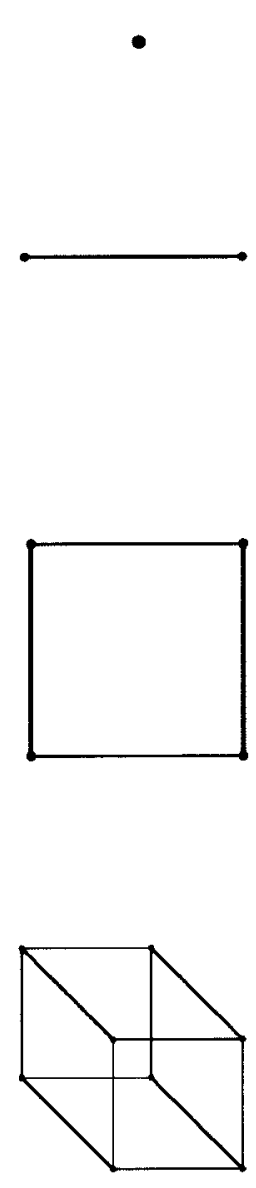

$3^{1}$ Three Dimensional Grid and Four-Dimensional Grid

$3^{2}$ Three Dimensional and Four Dimensional Axis Rotation

$3^{3}$ Unit Square, Cube, and Hypercube 40

$3^{4}$ Four-Dimensional Building Blocks.............................................. 41

$3^{5}$ Andorran Pavilion Prototype...................................................... 42

$3^{6}$ Andorran City Within the Valley................................................. 43

$3^{7}$ Andorra City Cobblestone Paths.................................................. 43

$3^{8}$ Andorran Pavilion Shell............................................................ 44

$3^{9}$ Andorran Pavilion Site Map........................................................... 45

$3^{10}$ Andorran Pavilion Exterior.......................................................... 45

$3^{11}$ Andorran Pavilion Interior.........................................................46

$3^{12}$ Andorran Pavilion Interior......................................................... 46

$3^{13}$ View of Main Exhibit From Main Balcony................................... 47

$3^{14}$ Andorra Physical Pavilion Sections............................................. 48

$3^{15}$ Andorra Physical Pavilion Plans................................................. 49

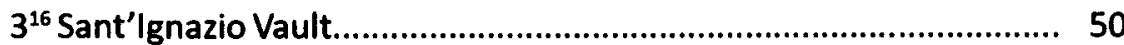

$3^{17}$ Physical Pavilion Access to 4D Pavilion............................................ 51

$3^{18}$ Online Pavilion Interface......................................................... 52

$3^{19}$ Two Dimensional Cross-Sections................................................ 53

$3^{20}$ First Cross-Section from Main Balcony......................................... 53

$3^{21}$ Four-Dimensional Colour Coded Grid.......................................... 54

$3^{22}$ Four-Dimensional Staircase....................................................... 55

$3^{23}$ Four Dimensional Exhibit.......................................................... 56

$3^{24}$ Four Dimensional Exhibit.......................................................... 56

$3^{25}$ Projection of 4D Onto Stone Wall................................................ 57

$3^{26}$ Stone Wall in Physical With 4D Influence................................... 58

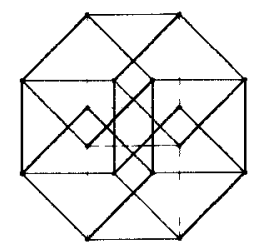


"As you yourself, superior to all Flatland forms, combine many Circles in One, so doubtless there is One above you who combines many Spheres in One Supreme Existence, surpassing even the Solids of Spaceland. And even as we, who are now is Space, look down on Flatland and see the insides of all things, so of a certainty there is yet above us some higher, purer region, whither thou dost surely purpose to lead me ... some yet more spacious Space, some more dimensionable Dimensionality, from the vantage-ground of which we shall look down together upon the revealed insides of Solid things, and where thine own intestines, and those of thy kindred Spheres, will lie exposed to the view of the poor wandering exile from Flatland, to whom so much has already been vouchsafed."'

Within this quote from the book by Edwin A. Abbott: Flatland, A Romance of Many Dimensions, the narrator, A. Square, a two-dimensional being, muses to his three dimensional companion the possibility of greater dimensions and how being brought into them would change his perspective. This idea, brought forward at the beginning of the twentieth century, to be pondered by artists, writers, mathematicians, scientists, and architects was not solely introduced through Abbott but by mathematician Charles Howard Hinton as well. Not happy with believing that the third dimension is the highest, they asked the question of how the fourth dimension can be visualized, utilized, and occupied. Unfortunately, the idea of a spatial fourth dimension became set aside and replaced with the physicist's view on the concept. This thesis plans on resurrecting and continuing forward with the forgotten view of a spatial fourth dimension and intends to show how the fourth dimension can expand three-dimensional architecture within the confines of the Internet.

If the fourth dimension is to contain architecture it needs to be defined clearly. To do this, analogy will be used with the assumption that the relationship between the third and 
fourth dimension is equal to that between the second and third or even the first and second. Once the comparison clearly defines the parameters of the fourth dimension, an examination into the dimensional relationship between the second and third dimensions found in select video games will be used to help define the relationship between the three-dimensional physical and the four-dimensional virtual contained in the Internet. With advances in computer graphics, video games have transformed from two-dimensional planes to three-dimensional worlds. By studying the transition and play between the two, the progression to the fourth dimension can be molded to contain a similar relationship. With this relationship outlined, it will be needed to explore how the fourth dimension has been tested in architecture. Architect Marcos Novak has experimented with manipulating architecture within the fourth dimension with the use of algorithms. Where he falls short to explain how the fourth dimension can be spatially understood, the University of Illinois' Beckman's Institute succeeds. By conducting a series of experiments, they strive to show that the fourth dimension is capable of being spatially understood and occupied by three-dimensional beings.

The application of the fourth dimension will expand three-dimensional architecture within the platform of the Internet. Expo 2010 Shanghai proves a perfect test case for this thesis' argument since it requests both a physical and virtual pavilion from its participating countries. Expo 2010 Shanghai and its virtual counterpart Expo Shanghai Online will place the focus on how physical architecture can be improved upon by extending it into a virtual setting. A three and four-dimensional pavilion will be designed for the unrepresented European country of Andorra. The four-dimensional design will show that the added dimension can bring new meaning to the former three-dimensional as well as show that it is capable of inhabiting a fourdimensional space within the Internet.

The Andorra pavilion design will focus on the relationship between the third and fourth dimension. It will strive to show how the fourth dimension relates to its lower counterpart and will utilize a series of techniques discussed in the precedence and the author's dimensional experiments. By maintaining a strong relationship between the dimensions, it is hoped that 
the newly introduced space will be understood by its inhabitants. If successful, the Andorran four-dimensional pavilion will show that the Internet is an ideal platform for extending threedimensional design. The four-dimensional addition will prove beneficial for expanding on ideas and architectural elements not completed or possible in the physical world. 


\section{1 dimensions}

In 1904, British mathematician, Charles Howard Hinton, wrote and published The Fourth Dimension. Although not his first work on the subject, this book refined his argument concerning a spatial fourth dimension. The text received a great deal of attention from artists, writers, musicians and other mathematicians of the time'. While Hinton's work on the fourth dimension was largely eclipsed by Einstein, this thesis extends his theory within the context of the Internet and considers what this intersection might bring to architecture.

\section{Dimensions Defined}

The fourth dimension cannot be occupied or seen while in three-dimensional space making the fourth dimension impossible to understand without the use of comparison and analogy. Conceptually, one can assume that the relationship between the fourth and third dimension is the same as that between the third and second as well as the second and first dimension. Each progression of different dimensional objects is made by moving one dimension parallel to itself in a new perpendicular direction. For example, a zero-dimensional point can be moved perpendicular to itself in the $x$ direction to become a one-dimensional line. That line becomes a two-dimensional square when it moves perpendicular to itself in the $y$ direction, and the square becomes a three-dimensional cube when it moves in the $z$ direction. Therefore, a hypercube, a four-dimensional extension of a cube, is formed when the cube moves perpendicular to itself in the unseen $w$ direction (figure $\left.1^{1}\right)^{\text {i. }}$. 


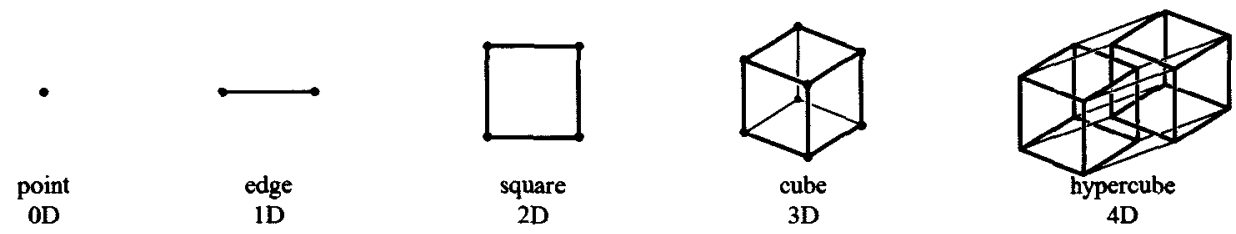

1 Dimensional Progression: illustrating the progression of a zero-dimensional point, to a one-dimensional line, to a two-dimensional square, to a three-dimensional cube, and finally to a four-dimensional hypercube.

The number of vertices, or terminal points, of the hypercube can be determined by using the following geometrical progression. A zero-dimensional point has one vertex, a onedimensional line has two, a two-dimensional square has four and a three-dimensional cube has eight vertices; therefore, a hypercube will have sixteen vertices. To determine the amounts of bounding elements in a hypercube, arithmetical progression must be applied. A point has zero boundaries, a line has two bounding points, a square has four bounding lines, and a cube has six bounding squares; therefore, a hypercube has eight bounding cubes ${ }^{\mathrm{iii}}$. The eight bounding cubes are identified in figure $\mathbf{1}^{2}$. This object is thus composed of the original three-dimensional cube, the new cube that is projected into four-dimensional space, and the six additional cubes formed from joining the sides of the other two cubes.

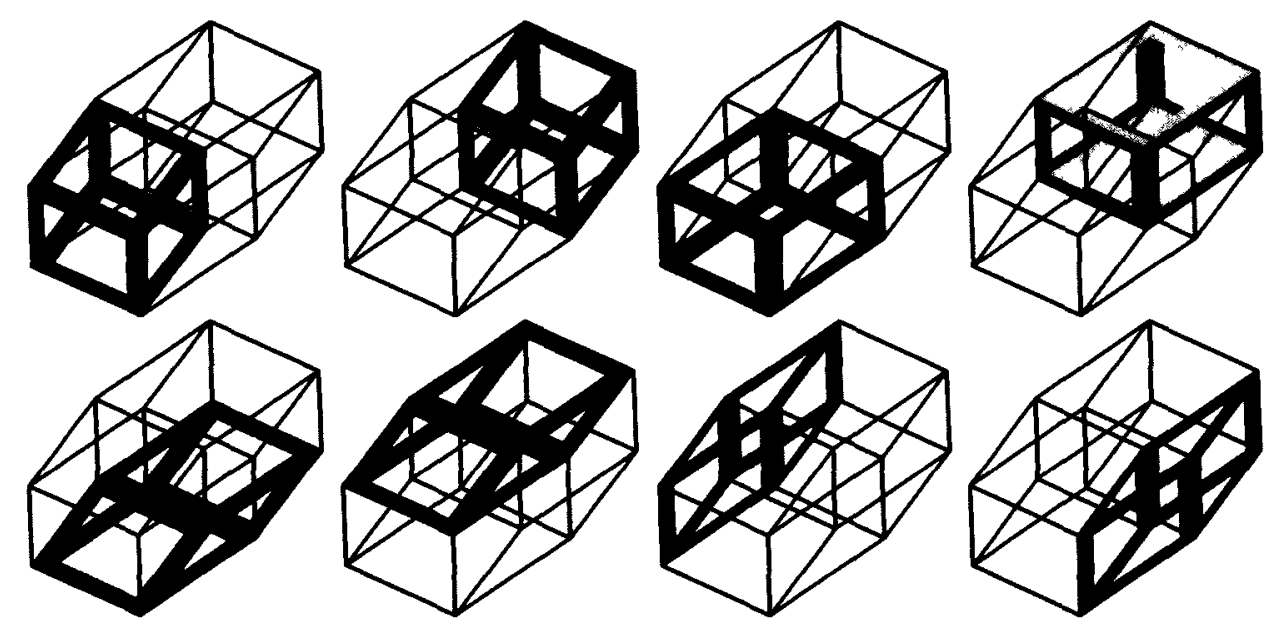

$1^{2}$ Hypercube Breakdown: A hypercube consists of eight cubes, the original, the one extruded into the $w$ direction, and the six cubes that are created from joining two cubes. 
A four-dimensional object interacts with our three-dimensional world in the same manner as any other dimension interacts with its lower dimension. For instance, a fourdimensional object remains completely invisible to three-dimensional objects, even though it might reside directly beside it, until it crosses into the third dimension. Much like how a square is not visible by a line since a line can only look forwards and backwards when the square is on its side ${ }^{i v}$. In the influential book, Flatland, A Romance of Many Dimensions by Edwin A. Abbot, the main character, A. Square, a two-dimensional being and resident of Flatland, is sent to Lineland, a one-dimensional universe. As seen in figure $1^{3}$, The King, ruler of Lineland, cannot see A. Square while the protagonist stays to the side of The King's one-dimensional world. Only once A. Square moves to intersect the line does the King see him².

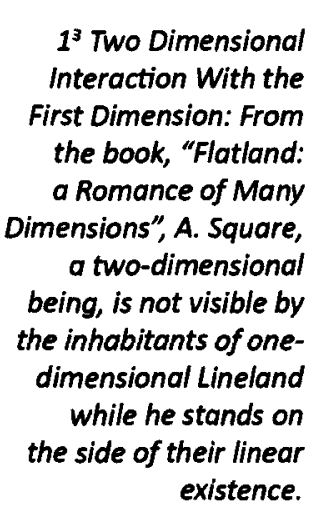

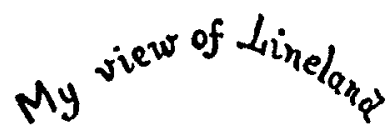
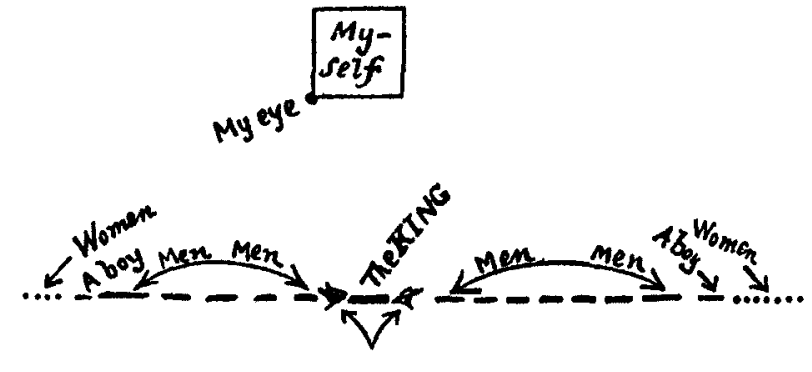

A four-dimensional being can see and touch inside any three-dimensional being or object, just like a three-dimensional being can touch the centre of a two-dimensional object ${ }^{\mathrm{vi}}$. For example, a two-dimensional creature could put all their valuables behind a locked door that is also guarded. There is no plausible way for anyone to steal the treasures without damage to the door or the guard noticing; at least, no way within their two-dimensional understanding of space. A three-dimensional creature can see down into the two-dimensional world and remove the treasures from above (figure $\left.1^{4}\right)$. No damage occurs to the door and the guard is never the wiser. Similarly, a four-dimensional creature could take all of a person's valuables that are locked within a jewelry box without ever opening the lid. 


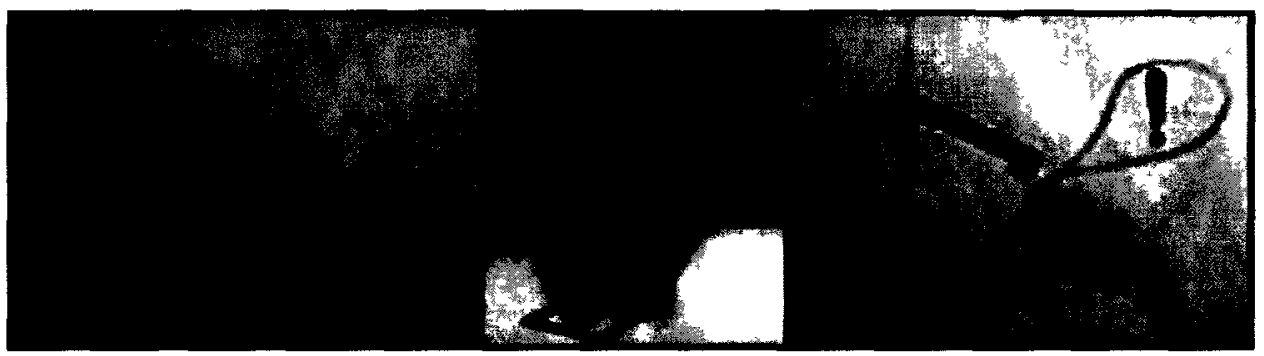

$1^{4}$ Three Dimensional Theft of a Two Dimensional Object: Taken from the French film, "La Quatrieme Dimension" by Jean Painleve, a higher dimensional being can steal a lower dimensional object that is safely locked away within its own dimension.

When a four-dimensional object enters our three-dimensional world, it does not take on its true form but appears, in fact, as its three-dimensional counterpart. This is similar to how a three-dimensional object appears two-dimensional when crossing a two-dimensional world ${ }^{\text {vii }}$. In the novel Flatland, A Romance of Many Dimensions, A. Square encounters a sphere in his twodimensional world. The sphere appears as a circle and when he moved up and down through Flatland, the circle appears to have different diameters ${ }^{\text {viii, }}$ as illustrated in figure $1^{5}$. Therefore, a four-dimensional hypercube would appear within three-dimensional space as its lower dimensional counterpart, the cube. Any three-dimensional object could, in fact, be a crosssection of a four-dimensional one. Although the four-dimensional object cannot appear fully in three-dimensional space, it is possible to deduce its true form by viewing its cross-sections as it moves through this dimension. Similarly to how A. Square can understand how the sphere is formed through its cross-sections.

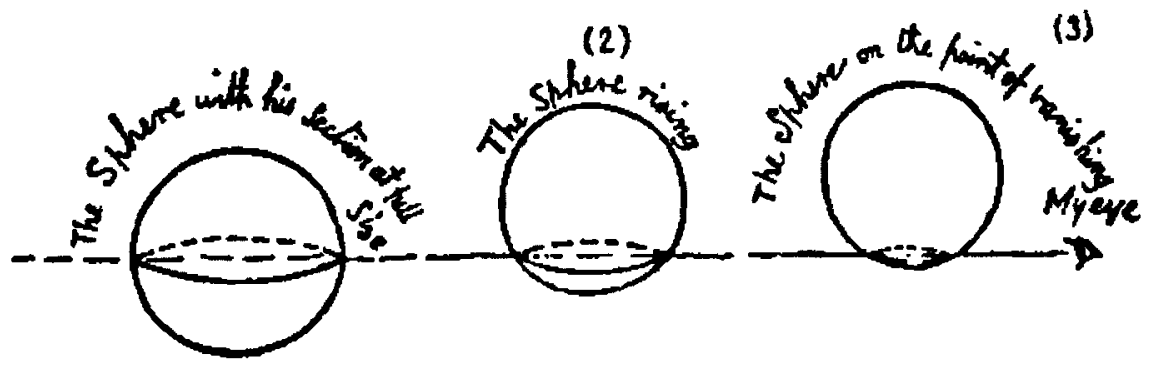

$1^{5}$ Sphere Passing Through Flatland: From the book, "Flatland: A Romance of Many Dimensions" illustrating that when a sphere passes through a two-dimensional plane it appears as different size circles. 
Lastly, a four-dimensional object will have a three-dimensional shadow (also referred to as a projection), much like how a three-dimensional object has a two-dimensional shadow. This implies that the shadow or projection of a three-dimensional object can appear within the two-dimensional world but will appear only as an oddly shaped two-dimensional surface. Only when understanding how the third dimension affects the second, does its existence mean more than just another two-dimensional shape. To this effect, a four-dimensional object's shadow or projection will appear within our three-dimensional world as only another solid.

With the addition of a fourth dimension, closed rooms become accessible and hidden spaces become viewable. This play between spatial dimensions creates new relationships in architecture. The transition between two dimensions, be it between the fourth and third or even the third and second, can reveal qualities of architecture that may be otherwise hidden.

\section{Dimensions and Video Games}

The entertainment industry has comically explored the comparison of the second and third dimensions through a few select video games. Since traditional video games often portrayed the world as two-dimensional, the shift to three-dimensional worlds, brought on by improvements in graphics and technology, revealed new possibilities in spatial exploration. Three video games, Super Paper Mario, Crush, and Looksley's Line Up, take the progression between the second and third dimension as a basis for building a playful story and innovative game play, and therefore, can help us to understand and design for inter-dimensional movement.

Super Paper Mario ${ }^{i x}$ begins as a traditional two-dimensional side scrolling plattorm game for the Nintendo Wii. In this game, Mario, the protagonist, must rescue his friends and save the world from an inter-dimensional rift that the villain has created. Shortly into the story, Mario is given the ability to "flip" into the third dimension for a short period of time; therefore extending the traditional Super Mario Universe into the newly discovered $z$ direction. Quickly it is revealed that the Super Mario Universe is constructed of both paper-thin two-dimensional objects and 
those with three-dimensional depth. In order to find hidden items, avoid enemies, and solve puzzles, those playing the game must learn to manipulate and alternate between the second and third dimensional universes. For example, certain items important to the completion of the game can only be found by flipping into the third dimension. This way, once the jump is made, items previously unavailable or invisible can now be reached beyond two-dimensional obstacles. Furthermore, sometimes enemies that are too difficult or even impossible to defeat in two-dimensional worlds often turn out to be only "paper-thin" within the third dimension; hence the flip between dimensions makes it possible to beat them or avoid them completely. When encountering such an enemy, if the user chooses to flip to a three-dimensional mode it is not always assumed that all elements from the two-dimensional world will follow suit. In this case, said enemy remains as a two-dimensional mono-pixel-thin sheet and no longer poses a threat. In this game, one of the most important tasks is the solving of puzzles. Within the two-

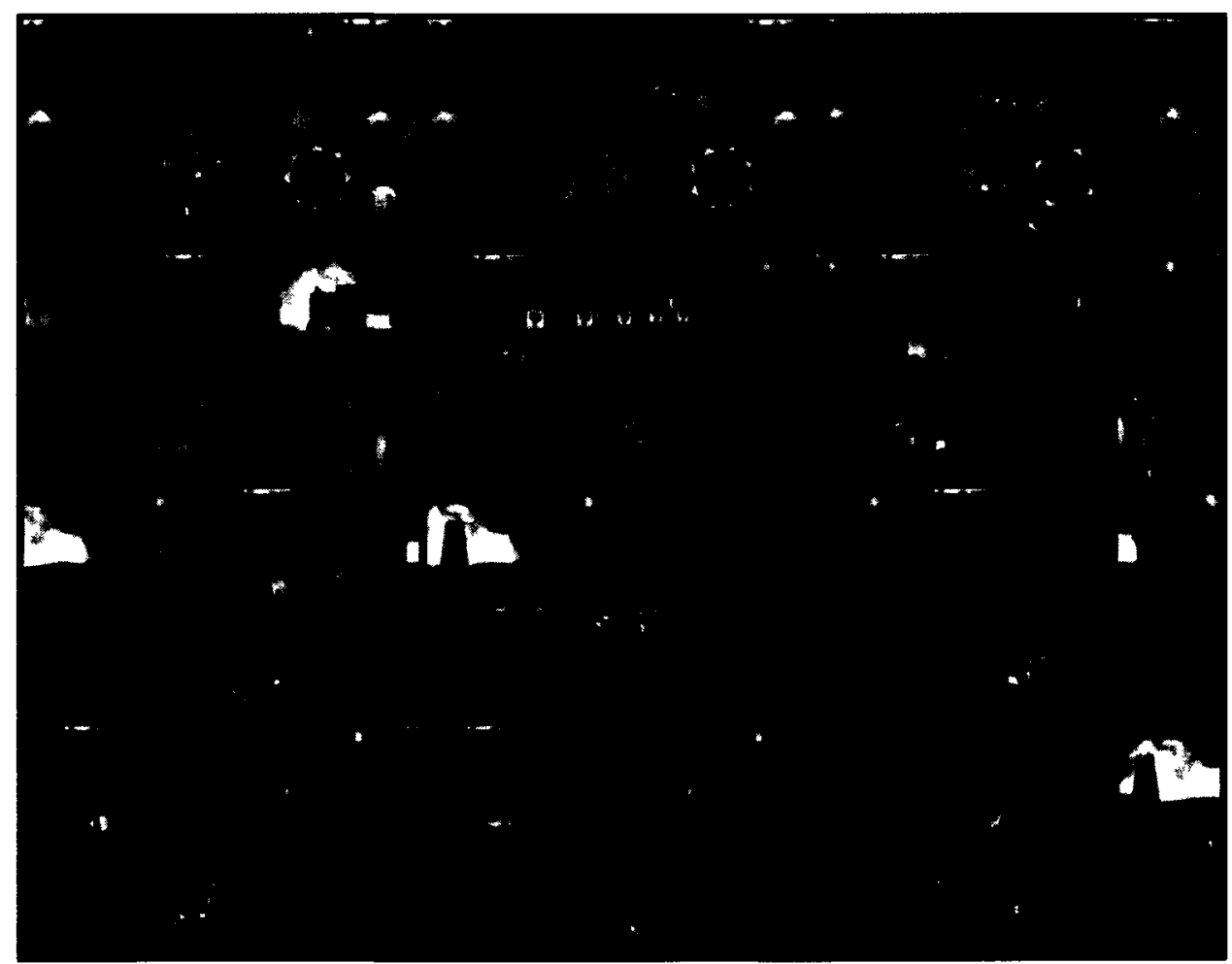

$1^{6}$ Super Paper Mario Storyboard: In this storyboard illustration of the game Super Paper Mario, when the character faces an impassable foe, such as the monster in the first row, he can flip into the higher dimension and avoid the enemy entirely. Here, the monster is only two-dimensional and easily avoidable once viewed in the third dimension. Entering into the third dimension might also reveal paths that were not visible in the second dimension. Areas not previously accessible or known become open to the character, such as the path shown in row three. 
dimensional world, the player may come across a wall that blocks the exit from that particular level. By flipping into the third dimension, the previously impassable wall appears to have an opening that Mario can easily squeeze through. Interestingly, Super Paper Mario explores the idea that not all items have to be expanded into the new dimension. This allows for more secret paths and items to be revealed when the character is "flipped" into the higher dimension. Figure $1^{6}$ explains the dimensional relationship found in the game through stills of the gameplay.

With a concept similar to Super Paper Mario, Crush ${ }^{x}$ presents an environment where the protagonist, Danny, must solve puzzles in order to find a cure for his insomnia. Unlike Super Paper Mario, this particular quest begins in a three-dimensional universe. Players, when confronted by a puzzle, must subsequently "crush" or collapse this three-dimensional world into its respective two-dimensional equivalent; essentially, removing one of the dimensional axes. Within Crush, unlike Super Paper Mario where the view was limited to a single elevation view in the second dimension and only a specific one-point perspective in the third-dimension, there is the option to change between different three-dimensional views. This freedom in the latter dimension allows the player to orbit around their character as to acquire the best angle to play the game. Once the desired view is chosen, the player has the option to crush the particular axis of that particular perspective. For instance, when one is faced with a wall too high to jump, the player's view can be altered to a top view that is then crushed down into two dimensions. In the case of a vertical object like a wall, it is the " $y$ " axis that is removed. This change in dimension now renders the previously impassable object's height irrelevant, therefore making its conquest as easy as if no wall was ever present. Similarly, one can find themselves at the end of a three-dimensional environment with no plausible exit or signs of game continuity. Just like the situation with the wall, once the correct view is chosen and the now irrelevant spatial axis condensed, a new opportunity arises and the game continues. Figure $1^{7}$ depict such obstacles and how they are resolved by the crushing of a particular axis. Crush adds an extra layer of complexity to the dimensional comparison by allowing multiple views in both dimensions. This method makes the player better aware of how each dimension relates to the other. 


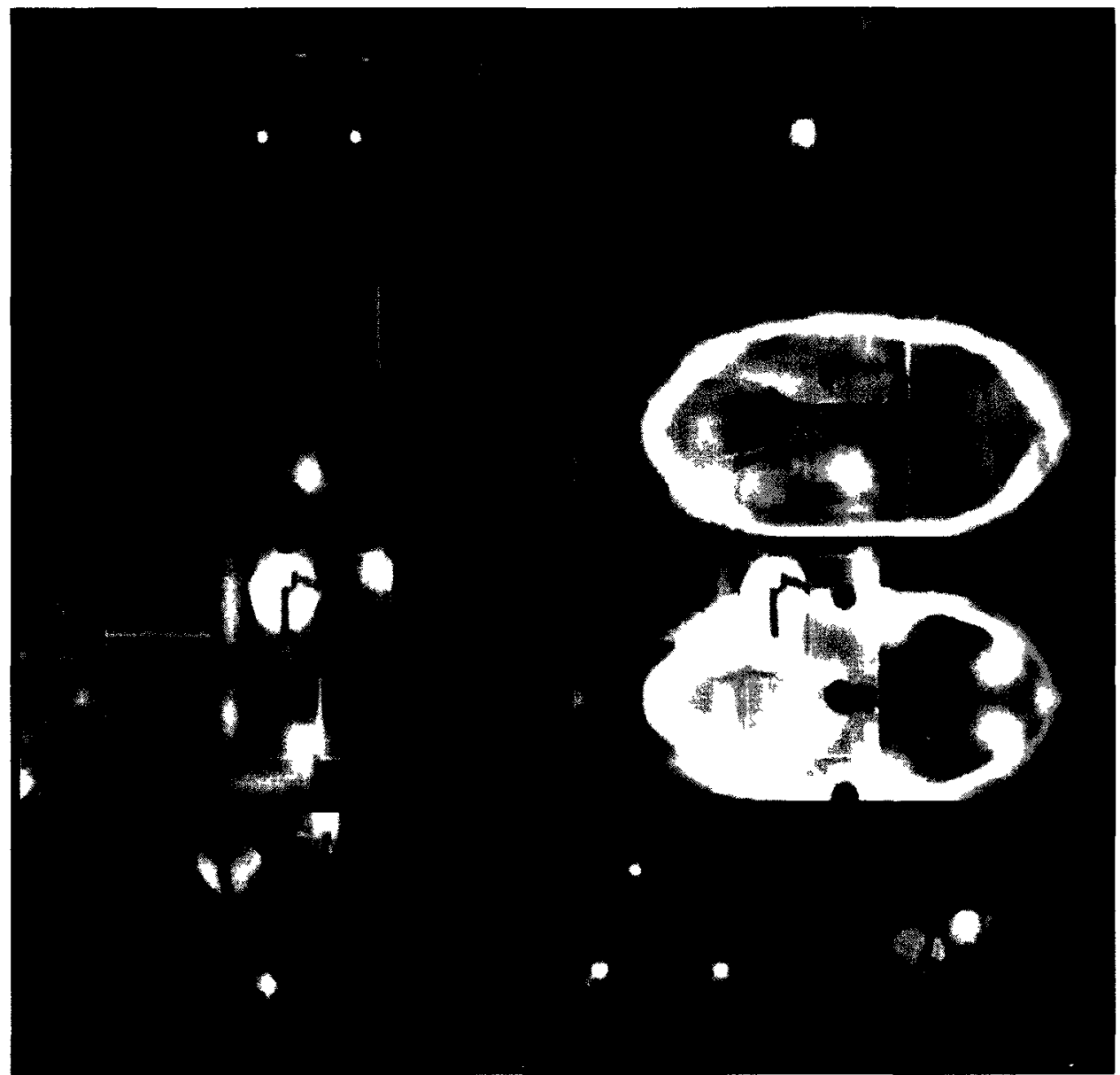

17 Crush Storyboard: from right to left and top to bottom, 1)a view of the three dimensional world the game level exists in, 2) the characters position at a dead end within the third dimension, 3/changing the perspective view to an overhead view, 4) the character crushes the dimension, 5) the character can now move within a two dimensional world and is no longer at a dead end, 6) the dimension is now uncrushed, 7) a top perspective view reveals the character to be on a higher level than before, 8) the character can now continue in his movements within the three dimensional world.

Another game, Looksley's Line U ${ }^{x \prime}$ for the portable Nintendo DSi, continues this idea but with more user interactivity. In this simple game, each level is a stagnant three-dimensional scene similar to a cardboard diorama. The goal of the game is to find hidden items within the available scenes in order to continue to the next level. To find these items, the player needs to rotate or tilt the hand-held screen to change the perspective of the scene. Such items can only be found within one specific perspective and are usually constructed from elements of different spatial depths that will line up just right when in one particular view ${ }^{x \prime \prime}$. In essence, the player is controlling a two-dimensional window or viewport into a three-dimensional world, 


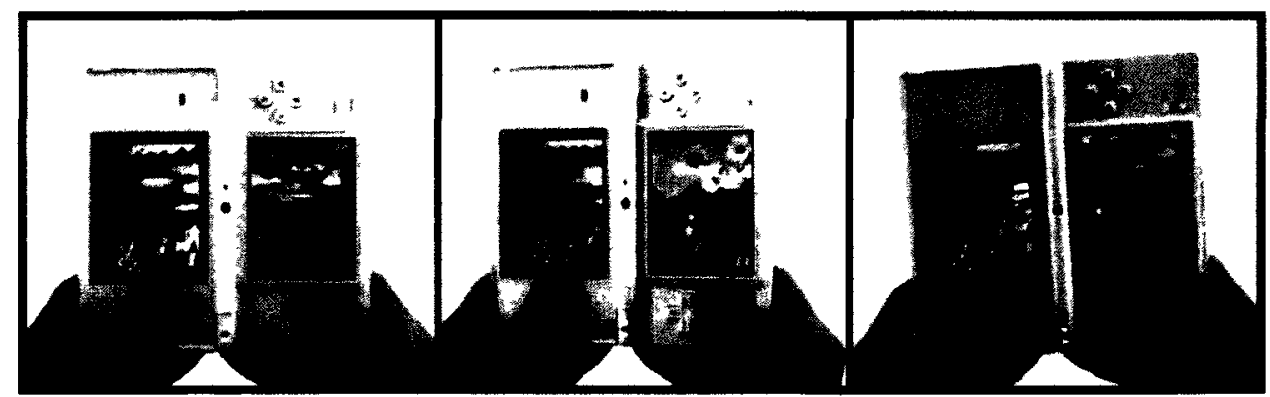

$1^{2}$ Lookley's Line Up: In this game, the player must rotate the screen of the hand held console to reveal the dimensional qualities found in the scene.

as demonstrated in figure $1^{8}$. Looksley's Line Up takes full advantage of how two-dimensional viewing can collapse three-dimensional objects. Even though the world is three-dimensional, the two-dimensional viewport can be misleading. Depth can disappear depending on how it is viewed.

The idea of jumping between the second and third dimensional worlds as well as controlling this concept through a two-dimensional window, as explored with the above video games, is a great example of dimensional play. This can be extended further into a relationship not limited to the second and third dimensions but between the third and the fourth dimension. Four-dimensional architecture needs to be observed, like shown in the Looksley's Line Up example, through some sort of viewport; but, unlike the referenced game's two-dimensional interactive window, four-dimensional architecture requires a three-dimensional viewport. Additionally, not all three-dimensional objects need to expand into the fourth dimension. These three-dimensional objects, which do not expand, can then be used to hide four-dimensional objects within the traditional three-dimensional viewport. Depending on how controlled the views are, different objects may be revealed or hidden when switching between different dimensions. New object may even be created by overlapping shapes that collapse into a lower dimension.

A four-dimensional world can reveal items, paths, and secrets that the threedimensional world cannot show. For example, as seen in Figure $1^{9}$ and Appendix A: Animation 1, a three-dimensional human figure has reached an apparently solid, impenetrable three- 


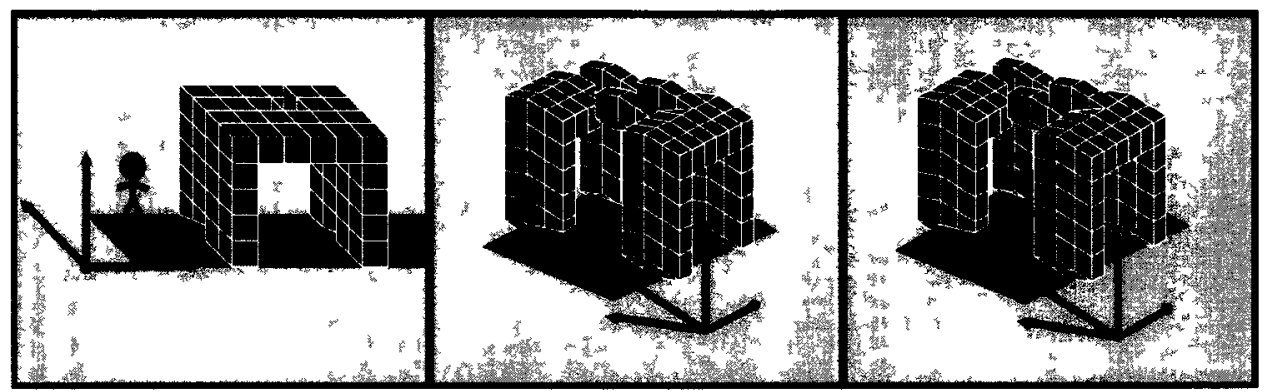

$1^{9} 3 D$ to 40 Environment When a three-dimensional dead end appears, the character can rotate to the fourth dimension and reveal an opening within the structure

dimensional object. As long as this person remains in a three-dimensional environment, he or she will not be able to pass through. When this virtual world rotates to reveal itself in fourdimensions, an opening in the wall is then revealed. This person is now able to pass through the formerly impenetrable three-dimensional barrier.

The relationship presented between the second and third dimensions in these video games can be directly applied to the relationship of three-dimensional architecture and how it could expand into the fourth-dimension within the space of the Internet.

\section{Paracube}

It is now plausible to imagine how four-dimensional architecture can be seen and explored; however, the question of how fourth-dimensional architecture can be created is still undetermined. Marcos Novak, a "transarchitect" working with virtual spaces, explores the fourth-dimension within architecture in his project, Paracube.

Paracube is a convincing example of a project demonstrating how the fourth dimension can be brought to architecture. Conceived between 1997 and 1998 by Marcos Novak, the Paracube began with a six-sided three-dimensional object. In this object, all sides are treated as unique: each with their own set of coordinates and properties. What is interesting is that where these surfaces connect, Novak places algorithms causing permutations at all affected 
adjoining points. In addition to these relationships, this object is further divided into a skeleton and skin. The skeleton, through the application of further algorithms, reaches its final structure once each of its points are mathematically extruded into the fourth dimension. The points become lines, the lines become polygons, the polygons become cubes, and the cubes become hypercubes. Once this four-dimensional skeleton is complete, it is rotated around a plane within this four-dimensional space and then returned back to the three-dimensional. The created lines, polygons, cubes, and hypercubes are all reduced back to points, lines, polygons, and cubes, respectively. The three-dimensional skin is a result of these skeletal changes; creating a rippling and non-homogeneous surface (Figure $1^{10}$ ) xiit.
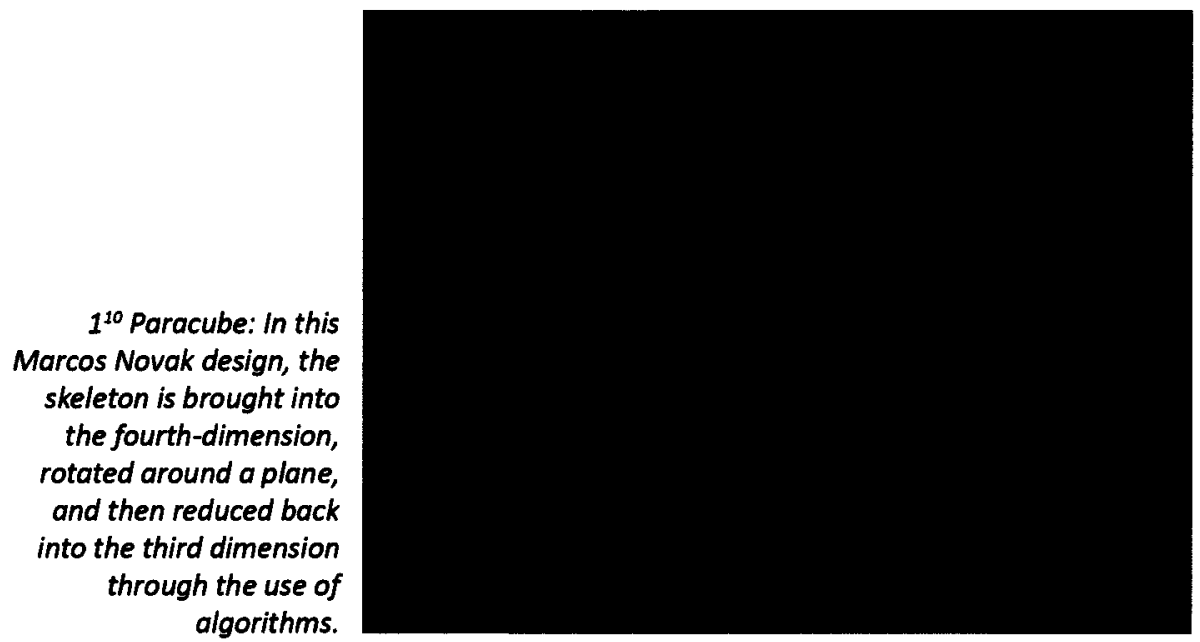

The Paracube described above is an early, computer enabled example of how a three-dimensional building can be transformed through raising it into four-dimensional space; however, the project is only visualized within three-dimensional space with all fourdimensional activities occurring within mathematical algorithms. Although Novak's Paracube shows one method of how higher dimensions can affect architecture, it does not explore how four-dimensional architecture can be explored and, more importantly, how three-dimensional humans can experience and occupy this higher dimension. A series of studies at the University of Illinois are presented below in order to further understand this component. 


\section{Beckman Institute Research Project}

While the fourth dimension begins to be understood through mathematics and analogy, understanding how one can interact with or occupy it is a little harder to grasp. At the Beckman Institute, University of Illinois, a series of studies were conducted in 2009 to determine whether individuals conditioned in the world of three dimensions could develop an intuitive understanding of four-dimensional space. After two experiments, it was evident that human perception is not limited to three-dimensions. The evidence suggested, rather, that a four dimensional space can be perceived by an individual ${ }^{\text {xiv }}$. These experiments were based on the premise that, if a person is able to recognize the correct length and angle of segments projected in the fourth dimension, than they grasp the spatial relationship of the higher dimension.

The research undertaken by the Beckman Institute lifts the observer into the higher dimension so that they can experience it directly. This approach is similar to Flatland: $A$ Romance of Many Dimensions where the character A. Square is lifted into the third dimension and for the first time sees his world from above ${ }^{\mathrm{xv}}$. With the advancement of computer technologies, it is now plausible to experience the fourth-dimension more directly, not just understand it with the use of analogy. The studies conducted at the Beckman Institute utilize computer technologies to achieve a greater spatial understanding of the fourth dimension and evaluates the overall understanding through the identification of distances and angles.

The first study utilized the Beckman Institute's Cube, a six sided fully immersive space equipped with rear projection and motion sensor technology ${ }^{x v i}$. Inside this space, a hypertetrahedron is created by five random four-dimensional vertices placed on a four dimensional grid and generated between -0.6 and 0.6 metres. These vertices are then connected with line segments and their faces triangulated. The hyper-tetrahedron is displayed within the Cube using a technique referred to as slice translation condition. This visualization method breaks the fourdimensional object down into three-dimensional cross-sections, which are viewed in succession as the viewer moves along the $w$ axis. The participant can then study the four-dimensional object through its many slices and mentally construct the four-dimensional shape. The 
participant can also control the speed at which they view the cross-sections as they move along the $w$ axis with the aid of a handheld gamepad (this gamepad's $w$ displacement is equal to its $z$ displacement in this instance). As the participant moves along the $w$ axis, the slices of the hypertetrahedron move as well, revealing the whole shape through these cross-sections over time (Figure $\mathbf{1}^{11}$ ). After about two minutes of viewing the hyper-tetrahedron, the participant is asked to identify the distance between two vertices as well as the angle they share. While this fourdimensional object passes through three-dimensional space, three key vertices are identified with markers. When asked to identify the four-dimensional distance, two of the markers appear on either end of a line segment which the participant adjusts the length. For identifying the angle, three markers are attached by line segments to form a $V$. The participant adjusts the angle to be equal to that within four-dimensional space ${ }^{\text {xvii }}$.

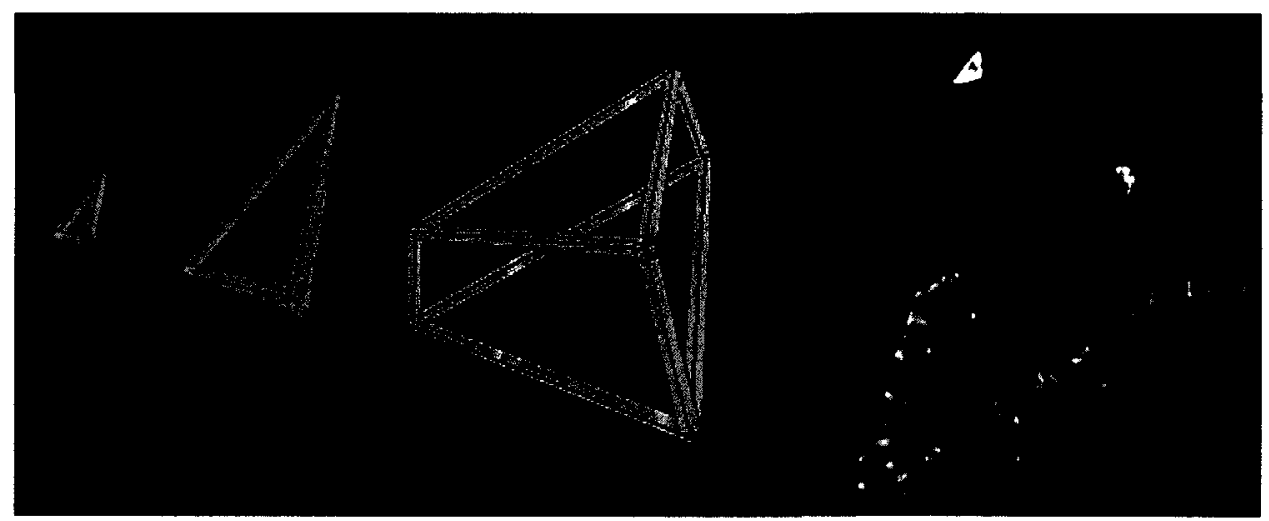

$1^{11}$ Beckman Institute Experiment: On the left, are the three-dimensional cross sections that the experiment participants view while controlling their movement along the $w$ axis. On the right is an image of a participant in the experiment. A game controller in their hand helps in their movements.

A second study introduces two new visualization techniques that allow a fourdimensional object to be displayed within three-dimensional space. In addition to the Slice Translation Condition, the study utilizes techniques called Slice Rotation Condition and Projection Rotation Condition. The Slice Rotation Condition technique has the hyper-tetrahedron rotate along the wx plane as opposed to moving along the $w$ axis as in the original experiment. The Projection Rotation Condition rotates as well in the wx plane but instead of appearing as slices, it appears as a constant parallel projection onto the three-dimensional observation cube ${ }^{\text {xiil }}$. In 
effect, the $z$ coordinate is dropped from each position. This technique is the same effect as a three dimensional shadow of a four dimensional object. In all techniques, the participant views the four-dimensional objects through a computer screen, which displays a wireframe observation cube with its $w$ coordinate set at 0 . This keeps the $y$ and $z$ coordinates constant while the $w$ and $x$ values change while rotating. No matter which visualization technique is used, the cross-sections or projections appear on the computer screen in a series of wireframe single points, tetrahedrons, or triangular prisms ${ }^{\mathrm{xix}}$.

In both studies, the participant was given approximately 20 trials to evaluate the distances and angles within four-dimensional space ${ }^{x x}$. In all the results, a significant correlation in the responses and the actual four-dimensional distance and angle could be seen. It is believed, that this shows a spatial understanding of the fourth dimension. The study proved that at least a subset of the population can make four-dimensional distance and direction judgments; however, further study is still needed ${ }^{\mathrm{xxi}}$.

The Research conducted at the Beckman Institute is proving that humans can have a spatial understanding of four-dimensional space. Through the use of computer graphics and advancing computer technology, it is possible to understand and immerse oneself into the fourth dimension. In the first experiment, the participant moved along the $w$ axis to see the crosssections, proving that four-dimensional space can be recognized and inhabited. The visualization techniques used at the Beckman Institute, especially that of the Slice Translation Condition, are informative and give some sense of the parameters for creating a four-dimensional architecture.

In conclusion, the fourth dimension is a spatial experience that can be understood through mathematics, analogy, and visually in augmented environments. Its relationship to its preceding dimension can be understood through the comparison of the second and third dimensions as well as the first and second. The exploration and play found in comparing the second and third dimensions within certain video games can be applied directly to how three and four-dimensional space relate to each other. Architectural projects can use mathematical algorithms to transform three-dimensional objects and spaces within the higher dimension and 
it is proving possible to actually occupy and spatially understand the fourth dimension. Can the Internet provide a platform for representing and exploring the fourth dimension in architecture? In the following chapter, the discussion will focus on the world exhibition, Expo 2010 Shanghai, that contains a proposed extension by its organizers, both temporally and spatially, via the Internet. In chapter 3, Expo 2010 Shanghai is proposed as a site for addressing the above question through a project of architecture.

Henderson, Linda Dalrymple,. The Fourth Dimension and Non-Euclidean Geometry in Modern Art. Princeton, N.J.: Princeton University Press, 1983. Pg xix.

ii Union College, Department of Mathematics. "Hypercube Basics." Some Notes On The Fourth Dimension. Union College. <http://www.math.union.edu/ dpvc/math/4D/basics-new/n-cubes-sweep.html> Nov 16, 2008, April 26, 2010.

iii Union College, Department of Mathematics. "Hypercube Basics." Some Notes On The Fourth Dimension. Union College. <http://www.math.union.edu/ dpvc/math/4D/basics-new/n-cubes-sweep.html Nov 16, 2008, April 26, 2010.

iv Schofield, A. T. (Alfred Taylor). Another World Or, the Fourth Dimension. Mt. View, Calif. : Boulder, Colo. : Wiretap ; NetLibrary, [199-?]. p15.

v Abbott, Edwin Abbott. Flatland, a Romance of Manv Dimensions. New York: Penguin Books, 1998. p66-67.

vi Schofield, A. T. (Alfred Taylor),. Another World Or, the Fourth Dimension. Mt. View, Calif. : Boulder, Colo. : Wiretap ; NetLibrary, [199-?]. p15.

vii Schofield, A. T. (Alfred Taylor),. Another World Or, the Fourth Dimension. Mt. View, Calif. : Boulder, Colo. : Wiretap ; NetLibrary, [199-?]. p15.

vii Abbott, Edwin Abbott. Flatland, a Romance of Many Dimensions. New York: Penguin Books, 1998. p.86.

ix Super Paper Mario. 2007, Wii Nintendo Console.

X Crush. Play Station Portable, 2007.

xi Looksley's Line Up. Nintendo DSi, 2010.

xii Thomas, Lucas M. "Looksley's Line Up Review: Could this be a glimpse at the 30 future of the DS?" IGN Entertainment Games. <http://ds.ign.com/articles/109/1091081p1.html> May 20, 2010. Visited fuly 24, 2010.

xiii Peter, Zeliner. Hybrid Space: New Forms in Digital Architecture. New York: Rizzoli, 1999. Pg 135.

xiv Ambinder, Michael S; Wang, Ranxiao Frances; et al. "Human four-dimensional spatial intuition in virtual reality." Psychonomic Bulletin \& Review. Vol. 16 No. 5, October 2009. Pg 818-823. Pg 818. Abbott, Edwin Abbott. Flatland, a Romance of Many Dimensions. New York: Penguin Books, 1998. Pg 93. Bulletin \& Review. Vol. 16 No. 5, October 2009. Pg 818-823. Pg 819.

xvii Ambinder, Michael S; Wang, Ranxiao Frances; et al. "Human four-dimensional spatial intuition in virtual reality." Psychonomic Bulletin \& Review. Vol. 16 No. 5, October 2009. Pg 818-823. Pg 819. 
xviii Wang, Ranxiao Francis. "A Case Study on Human Learning of Four-Dimensional Objects in Virtual Reality: Passive Exploration and Display Techniques." 2009 International Conference on Frontier of Computer Science and Technology. December 17-19, 2009, p 519 - 523. Pg 521.

xix Wang, Ranxiao Francis. "A Case Study on Human Learning of Four-Dimensional Objects in Virtual Reality: Passive Exploration and Display Techniques." 2009 International Conference on Frontier of Computer Science and Technology. December 17-19, 2009, p 519 - 523. Pg 520. Ambinder, Michael S; Wang, Ranxiao Frances; et al. "Human four-dimensional spatial intuition in virtual reality." Psychonomic Bulletin \& Review. Vol. 16 No. 5, October 2009. Pg 818-823. Pg 819.

xxi Ambinder, Michael S; Wang, Ranxiao Frances; et al. "Human four-dimensional spatial intuition in virtual reality." Psychonomic Bulletin \& Review. Vol. 16 No. 5, October 2009. Pg 818-823. Pg 822. 


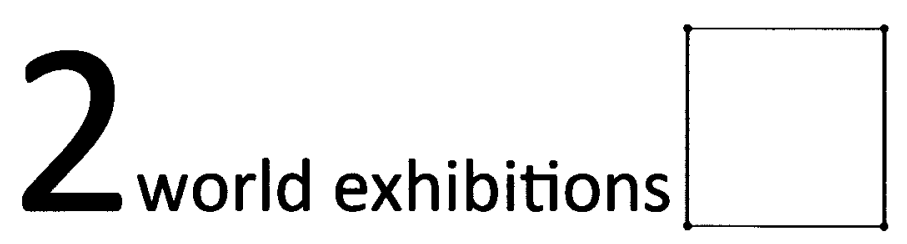

The year $\mathbf{2 0 1 0}$ held great significance for the People's Republic of China and for Internet architecture. Between the months of May and October, the city of Shanghai held the World Exhibition-Expo 2010 Shanghai. With the theme of "Better City, Better Life", Expo 2010 Shanghai was the first world exhibition to not only have a physical site but an online, virtual site as well. Expo Shanghai Online, is a significant milestone in the development for architecture on the Internet and a unique opportunity to explore an architecture for the fourth dimension.

World exhibitions are a long-standing tradition that began in London England's Hyde Park in 1851 with a fair entitled, "Great Exhibition of the Works of Industry of All Nations"i. Held roughly every five years, world exhibitions aim to unite the world under a single interest or theme, bring together cultures and commodities from around the world to one location, and display the latest and greatest in the arts, sciences and technology of the timeii. From the beginning in London, these world exhibitions grew to become a way to educate the general public on other nations and their respective innovations. The 1851 fair saw 32 foreign countries present their culture and goods to over six million visitors, many of which had no previous knowledge of the true identity of the foreign nations ${ }^{\text {iil. }}$ Expo 2010 Shanghai is host to 189 countries $^{i v}$ and 73 million visitors ${ }^{v}$. Only two countries that share diplomatic relations with China did not participate in the Expo: Andorra and Columbia. For the purpose of exploring the ideas set forth in this thesis, a pavilion for the third dimension and a pavilion for the fourth dimension will be developed for the country of Andorra as a way of introducing this relatively unknown nation to the world. 
World Exhibition Themes

Expo 2010 Shanghai has an individual focus on the increasing densification of cities and the quality of urban life; however, the overall goals of showcasing new scientific and technological advances, introducing or improving country images and cultures, and uniting the world under common interest remain prominent in this exhibition and those that came before it. With the intent of demonstrating what better future lies ahead, the introduction of new inventions and technologies remains a large component of the world exhibition tradition. At the London fair of 1851, for example, the largest refracting telescope in the world was put on display, allowing the public to look to the stars and envision a future among them ${ }^{\text {vi. Technologies }}$ of this nature are meant to change the way visitors to the exhibition see their surroundings and introduce them to possibilities for the future. This includes new engineering and architectural technology that may be featured in the construction of the exhibition buildings themselves. During the 1851 London fair, the Crystal Palace, designed by Joseph Paxton used a remarkable new technology in its construction. This building, similar in the style to the greenhouses of the time, was a composition of modular wrought iron, glass and wood. The Crystal Palace was one of the first buildings to be built in sections elsewhere and then assembled on site, marking it as one of the first examples of prefabricated architecture. This particular building shows the importance of architectural experimentation in world exhibitions $\mathrm{s}^{\mathrm{vii}}$.

Most of the pavilions in world exhibitions are temporary and almost all are dismantled after the completion of the event. This temporary element allows for more architectural experimentation viii; however, it also removes the memory of the exhibition from the city landscape. Only a few buildings, such as the Eiffel Tower in Paris, remain as evidence that an exhibition has occurred. Besides the few exceptions and before Expo 2010 Shanghai, it was only through memorabilia, stamps, photos, and memories that the exhibitions lived on. Expo Shanghai Online will have the ability to continue the experience passed the short life expectancy of the built pavilions. This virtual counterpart to the exhibition will archive the physical exhibition, expand beyond it, and allow for a longer life and wider range of visitor experiences.

World exhibitions divide their visitor areas into several small pavilions designated for 
specific countries, companies, and themes. The individual pavilion design becomes twofold with the exhibition displays as well as the architectural design showcasing the country's specific culture, identity, and national achievements. For example, the exhibition displays often revolve around a particular heroic figure, landscape, or examples of technological innovations and cultural contributions (literature, arts, music, etc) ${ }^{\text {ix }}$. These exhibition displays are housed within a pavilion design chosen to express the country's image through specific architectural languages, materials, spatial volumes, and engineering or architectural construction innovations. By demonstrating certain architectural choices (or omissions), these pavilions express the desired cultural values and ideologies of their namesake countries ${ }^{x}$.

Often, the national style of a country is used in the pavilion design to best express cultural or political objectives. This style may take cues from the architecture of past societies with similar political and social ambitions; such as in the case of Nazi Germany's use of Imperial Rome to define its style of architecture to express an obsession for order, discipline, and a clearly defined social and political hierarchy ${ }^{x i}$. This is best understood when comparing the German Congress Hall, shown in figure $2^{1}$ and built in 1938, to the Roman Colosseum shown in figure $2^{2}$. Alternatively, and in the case of Andorran architecture, a national style is determined by the availability of certain materials and limitations in construction methods. Due to its isolation, the
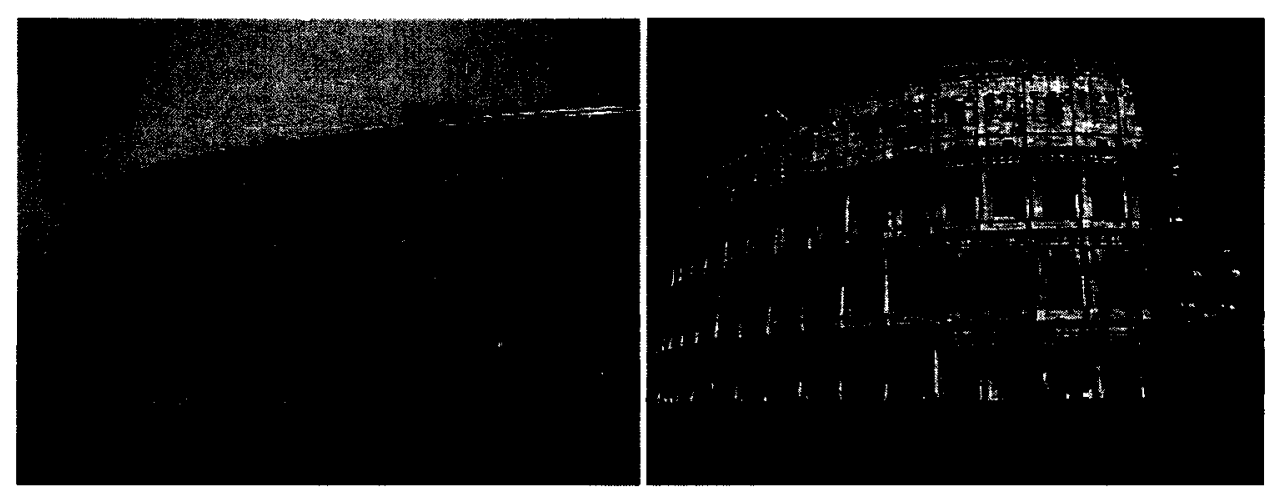

$2^{1}$ and $2^{2}$ German Congress Hall and Roman Colosseum: The 1938 German Congress Hall when compared with the $1^{\text {st }}$ Century Roman Colosseum shows the Roman influence in the Nazi architecture. 
architecture of Andorra is very subdued and uses the natural materials of the area. Rough but solid stone houses with small windows and broad wooden balconies fill the small towns that dot along the country's valleys (figure $2^{3}$ ). The churches, all in a twelfth-century Romanesque style (figure $2^{4}$ ), are made as well with this local field stone. Tall square towers unique to the Andorran church design become a significant and distinctive Andorran character. Furthermore, the field stone used in both house and church construction, after prolonged exposure to the weather, has the tendency of turning black. This weathering effect gives the architecture a strikingly somber and forbidding feelexii. These material qualities are what defines Andorran architecture as unique and will be used to express the Andorran ambience within the physical pavilion design.

\section{$2^{3}$ Andorran Architecture:}

As seen in the small Andorran city of Ordino, the houses are constructed of local field stone with wood detailing found in the windows and balconies.

$2^{4}$ Andorran Churches: The church of Esglesia Sant Miquel d'Engolasters from the $12^{\text {th }}$ century and located in Engolasters, Escaldes-Engordany, Andorra demonstrates the unique Andorran architecture character found in the tall square towers and stone construction.

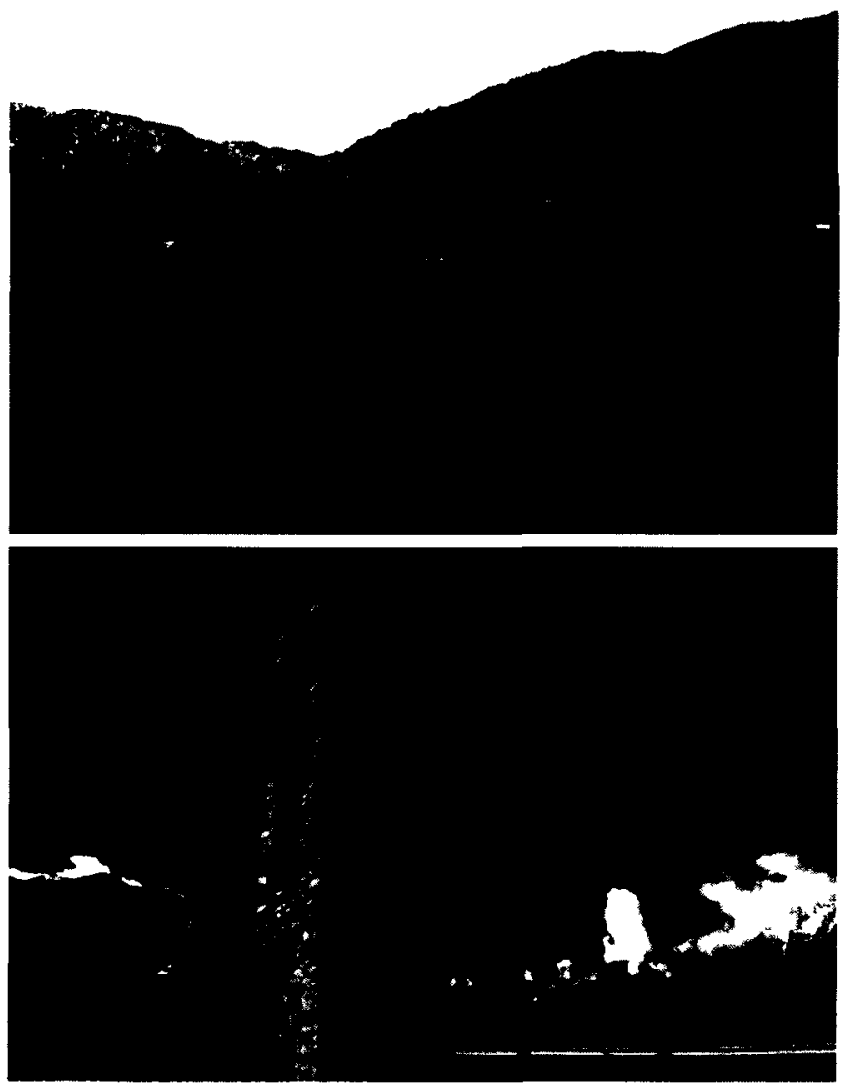




\section{Expo 2010 Shanghai - The Physical}

Expo 2010 Shanghai runs within the Puxi and Pudong districts of Shanghai (figures $2^{5}$ and $\left.2^{6}\right)$. Its aforementioned theme of "Better City Better Life" is explored through the examination of urban and sustainable developments and is intended to spark discussions on new approaches to human habitation. Concepts such as city harmony are explored through the exploration of culture, economy, science, technology, communities, and rural-urban linkages. Each individual country pavilion is encouraged to explore these themes through their own historical, contemporary, and futuristic approaches ${ }^{\text {xiii. }}$

$2^{5}$ Expo 2010 Shanghai Expo Rendering: The exhibition site is $5.28 \mathrm{~km}^{2}$ and split between the Puxi and Pudong districts of Shanghai on either side of the Huangpu River.

$2^{6}$ Expo 2010 Shanghai Expo Site: The exhibition site is divided into five zones. The Andorran pavilion will be in Zone $C$, located at the bottom left of the site map.
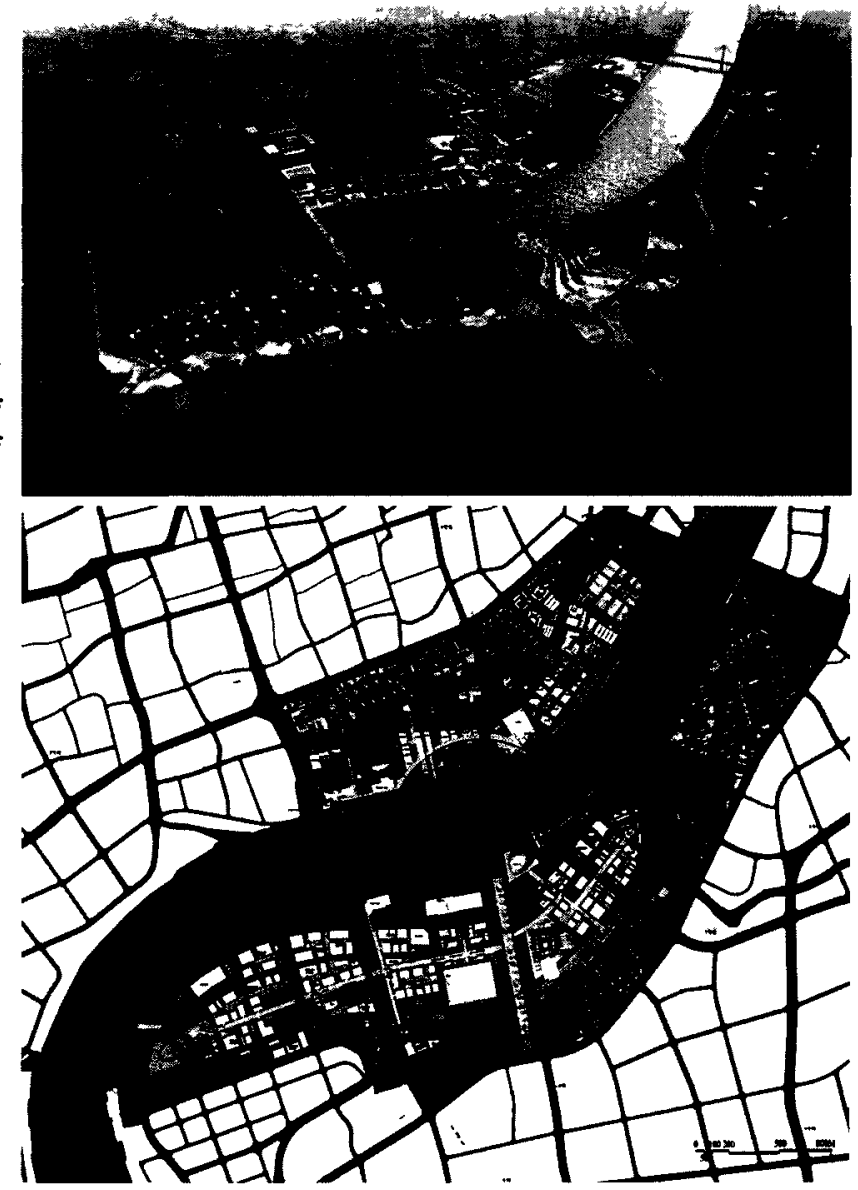
Expo 2010 Shanghai covers a total area of 5.28 square kilometres spanning both sides of the Huangpu River. Of this area, roughly 4 square kilometres are located in the financial district of Pudong with the rest in Puxi, a more residential and cultural district. The exhibition's pavilions are divided by geological location into 5 zones. Andorra, being a European country, will be located in Zone $\mathrm{C}$ with the other European nations as well as the American and African Pavilions ${ }^{x i v}$.

The exhibition consists of pavilions for corporations, themes, and countries. Within the country pavilions, there are three types of physical pavilions available at Expo 2010 Shanghai in order for countries of all economic levels to participate.

Type one comprises of pavilions designed and built by individual countries that are not limited financially. These are limited to a plot size ranging between $1000 \mathrm{~m}^{2}$ to $6000 \mathrm{~m}^{2}$ with a $60 \%$ to $80 \%$ building coverage permitted and a maximum height of 20 meters ${ }^{\mathrm{xv}}$. Other than the size constraints, there are no limits to the pavilion design, as seen in the following examples.

The Latvian type one physical pavilion hails the individual theme, "Technology of Happiness", implying that happiness is achieved through the harmony of nature and technology $y^{x i}$. The Latvian pavilion (figures $2^{7}$ and $2^{8}$ ) displays the achievements of Latvian citizens who have, through hard work and perseverance, become world renowned and respected in their respective fields. Through the advances in technology and new inventions, these individuals have helped to create a better quality of life for the world, therefore creating happiness. The Latvian pavilion bestows on its visitors a great sensation of happiness through the experience of flight in its centerpiece, a vertical wind tunnelexii. The pavilion's façade is composed of 100000 colourful and transparent plastic plates with a diameter of $15 \mathrm{~cm}$ which provides a dynamic and kinetic effect. One enters the pavilion by ascending up a spiral staircase that symbolizes the continuing, progressive development of humanity. Once the ascent is complete, the visitor arrives in a room with audiovisual material on its walls displaying the Latvian nation and the central glass wind tunnel containing flying participants. The visitor is able to learn about Latvia and its people through the exhibits and then conduct a quiz. If the quiz is answered correctly, the visitor is granted admittance to the wind tunnel where they will 
be able to experience the sensation of flying ${ }^{x v 1 !}$. The Latvian pavilion is very simple in context and minimal in content but it is sure to provide a lasting memory of happiness to its visitors, achieving its intent.
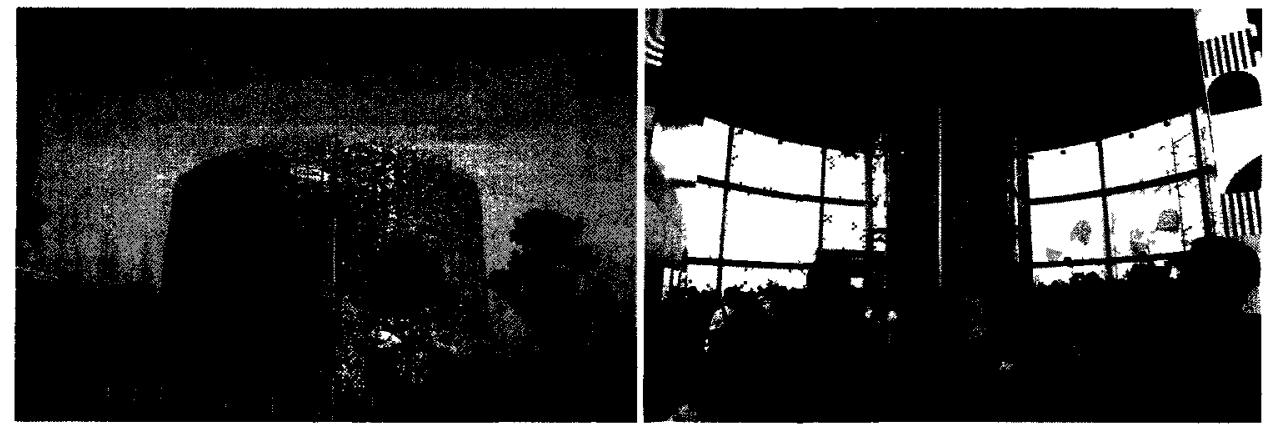

$2^{7}$ and $2^{8}$ Latvian Physical Pavilion: The Latvian pavilion has the individual theme of "Technology is Happiness". Its centrepiece is a vertical wind tunnel where visitors have the opportunity to fly.

With the sub-theme "From the City of Our Parents to the City of Our Children" the Spanish pavilion (figures $2^{9}$ and $2^{10}$ ) is one of the largest type one pavilions at Expo 2010 Shanghai. As its façade, the Spanish pavilion uses a hand-weaved wicker basket structure to both act as a bridge between a shared basket weaving tradition between Spain and China ${ }^{\mathrm{xix}}$, and to experiment with its technical potential as a sustainable materialxx. Environmentally responsible material is the first aspect the visitor is confronted with that informs of how Spain
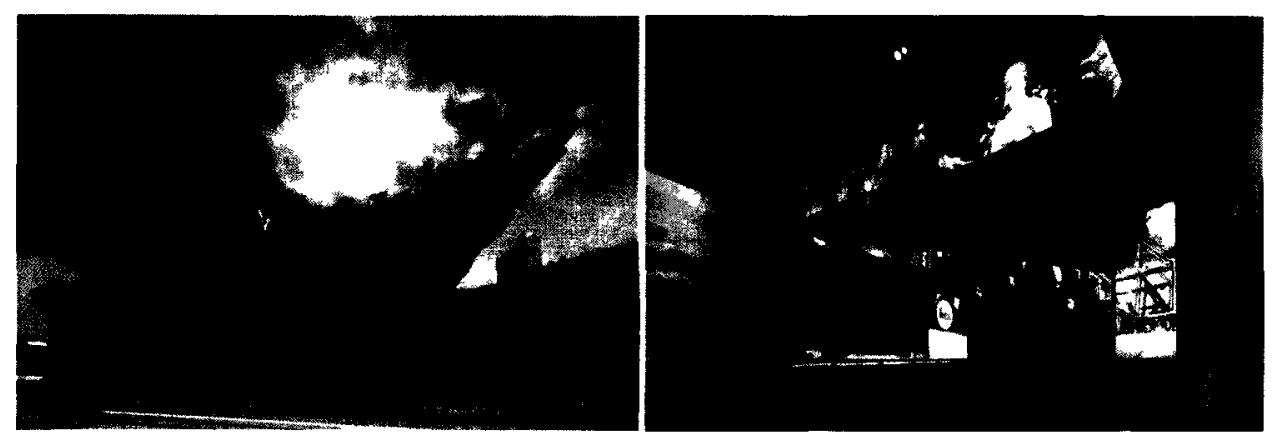

$2^{9}$ and $2^{10}$ Spanish Physical Pavilion: The Spanish pavilion's exterior is constructed out of a hand-weaved wicker basket structure to show the shared tradition between the Spanish and Chinese cultures. The interior follows the individual theme of "From the City of Our Parents to the City of Our Children" through cinematic displays. 
desires to pass on a better world to its children. The interior is divided into three exhibits, each produced by its own renowned Spanish director. Video displays, audio, and live performances are choreographed together to provide a complete experience ${ }^{\mathrm{xxi}}$. Exhibit one is a journey through time used to convey the Spanish identity. Exhibit two expresses a half century worth of changes in Spanish cities and its people through aspects such as transport, education, food and fashion. The final exhibit is of a dream of the future desired to be left to the children. As this exhibits centerpiece, is a giant life-like animatronic baby that oversees the space and the dreams for its generation's future ${ }^{x x i}$. The Spanish pavilion uses cinematic style exhibits to express how their nation is unique and how they strive to provide the next generation with a world worth living in.

The possibilities of how a nation can express itself are only limited by time, physics, and budget. The type one pavilion is geared towards countries that are not limited financially and who want to make a large architectural impact within the context of a world exhibition. The other pavilion types are more subdued than those falling under type one.

Type two pavilions are structural shells rented out by the exhibition organizers and decorated by the participating country. This second type, chosen for representing Andorra, is available in three sizes: $500 \mathrm{~m}^{2}, 1000 \mathrm{~m}^{2}$, and $2000 \mathrm{~m}^{2}$. Participants renting type two pavilions can add external facades, internal walls, floors, windows, ceilings, and decorations as long as the original structure and facilities provided by the exhibition's organizers are not altered ${ }^{x \times i i l}$.

The Slovenian pavilion is an example of a type two pavilion with the individual theme of "Open Book" in reference to the nation's capital city being the 2010 UNESCO World Book Capital ${ }^{x x i v}$. The exterior façade is decorated over the rented structure to give the impression of books on a bookshelf, as seen in figure $2^{11}$. The Interior pavilion design further continues the book theme by dividing the exhibit into eight stories depicted in eight large books that visitors walk through as they travel the designated path (figure $2^{12}$ ). Each story focuses on one of eight important Slovenian topics relating to the overall exhibition theme $e^{x v v}$. These exhibits contain display cabinets within the large books and use video screens and images to display their story xwi. The first book celebrates the Slovenian philosopher and author Slavoj Žižek by 


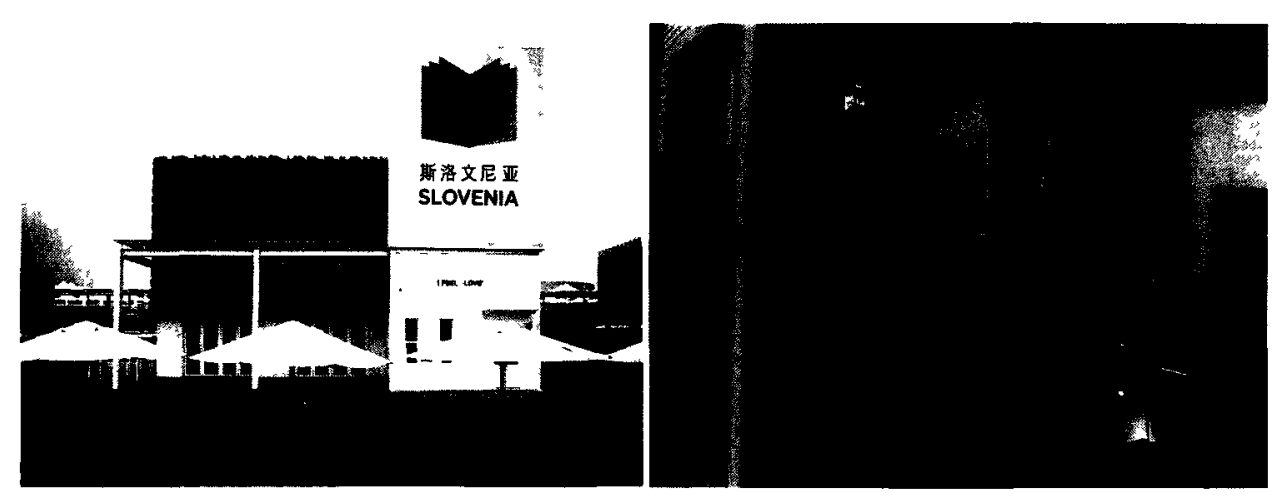

$2^{11}$ and $2^{12}$ Slovenian Physical Pavilion: To celebrate their capital being awarded the 2010 UNESCO World Book Capital title, the Slovenian pavilion follows the individual theme of "Open Book". The exterior is clad to appear like a book shelf

providing the visitor with an example of his work. The second expresses the importance of Slovenia's history with the lamp designed by architect Jože Plecnik illuminating the Abecedarium, the first printed book in the Slovene language. The third story is a dedication to Slovenian design from jewelry to cars while the fourth depicts the beauties of the Slovenian landscape and the fifth focusing on the coastal region of the nation. The sixth story focuses on the Karst, a tourist region of caves, intermittent lakes, wine, and an area unique amphibian-like creature. The seventh shows Slovenian housing and how it is environmentally conscious while the eighth and final story is an exhibit dedicated to the $20^{\text {th }}$ Century Slovenian scientist Herman Potočnik Noordung ${ }^{x v i i}$. The Slovenian pavilion focuses on aspects of Slovenian culture and history that are deemed influential or remarkable by their nation. This is all done by transforming the structural shell provided by the exhibition organizers into a unique pavilion.

Type two pavilions are constrained by the structural shell they are housed within; however, this does not mean they cannot contain a complex and thorough exhibit. This type of pavilion only reduces the architectural impact the building has in relation to its neighbours, requiring it to have a more interesting exhibit to bring visitors in. Although a more economic type than type one, it is still financially out of reach for many nations, providing the need for the third pavilion type.

Type three are large joint pavilions constructed by the organizers for developing countries and provided free of charge ${ }^{x x v i l l}$. Each country in need of this pavilion type is provided 
with a $324 \mathrm{~m}^{2}$ space within a larger pavilion structure where they are grouped with other nations that share similar geographical qualities ${ }^{\text {xxix }}$.

For example, the Joint African pavilion (figure $2^{13}$ ) holds exhibits for 42 African nations and the African Union within one large structure. Three themes are shared by each participating country of the extended history, vast diversity, and vitality of the African continent and its nations. Through the application of these themes, each nation's area tries to express the true African culture, city, and landscape, correcting the often misunderstood belief held by the rest of the worldxxx . Comoros, for example, uses their pavilion area (figure $2^{14}$ ) to introduce to the world their unique wildlife, landscape, and cultural achievements, as well as their citizen's harmonious relationship with nature and their strive for sustainable development. They do this by dividing the pavilion into three parts: a replication of the traditional architecture found in the Old Vendredi Mosque that illustrates a coexistence between the manmade and nature, an exhibit on the Karthala Volcano that is responsible for the creation of the Comoros land and home to numerous forms of wildlife, and a representation of the ocean to demonstrate its importance to the nation ${ }^{\mathrm{xxx}}$. The Comoros pavilion, like the other nations', provides a full exhibit experience where the visitor can inhabit a piece of African culture. Uniting each country's designated spaces is a communal area displaying "The African Smile", a sculpture of a human face representing the smile of Lucy, the believed foremother of human beings, which speaks of Africa as the birth place of mankind ${ }^{\text {xxxil. }}$.

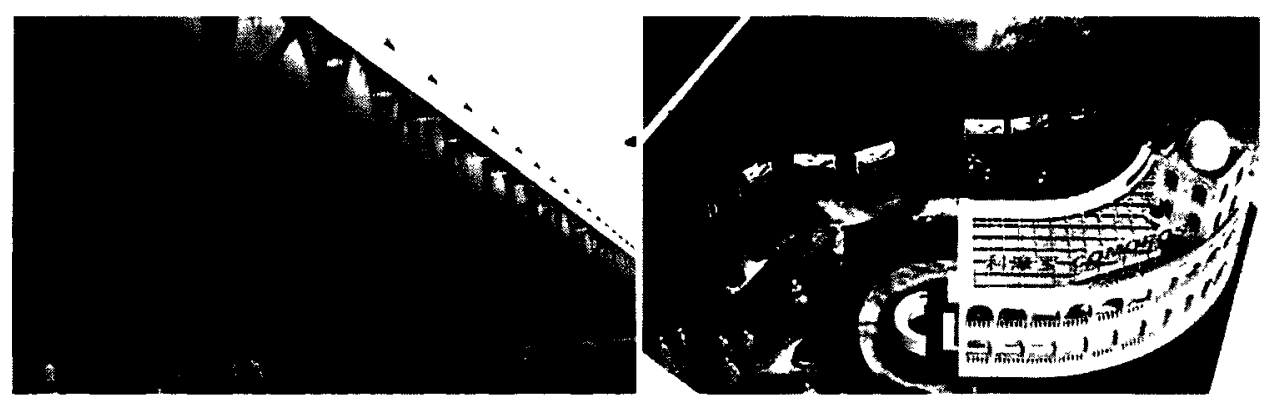

$2^{13}$ and $2^{14}$ African Physical Pavilion and Comoros exhibit: The African Joint Pavilion contains 42 African nations within one large pavilion shell. Countries, such as Comoros, are able to express the true African culture, city, and landscape within the $324 \mathrm{~m}^{2}$ exhibit. 
The Joint African Pavilion, as well as other joint pavilions allows for the poorer nations to still be present at Expo 2010 Shanghai by providing them with a free space for a small exhibit within a greater whole. This allows for the complete exhibition to contain almost all of the world's nations.

As mentioned above, the Andorran pavilion will be a type two with the minimal size of $500 \mathrm{~m}^{2}$. By using the pre-made pavilion structure and by keeping its architectural features to a minimum, this physical pavilion may be overlooked by many, much like the country it represents. With this small landlocked country's situation in the Pyrenees Mountains between Spain and France, its area of only 468 square kilometres, and its low population of 88,815 as of $2009^{\times x \times 1 !}$, it is no wonder that many have never heard of this countries existence. This isolation is a key part of the Andorran identity and will be a key component to the pavilion design.

\section{Expo 2010 Shanghai - The Virtual}

Expo 2010 Shanghai differs from previous exhibitions by requiring participating countries to include a virtual pavilion in addition to the regular physical installation. This additional virtual pavilion is incorporated within an online version of the overall exhibition site, Expo Shanghai Online. The intent of Expo Shanghai Online is to represent all physical constructions within the Internet exhibition with the recommendation that each virtual version contain an additional space expanding on the former's original ideas. The online exhibition also provides worldwide access to the exhibition, allowing the vast majority of the world unable to attend the physical event to still experience it. Expo Shanghai Online will continue to be available long after the physical version of the exhibition is torn down, creating a permanent virtual version of the temporary exhibition. This virtual element of Expo 2010 Shanghai will be an ideal format for developing an architecture of the fourth dimension.

Expo Shanghai Online opens to an aerial view of the virtual recreation of the exhibition site (figure $2^{15}$ ). As one hovers their mouse over the different zones, each becomes highlighted. 
After selecting a zone, a list of all the pavilions in it appears allowing one to jump to an individual virtual space. An alternative navigation method, which is more indirect but provides a better experience of the whole exhibition site, is to go to the "site tour". A new aerial view appears of the whole site and once again the viewer can select an individual zone to explore; but this time, the view changes to an aerial view of the zone with each pavilion labeled (figure $2^{16}$ ). Here, the viewer can select a pavilion and travel to its exterior view. The viewer can now rotate around the pavilion, switching from eye level to bird's eye and from day and night. After being provided

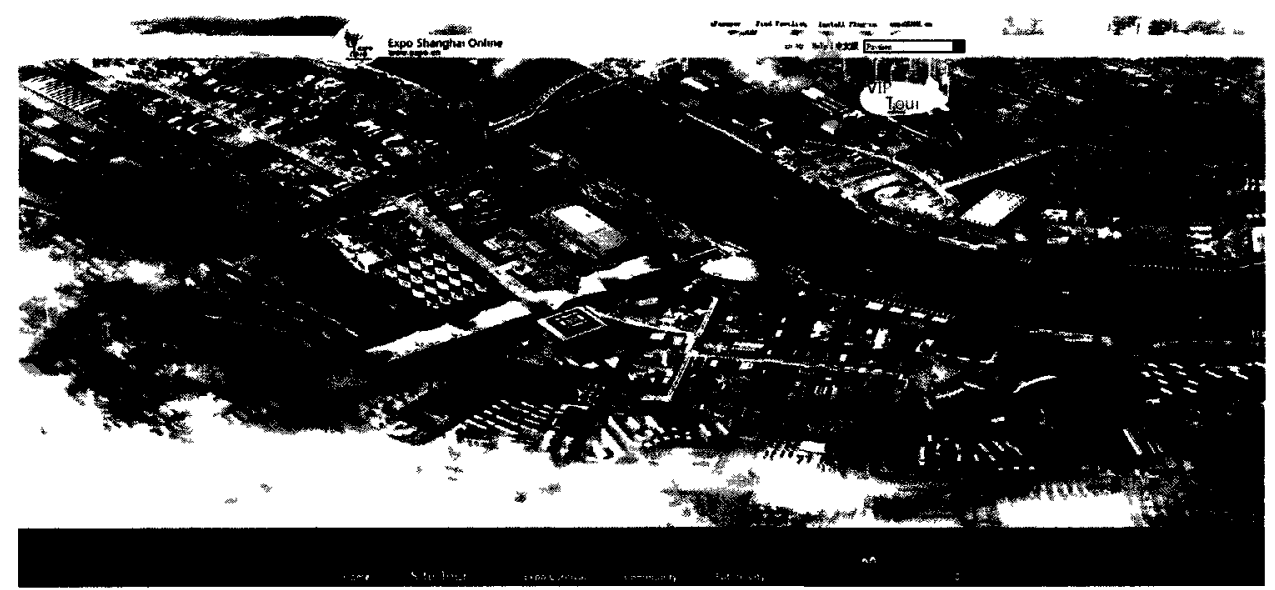

$2^{15}$ Expo Shanghai Online: The virtual expo opens to an aerial view of virtual site. The visitor can select different zones to see a list of all pavilions it contains as well as go to the individual pavilions.

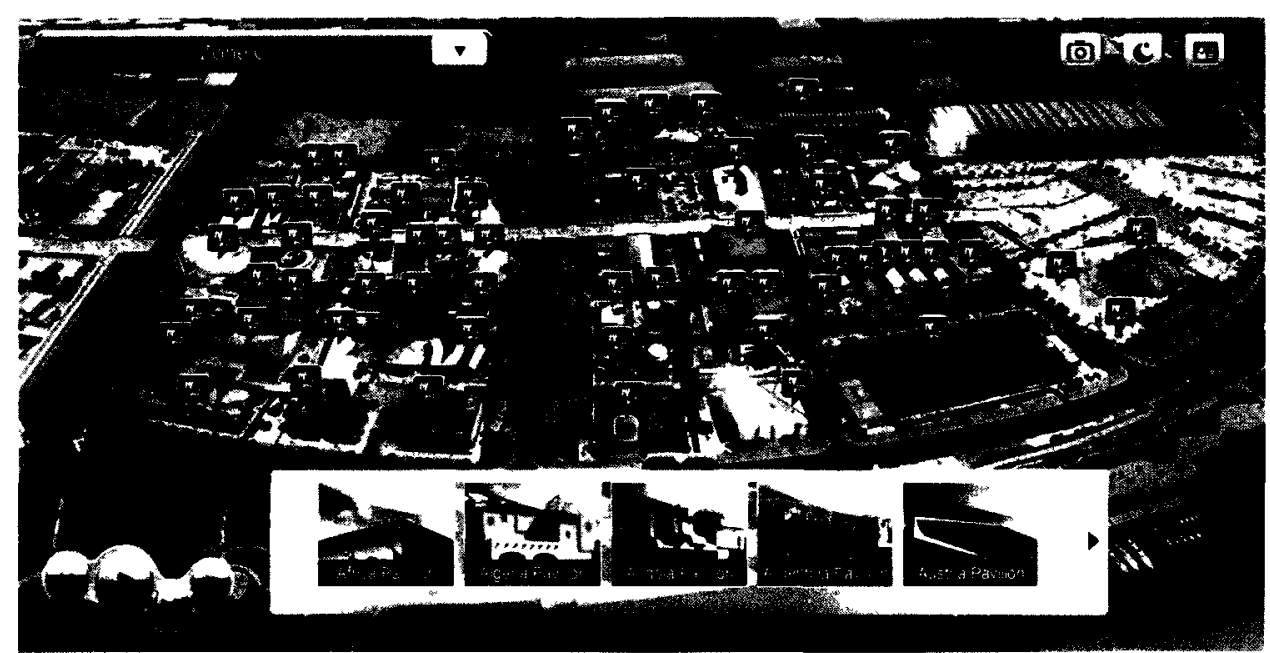

$2^{15}$ Expo Shanghai Online Zone C: By exploring Expo Shanghai Online through the Site Tour, the visitor can see an aerial view of the zones. Here is zone $C$. 
with a brief description of the pavilion, the viewer can enter the pavilion where they will become a virtual inhabitant able to explore the various exhibits each individual virtual pavilion provides. Participating countries have the option of two online pavilion types: the Browsing and the Experiencing Pavilion.

A Browsing Pavilion is created by the exhibition organizers for countries unable to create an experiencing pavilion to ensure that all countries have a presence on Expo Shanghai Online. These generic spaces provide an overall view of the physical pavilion's layout and main concepts through the availability of minimum Internet browsing, text, and image functions but do not extend on the physical pavilion concept.

The Latvian Browsing Pavilion is a good example of all browsing types. The visitor is first provided a textual description of the pavilion design overview. Once reading is completed, the visitor is in the interior of the pavilion at a fixed position (figure $2^{17}$ ). The visitor can use their mouse controls to rotate around from the fixed position and see the virtual reconstruction. Other fixed locations within the pavilion can be reached by using the feet icon at the bottom of the screen to jump to the previous or next position. In the case of the Latvian pavilion, there are three positions on different sides of the vertical wind tunnel described in the previous section. Within a view, certain object on the screen will have a plus icon over them, indicating that supplementary textual information is available, such as a description of the vertical wind tunnel.

\footnotetext{
$2^{17}$ Latvian Virtual Pavilion:

This browsing pavilion allows the visitor to jump from different viewpoints via the feet icons bottom middle. The plus icon on the wind tunnel allows the visitor to click for more information on that particular element of the pavilion.
}

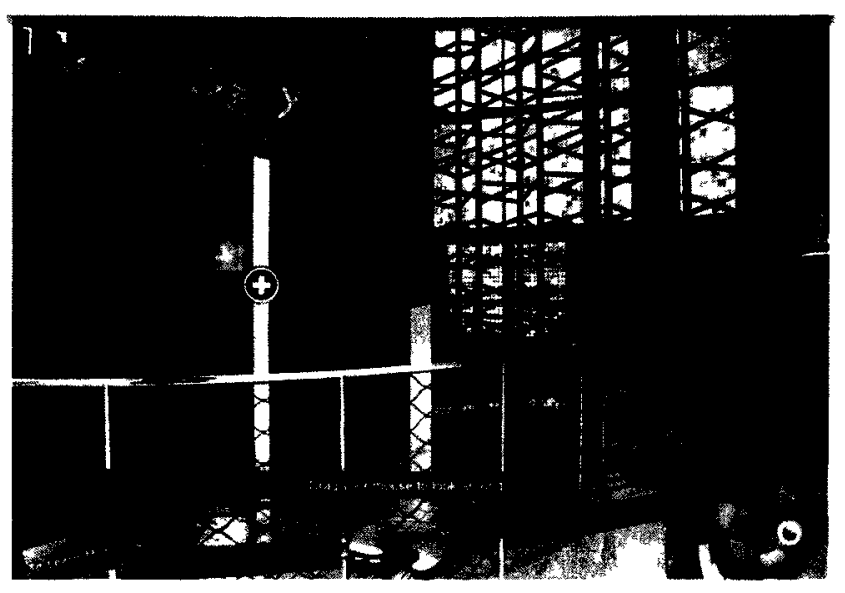


The Latvian browsing pavilion provides the visitor with an overview of the pavilion but does not provide the full experience. The exuberating experience of flying one can experience within the physical pavilion, described earlier, is not provided and therefore, the overall pavilion intent within the physical is not achieved.

For the Browsing Pavilions, the intent is to demonstrate the presence of all nations participating in the exhibition as well as providing an overview of information related to the pavilion. The Browsing Pavilions are useful in that they create a complete online exhibition site and provide an online experience of the entire World's Fair, rather than focusing on individual pavilions.

The Experiencing Pavilions are constructed by the individual nations participating in the online exhibition and can be much more in depth than the Browsing counterpart. In this second type of virtual pavilion, the visitor can be allowed free movement to explore the various animations, games, images, and texts that may populate the space. The Experiencing Pavilion is intended to share a similar interior layout with its physical counterpart built in the Shanghai site; however, the online pavilion has the opportunity to create an extended, and in the case of this thesis, four-dimensional space that can expand on the original ideas and themes presented in the physical pavilion ${ }^{\text {xxiv }}$. More importantly, and in reference to this thesis' main argument, the experiencing pavilion can progress with ideas unable to be realized in the physical due to financial, space, time, or physical constraints.

The Slovenian Experiencing Pavilion (figure $2^{18}$ and $2^{19}$ ), is a straight copy of the physical. The visitor walks through the designated path mentioned in the description of its type two physical pavilion, where they pass videos that can be played and display cabinets that can be zoomed into to provide additional text and imagery. The pavilion contains all information provided in the physical and does not provide an extended online space. Although no additional information is provided, the virtual pavilion allows for smooth movement in both walking and viewing, which is an improvement on many of the other national pavilions. The replica of the information contained allows for the viewer to experience the pavilion fully, unlike the Browsing Pavilions that only contain portions of the exhibit. This pavilion would have been an even more 

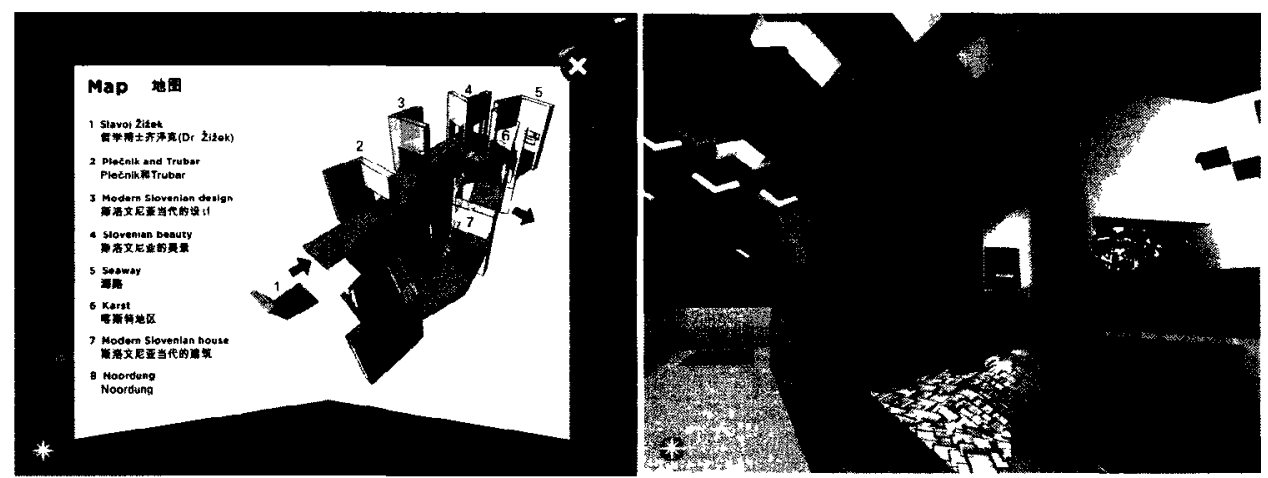

$2^{18}$ and $2^{19}$ Slovenian Virtual Pavilion: On the left one can see the layout of the virtual pavilion, which is identical to the physical Slovenian pavilion. On the right is the virtual pavilion that can be easily navigated by the virtual inhabitant.

successful virtual construction if it had continued the already existing path into the extended virtual.

The Spanish Experiencing Pavilion uses an avatar to go through a replication of the physical version described earlier (figure $2^{20}$ ). Audio stimuli are played while the visitor passes through visual displays. The avatar can walk, run, and turn within the space, experiencing the exhibits freely. Unfortunately, some complexity of the exhibits is lost when translated to the online experience since the live performances are removed entirely. Despite this, new perspectives are gained through the creation of an extended space not present in the pavilion built in Shanghai. Once the visitor reaches the pavilion's final exhibit, an illuminated indicator

\footnotetext{
$2^{20}$ Spanish Virtual Pavilion: The Spanish virtual pavilion uses an avatar to move throughout the virtual exhibit space.
}

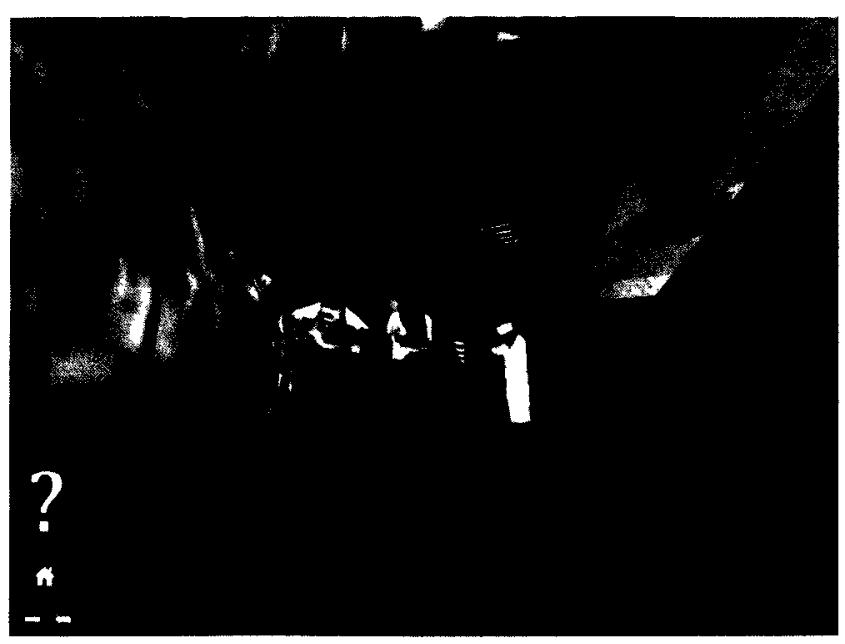


shines from the floor. After walking into it, the visitor is asked to play a short game correctly identifying light patterns in a fashion similar to the game Simon ${ }^{x \times x}$. Once completed, the viewer can enter the "extended" (figure $2^{21}$ and $2^{22}$ ). Here, one can zoom into photographs of the pavilion building taken by visitors of the Expo 2010 Shanghai and uploaded to online social networking sites like Facebook and Twitter. The extended space provides the online visitor with an experience based on a physical visit. Although a successful spatial extension, it would have benefitted from greater integration with the replica of the built pavilion.
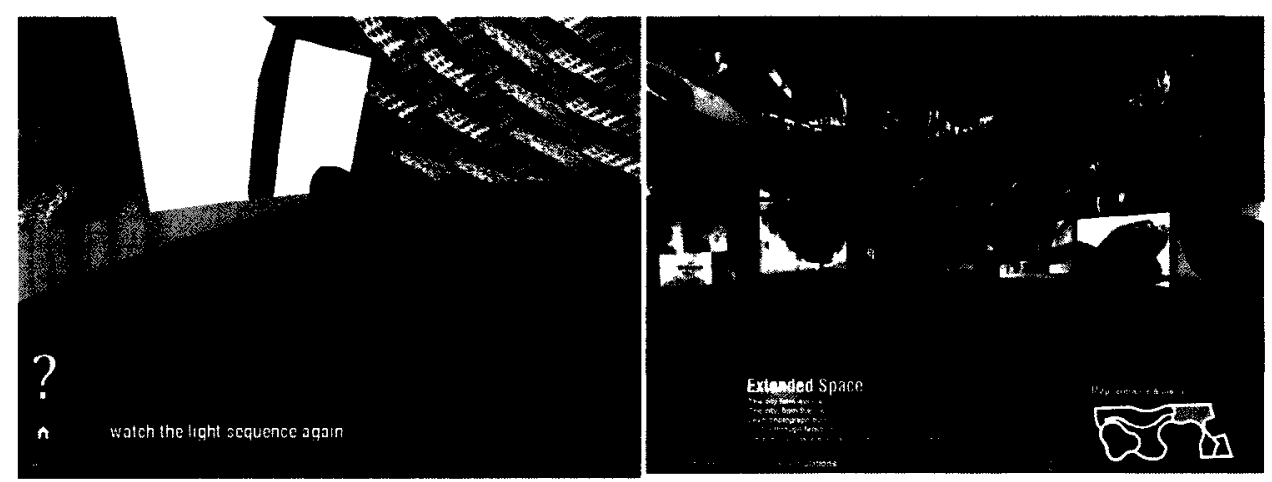

$2^{21}$ and $2^{22}$ Spanish Virtual Pavilion: To enter the extended virtual space the avatar must enter an illuminated area and play a short pattern game. The extended virtual space contains photos of the physical pavilion taken by the exhibition visitors and uploaded onto the Internet.

Expo Shanghai Online has the opportunity to explore ideas and concepts not possible in the built exhibition as well as being accessible after the Shanghai site is closed. The online pavilions are given the chance to extend ideas developed in their physical counterparts. Physicsdefying structures, economics, time, or space breaking elements, even expanding constructions are now possible within the space provided by Expo Shanghai Online; however, even the most successful online Experiencing Pavilions, such as the Slovenian and Spanish pavilions, do not take full advantage of the platform and the possible spatial extensions. The Browsing Pavilions are successful in helping complete the online exhibition site and in allowing those from around the world to view the individual pavilions; but they do not add anything to the built pavilions' concepts. This virtual Andorran pavilion developed through this thesis will take full advantage of the available platform and become a clear progression from the built counterpart. This pavilion will take the three-dimensional pavilion and translate it into the fourth dimension. 
i Jackson, Anna. Expo: International Expositions 1851-2010. New York: V\&A Publishing, 2008. Pg 10.

ii Jackson, Anna. Expo:International Expositions 1851-2010. New York: V\&A Publishing, 2008. Pg 7.

iii Jackson, Anna. Expo: International Expositions 1851-2010. New York: V\&A Publishing, 2008. Pg 10, 12, 13.

iv Zhenghua, Wang. "Number of Participants at 2010 Expo hits record." China Daily. <http://www.chinadaily.com.cn/ china/2010expo/2010-04/29/content_9789076.htm> April 29, 2010. Visited October 10, 2010.

v Expo Shanghai Organizers. Expo 2010 Shanghai China. <http://en.expo2010.cn/> Unknown Date. Visited October 10, 2010.

vi Jackson, Anna. Expo: International Expositions 1851-2010. New York: V\&A Publishing, 2008. Pg 101.

vii Jackson, Anna. Expo: International Expositions 1851-2010. New York: V\&A Publishing, 2008. Pg 43.

viii Jackson, Anna. Expo: International Expositions 1851-2010. New York: V\&A Publishing, 2008. Pg 44.

ix Harvey, Penelope. Hybrids of Modernity: Anthropology, the Nation State and the Universal Exposition. [electronic resource]. London : Taylor \& Francis e-Library, 2003. Pg 54.

x Massicotte, Isabelle. The Architecture of Expo 67: National Identities and the Signs of Time. Ottawa:Carleton University, 2003. Pg 1.

xi Scobie, Alexander. Hitler's State Architecture; the Impact of Classical Antiquity, University Park,: Pennsylvania State U., 1990. pg 2.

xii Collier, Basil. "Over the Pass: a Visit to the Co-Principality of the Valleys of Andorra ", Architectural Review. 1940, Aug., v.88, P 47-50. Pg 50.

xiii Shanghai Expo.World Exhibition Shanghai China 2010 Participation Guide (For Official Participants) p A-16

xiv Shanghai Expo.World Exhibition Shanghai China 2010 Participation Guide (For Official Participants) p ?.

xv Shanghai Expo.World Exhibition Shanghai China 2010 Participation Guide (For Official Participants) p D-3.

xvi Latvia Pavilion Organizers. "About Us." Latvia Pavilion. < http://pavilion.expo.cn/c2080/ssize/en/html/01.html> Unknown Date. Visited October 20, 2010.

xvii Latvia Pavilion Organizers. "Theme." Latvia Pavilion. < http://pavilion.expo.cn/c2080/ssize/en/html/03.html> Unknown Date. Visited October 20, 2010.

xviii Latvia Pavilion Organizers. Latvia Expo 2010. < http://www.latvijaexpo2010.lv/en/latvijas-paviljons/ > Unknown Date. Visited October 20, 2010.

xix Expo Shanghai Organizers. "Spain Pavilion." Expo_2010 Shanghai China. <http://en.expo2010.cn/c/en_gj_tpl_74.htm > Unknown Date. Visited October 24, 2010.

xx Spanish Pavilion Organizers. Pabellón de Espana. < http://www.pabellonshanghai.es/en/pabellon/156> Unknown Date. Visited October 10, 2010.

xxi Spanish Pavilion Organizers. Pabellón de Espana. < http://www.pabellonshanghai.es/en/pabellon/157> Unknown Date. Visited October 10, 2010

xxii Spanish Pavilion Organizers. Pabellón de Espana. < http://www.pabellonshanghai.es/en/pabellon/157(162, 163, 164)> Unknown Date. Visited October 10, 2010.

xxiii Shanghai Expo.World Exhibition Shanghai China 2010 Participation Guide (For Official Participants) p D-6-8.

xxiv Innovatif. Shanghai Expo 2010: Slovenian Pavilion. <http://www.expo2010.si/en/slovenian-pavilion/> Unknown Date. Visited October 24, 2010.

xxv Innovatif. Shanghai Expo 2010: Slovenian Pavilion. <http:// www.expo2010.si/en/slovenian-pavilion/ presentation-of-thepavilion / $>$ Unknown Date. Visited October 24, 2010.

xxvi Republic of Slovenia. Slovenia.si:Your Gatewav to Information on Slovenia. <www.slovenia.si/ spotlights/201007/201007211051467> Unknown Date. Visited October 9, 2010. 
xxvii Innovatif. Shanghai Expo 2010: Slovenian Pavilion. <http:// www.expo2010.si/en/slovenian-pavilion/stories> Unknown Date. Visited October 24, 2010

xxviii Shanghai Expo.World Exhibition Shanghai China 2010 Participation Guide (For Official Participants) p D-2.

xxix Shanghai Expo.World Exhibition Shanghai China 2010 Participation Guide (For Official Participants] p D-9.

xxx Zhongxiang, Zhang. "African Joint Pavilion - Shanghai Expo: Not to be missed." Forum on China-Africa Cooperation. <http:// www.focac.org/eng/zfgx/t696790.htm> May 25, 2010. Visited October 19, 2010.

xxxi Unknown Author. "Comoros Pavilion." World Expo 2010 Shanghai. <http://expo2010shanghai.com/?s=comoros> September 3, 2010. Visited October 20, 2010.

xxxii Zhongxiang, Zhang. "African Joint Pavilion - Shanghai Expo: Not to be missed." Forum on China-Africa Cooperation. <http:// www.focac.org/eng/zfgx/t696790.htm> May 25, 2010. Visited October 19, 2010.

xxxiii Unknown Author.Andorra Country Review [electronic resource]. Houston: CountryWatch Incorporated, 2010. Pg 1.

xxxiv Shanghai Expo.World Exhibition Shanghai China 2010 Expo Shanghai Online: Guide For Development and Construction or the Experiencing Pavilion. p 2-3.

$x x x v$ Simon is a game of memory that tests a person's concentration by having them repeat a series of patterns. 


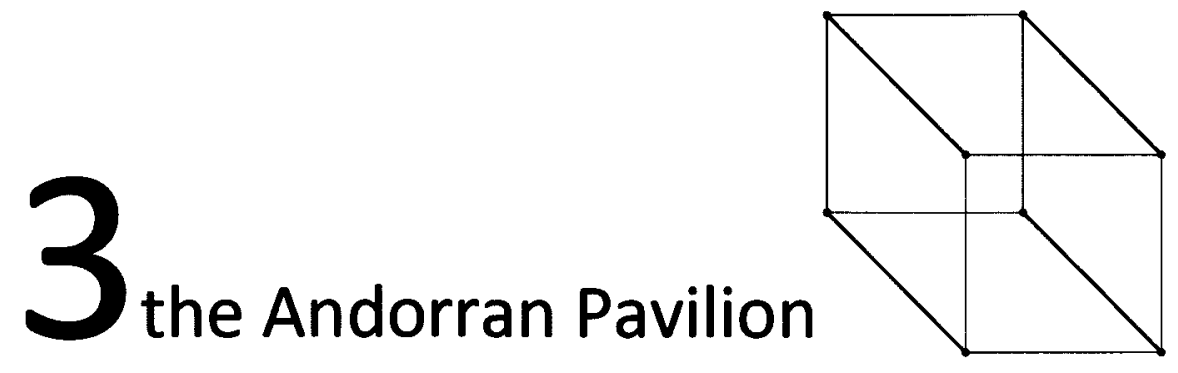

\section{Building Blocks of the Fourth Dimension}

In order to begin the translation from an architecture of the third dimension to an architecture of fourth, it is necessary to develop a set of tools. The tools, discussed below, are comprised of: the four-dimensional axis, the four-dimensional grid, and the unit hypercube ${ }^{i}$ building blocks. These tools will be discussed individually before proposing a comprehensive, four-dimensional pavilion for Andorra's entry into the 2010 exhibition.

The first of these tools, the four-dimensional axis, is generated through a computeraided design (CAD) software. These programs provide a three-dimensional modeling space where items such as a traditional three-dimensional axis $(x, y$, and $z)$ are easily created. The four-dimensional axis is created when a new ' $w$ ' directional arrow is added to the modeled three-dimensional axis at an angle equal to the other three. To create the four-dimensional grid, planes are created connecting each axis arrow to the other. The usual $x y, x z$, and $y z$ planes are present with three new planes joining each former directional arrow to the new $w$ arrow. The placing of the $w$ directional arrow in a direction representing perpendicular to the other grids as well as the drawing of grid within the axis can be described in a similar way as to how a three-dimensional grid is represented on paper: a three-dimensional object represented on a two-dimensional medium. By inserting the axis and grid for an alien dimension into the twodimensional plane or three-dimensional space, the illusion of the higher dimension is observed, as seen in figure $\mathbf{3}^{1}$.

This new axis, when in the context of three-dimensional modeling programs, is also a common tool used for orientation. Demonstrated in the images below in figure $3^{2}$, as one 

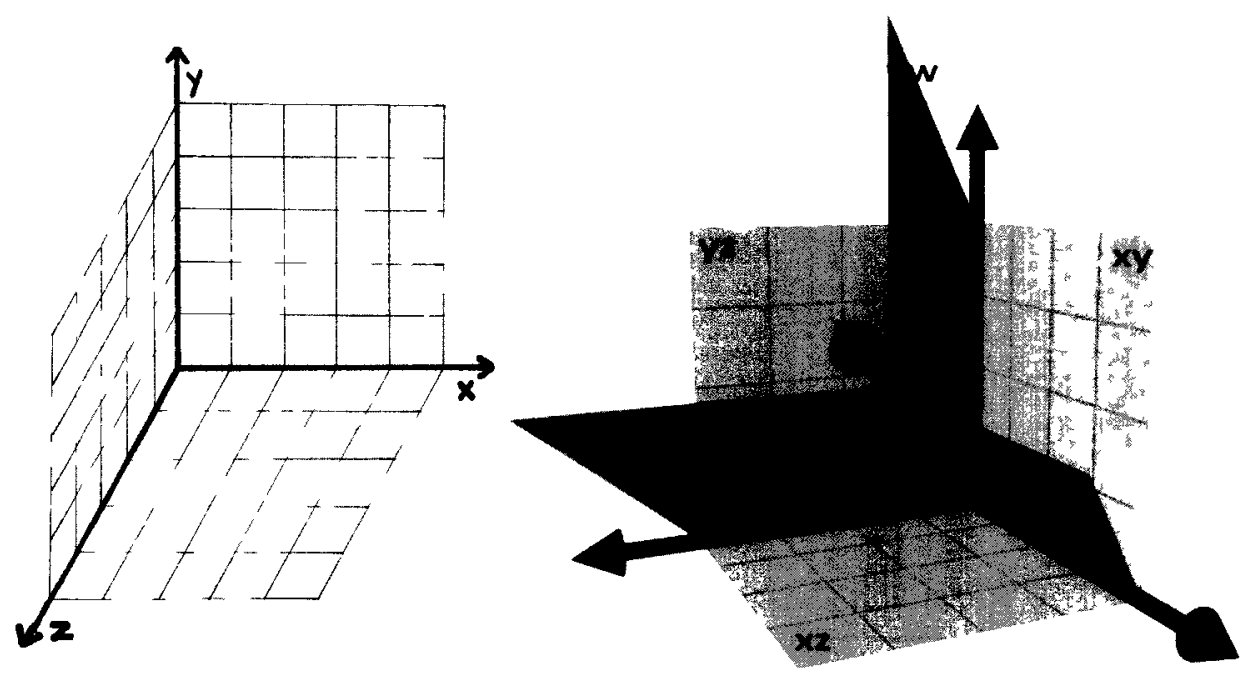

$3^{1}$ Three-Dimensional Grid and Four-Dimensional Grid: The three-dimensional grid is drawn on two-dimensional paper. The illusion of a third dimension is provided with the use of angles. The four-dimensional grid is created within a three-dimensional space with the fourth dimension alluded to through angles as well. New planes are added within the

$x w, y w$, and $z w$ planes.

$3^{2}$ Three-Dimensional and Four-Dimensional Axis

Rotation: As an axis rotates, certain views will eliminate the higher dimension.
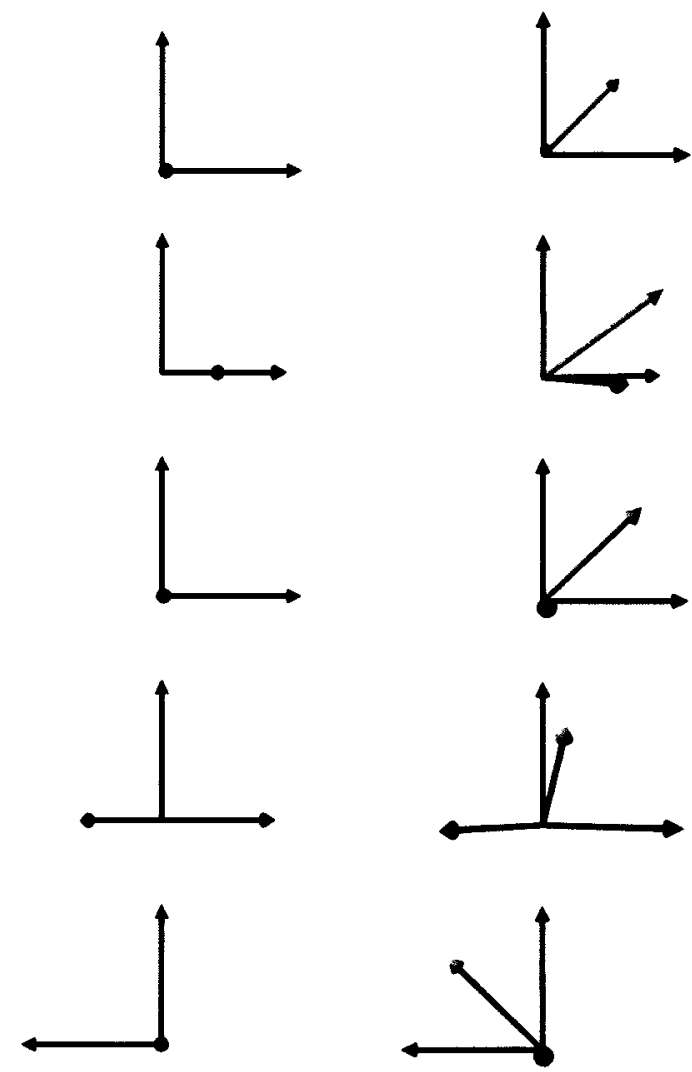
rotates their view, the selected axis rotates as well, showing clearly the orientation as it changes from elevation to axonometric view. When expanded in the $w$ direction, the four-dimensional axis allows an easy understanding of how this new dimension relates to its lower dimensional counterparts and how it can be broken down into its smaller components. Much like how a three-dimensional object can break down into plans and elevations, a four-dimensional object can break down into its three-dimensional equivalent. This implies that if viewed orthogonally, or through a strict perspective, a four-dimensional form, a hypercube in this example, can rotate to only reveal its three-dimensional 'sides'.

With this grid created, it is now possible to generate the next four-dimensional element: the unit hypercube. This is achieved by first outlining a square measuring one grid unit along the $x$ and $y$ grid. The next step is to extrude the square one unit along the $z$ grid to form a unit cube. This unit cube is then extruded one unit along the $w$ grid to form the unit hypercube, the building block of the fourth dimension (figure $3^{3}$ ).

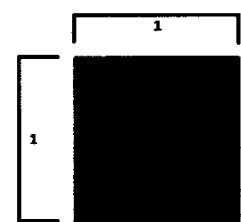

unit square
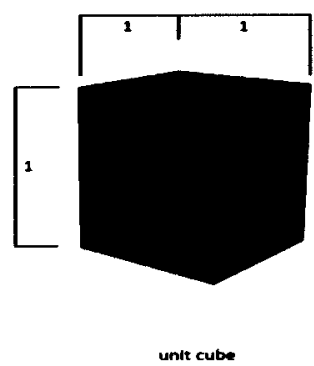

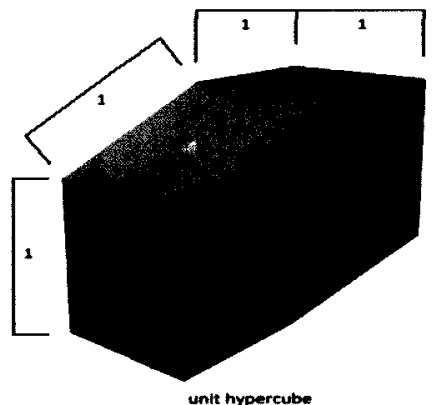

$3^{3}$ Unit Square, Cube, and Hypercube: $A$ unit object measures one unit it every direction, be it within the second, third, or fourth dimension.

With these tools in hand, we can proceed to the construction of a four-dimensional architecture that addresses Charles Howard Hinton's theory of a "spatial fourth dimension." Here, the unit hypercubes are treated similarly to traditional children's toy blocks, where the act of stacking to create objects and spaces occurs in a higher dimension. The result is basic geometric configurations as seen in figure $3^{4}$. 

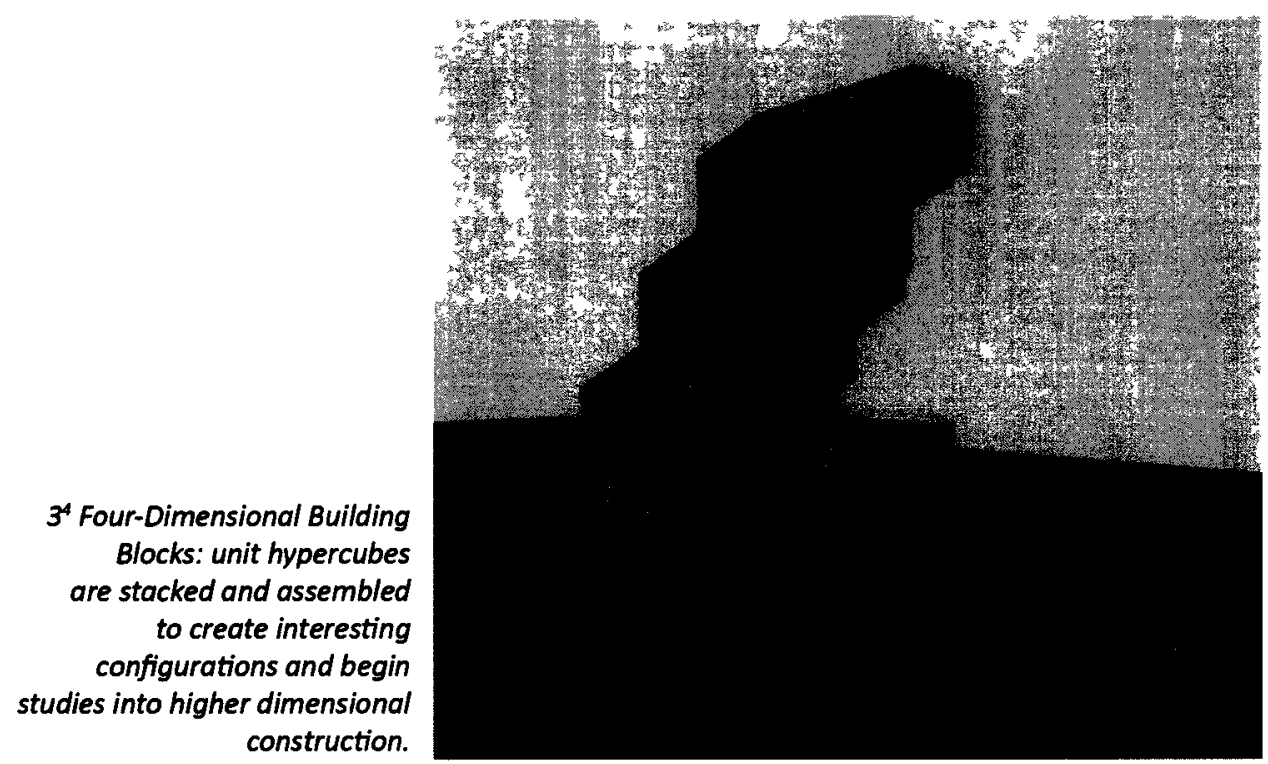

\section{A Prototype for Andorra's Pavilion in the Fourth Dimension}

The first design strategy utilizes the tools discussed above while incorporating quantitative data acquired prior to travelling to Andorra. The focus here is on three facts of Andorra: its small footprint of 468 square kilometres, its high altitude within the Pyrenees Mountains, and its co-sovereignty between Spain and France. Over the last several centuries, this small nation has passed between French and Spanish ownership until, in 1278, an agreement was signed between the two countries to make Andorra its own nation under the cosovereignty of both French and Spanish rule. Andorra, although still described as co-sovereign, reduced the amount of power held by both France and Spain with the writing of a constitution in $1993^{\prime \prime}$. These three points will be manifest in the first iteration of a translation of an architecture of the fourth dimension.

By stacking unit cubes, a tall narrow three-dimensional physical structure emerges. This structure consists of two unique paths, path $A$ and path $B$, which are in a constant state of interaction. Together, they form a solid shape measuring three grid units in both its $\mathrm{x}$ and $z$ direction and six in its $y$ direction. Extending this arrangement into four-dimensional space reveals the two paths to not be touching but to be separated by a new volume along the $w$ axis. 
Path $B$, shown in blue, shifts two units along the $w$ axis and reveals a new surface connecting the two paths, indicated in red. This surface, only visible within the higher dimension, holds further exhibition space that is not available within the three-dimensional pavilion (figure $3^{5}$ ).

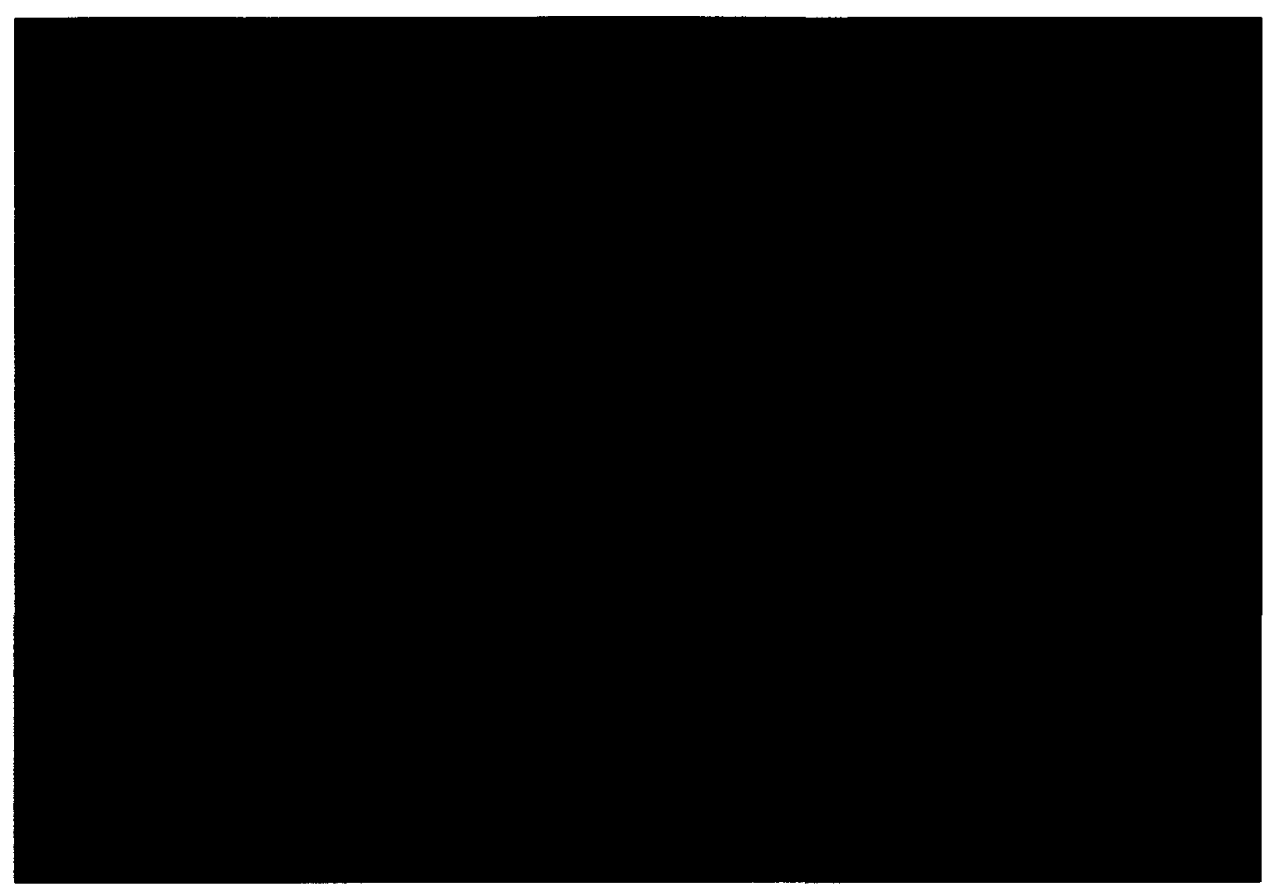

$3^{5}$ Andorran Pavilion Prototype: Path A (blue) and path B (yellow) fill two halves of the physical pavilion. Once the pavilion is viewed in the fourth dimension, a new element shown in red separates the previous joining paths.

The use of these basic tools to construct a prototype for Andorra's pavilion allows for a better understanding of the relationship between the three and four-dimensional. Breaking the design process into its fundamental shapes and components, demonstrated in this first example, provides a way to begin the explorations into how three-dimensional constructions expand into the four-dimensional space without complicating the process with complex geometries. This prototype, while simplistic, sets the stage for a more complex design and dimensional exploration. 


\section{A Pavilion for Andorra, Shanghai Expo 2010}

\section{Andorra's Pavilion in the Third Dimension}

Where the fourth dimensional prototype was designed with readily available information, the final project is informed by a short research trip to Andorra. After experiencing the country in first-person, it was possible to explore the integration of the more intangible qualities related to a visit to Andorra for the first time. From this visit, it became evident that, although the country is located high in the Pyrenees Mountains, as previously described, the majority of the cities are located in valleys. This geographical situation gives the sense that the population is tucked away below the mountains and not among their peaks as shown in Figures $3^{6}$. To further disorient the visitor, the few roads available for one to enter Andorra wind up, down and around the slopes, making one almost feel lost as they wander through the mountains. After the breathtaking and completely disorienting journey through the looping roads, with every step completely devoid of civilization, with the exception of the ribbon of asphalt highway, one last turn brings you to the Andorran border. The small country appears, opening up within the mountains. Every further turn of the road begins to reveal more hidden communities and treasures, proving Andorra was worth the long journey. Within the small cities of Andorra, these long winding roads turn into cobblestone paths (figure $3^{7}$ ). Here, they wind around and take the visitor through secret passageways often leading to private courtyards,
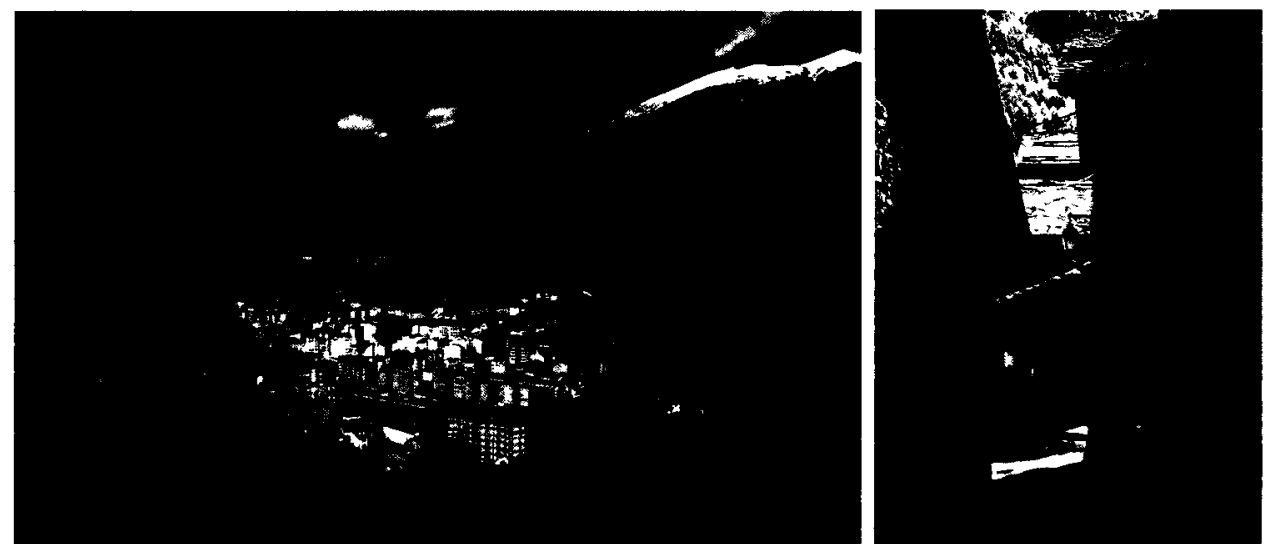

$3^{6}$ and $3^{7}$ Andorran City Within the Valley and Andorra City Cobblestone Paths: The Andorran cities are all contained within the Pyrenees Mountain's Valleys. The streets within these towns are often narrow and cobblestone. 
popular shopping districts, and beautiful lookout points. In one case, the path takes the visitor up a series of public stairs to the roof of a building with a simple children's play structure set against the breathtaking backdrop of the Pyrenees Mountains. Another path leads to a grassy hill, home to a dozen stray cats, and encroaches on the roofs of centuries old buildings. This journey through a hidden nation that reveals itself by awe-inspiring spatial moments is the central narrative for the Andorran Pavilion.

The Andorran pavilion for the third dimension fits within the smaller of the Expo 2010 Shanghai type-two pavilion shells: a simple steel-frame construction 20 metres wide by 25 metres long and 10 metres in height (figure $3^{8}$ ), providing a total area of $500 \mathrm{~m}^{2}$ or spatial volume

$3^{8}$ Andorran Pavilion Shell: The Andorra pavilion will use a Type 2 steel pavilion shell that measures 20 metres wide by 25 metres long and 10 metres tall. The exhibition organizers will rent the $500 \mathrm{~m}^{2}$ shell to the country.

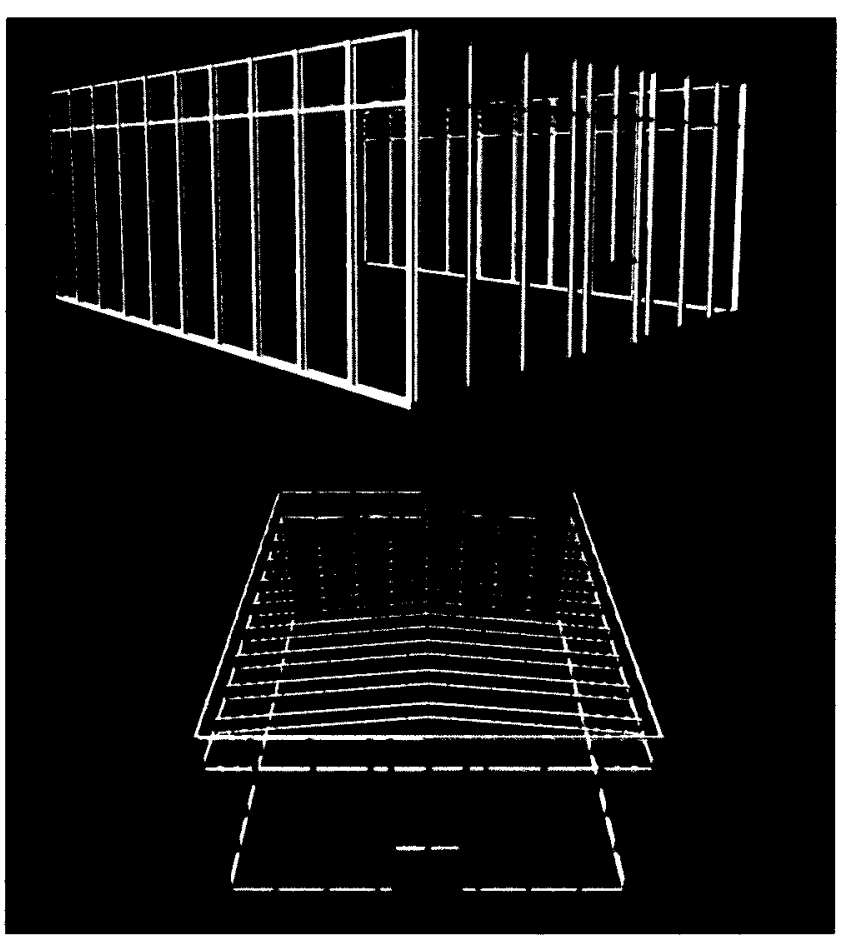

of $5000 \mathrm{~m}^{3}$. The location of the Andorran pavilion is within Zone $\mathrm{C}$ of the exhibition grounds in the same block as the Spanish and French pavilions (figure $3^{9}$ ). The façade (figure $3^{10}$ ) is a simple, white reflective box that's only unique feature is a wooden canopy that breaks up the plain exterior to reveal a small stone wall. What distinguishes the Pavilion is hidden behind two wooden doors located in the stone portion under the canopy. Passing through the doors, the visitors stand before a wall of moving water. The translucency of the water distorts the view of the access to a balcony overlooking the main exhibit space beyond a full-height stone wall 

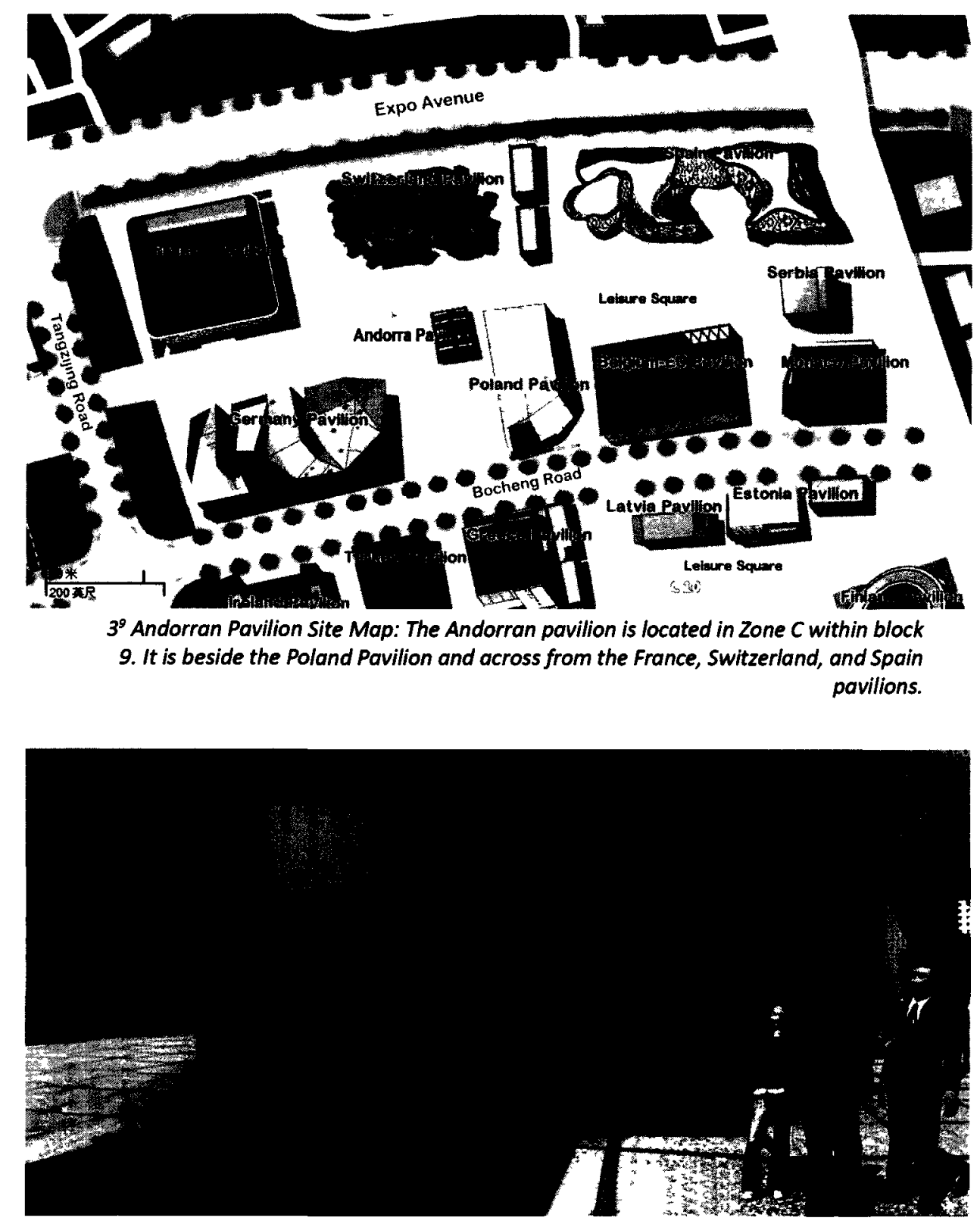

$3^{10}$ Andorran Pavilion Exterior: The Andorran Pavilion sits between the Poland and German Pavilions.

dividing the length of the pavilion. Following the initial spectacle of the water wall, the ambient noise of the water contributes to a sense of tranquility. Wooden benches on stone platforms allow the exhibition visitors to take a break from the noise of the exhibition and to listen to the water and their own thoughts. Shrubbery from different altitudes of the Andorran landscape and growing between the benches, provide an aroma of the Pyrenees. For a moment, the visitor hears and smells a small piece of Andorra (figure $3^{11}$ ). 
Located to the right of the entrance is a staircase with fieldstone risers and old wood plank runs leading up to a loft space overlooking the ground level resting area (figure $3^{12}$ ). Once at the top of the stair the visitor is facing the stone wall that separates them from the main exhibit. The stone wall and all other stone details found in the pavilion are salvaged from the disassembly of three houses from three different Andorran towns: Sant Julia de Loria in the south, Ordino in the west, and Encamp in Central Andorra. Once the exhibition is complete, the stone will be returned to the country and used in a new construction in the nation's capital, Andorra la Vella.

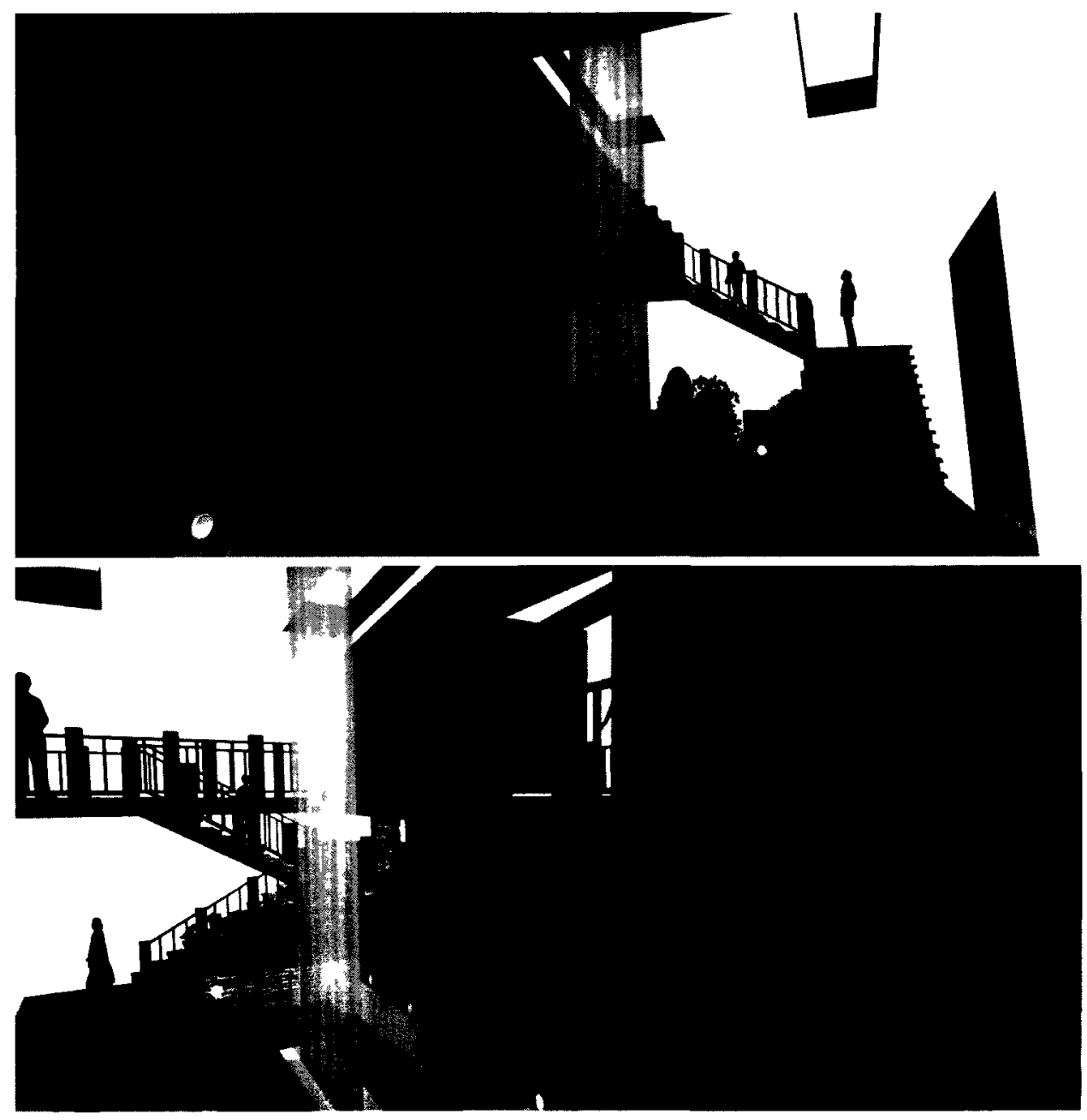

$3^{11}$ and $3^{12}$ Andorran Pavilion Interior: The front area of the Andorran pavilion is constructed of elements from Andorra. This makes this front area an artifact of Andorra. The front area is for relaxing. 
At the centre of the upper level are two wooden barn doors, each three metres tall, breaking up the stone wall. The barn doors are reclaimed from an old Andorran farm in the northern, rural part of the country. The wood planks of the door have darkened over time and show the signs of decades of ụse. The dry wood holds a slight tobacco smell from the harvesting and drying of tobacco plantsiii. These doors open onto a balcony that looks down at a relief map of Andorra. The map presents the country's key architecture, art, and numerous walking trails, ski hills, roads and cities (figures $3^{13}$ ). One important thing to note here is that the map can only

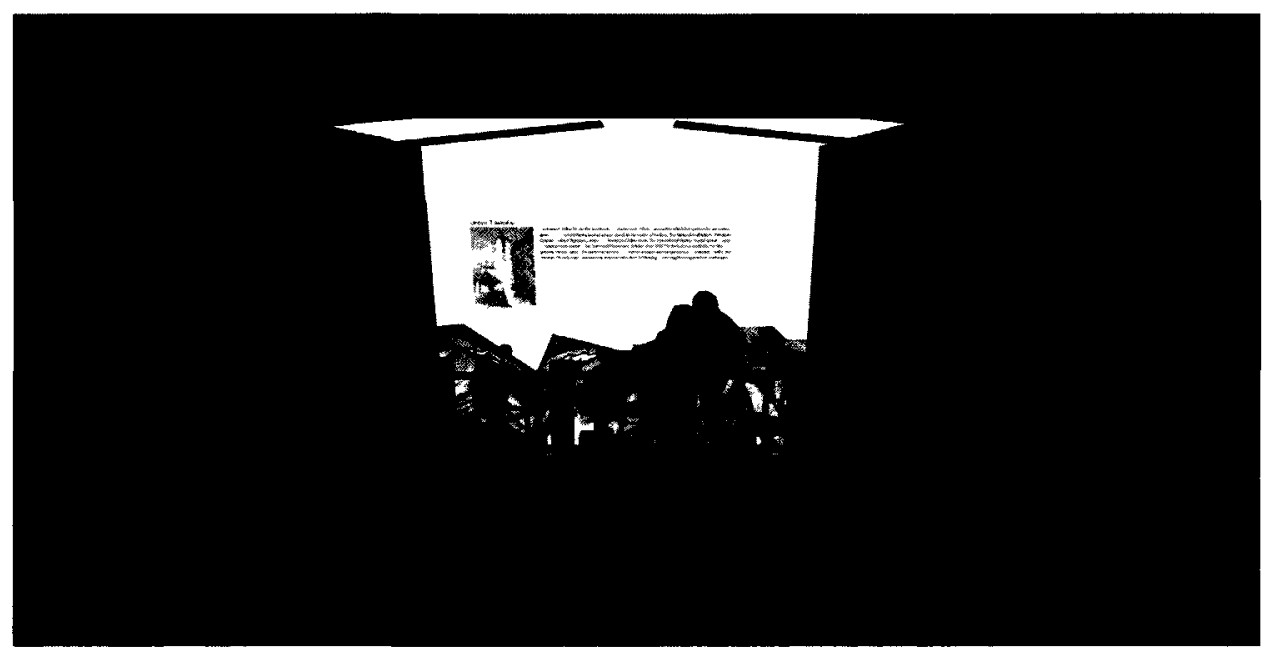

$3^{13}$ View of Main Exhibit From Main Balcony: The main exhibit is only viewable from the two balconies provided along the pavilion's internal route. The exhibit is a representation of Andorra and not comprised of real elements of Andorra. The exhibit is therefore a virtual representation of Andorra. The different exhibit elements are presently represented with symbols and the walls act as screens to show additional information.

be viewed from the balcony and not touched. Leaving the balcony and moving further along the double height space, the visitor comes to another staircase leading downwards. The wood of the railing the visitor holds for support contains small amounts of insect and weather erosion. This wood, as well as all wood found in the staircases, are taken from the Andorran landscape. Along the many Andorran walking trails are wooden details found in steps, railings, borders, and bridges. Through these paths maintenance, old wood is often replaced with new. The old wood has been salvaged for the pavilion. The landing of this staircase wraps into a secondary balcony over the main exhibit space. Once again, the visitor is allowed to look at the main exhibit, but cannot touch. The staircase ends at the ground level to the left of the resting area and the visitor 
now has the option to take advantage of the tranquil space and relax, or to exit the pavilion and continue with their Expo 2010 Shanghai adventures. The Pavilion is represented in plans and sections in figures $3^{14}$ and $3^{15}$.
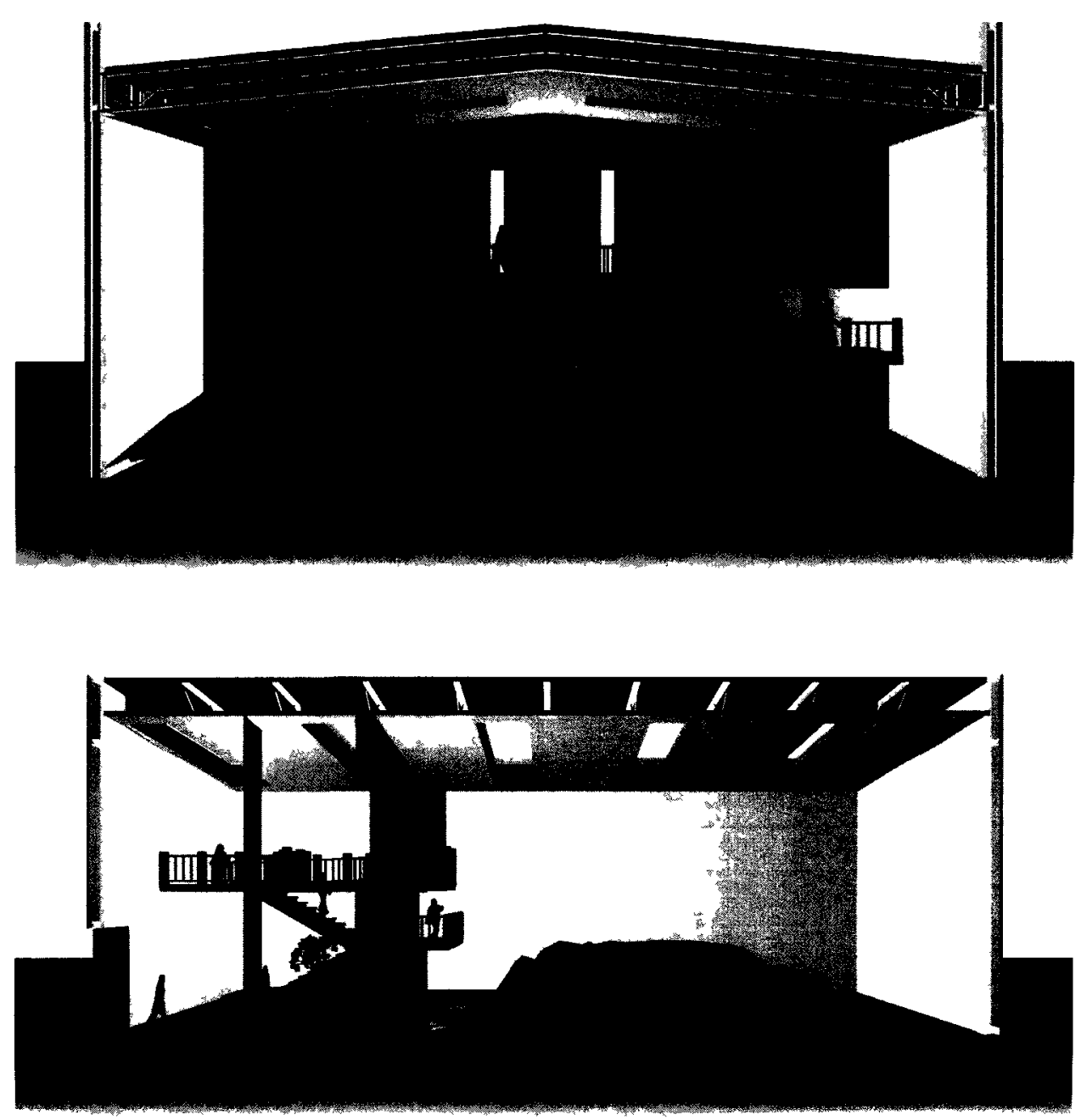

$3^{14}$ Andorra Physical Pavilion Sections: The top section shows the two balconies overlooking the main exhibit space. The bottom section depicts how the front resting area and the back exhibit area are separated with the stone wall. 

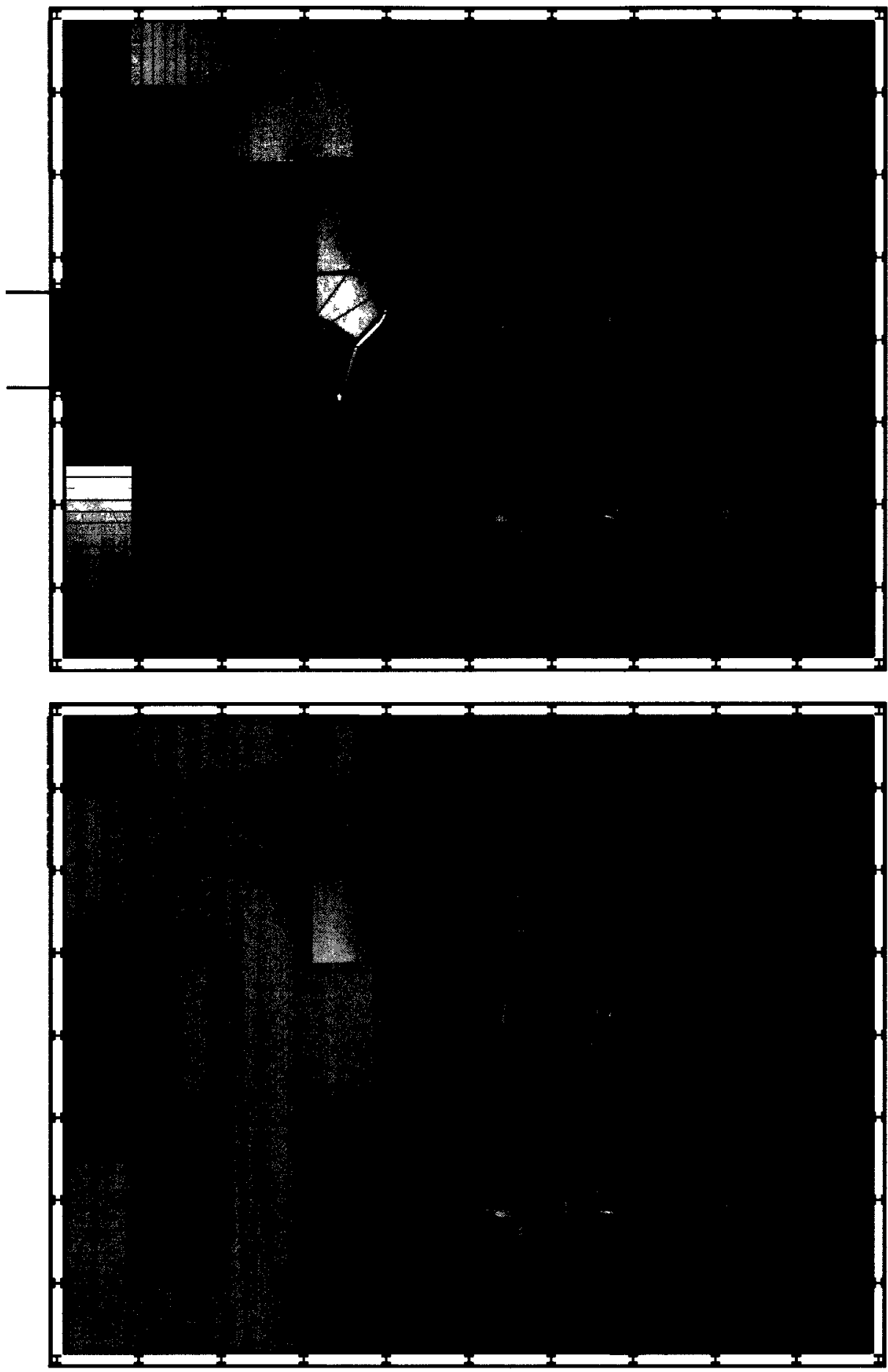

$3^{15}$ Andorra Physical Pavilion Plans: The top plan shows the ground level of the Andorran three-dimensional pavilion. The resting area with benches and water feature are represented. The bottom plan shows the staircase and second level balconies. 
The use of reclaimed materials in the interior of the Pavilion creates a phenomenal and sensory artifact set inside the undistinguished white box provided by the Expo 2010 Shanghai authorities. This is not a "miniature Andorra", but a piece of it. The fragments taken from the Andorran landscape create an Andorran artifact within the steel box. The main exhibit of the map, in the third dimension, is not an artifact of the nation but a representation. The map is reminiscent of the Andrea Pozzo's trompe l'oeils found in Rome's Chiesa de Sant'Ignazio where the trompe l'oeils extend the physical space into an imaginary or virtual (figure $3^{16}$ )v. Visitors to Sant'Ignazio experience the virtual world depicted in the paintings. Similarly, the map extends the Andorran artifact into the virtual Andorra shown in the main exhibit while keeping the virtual as only a visual element and not one to touch or interact with.

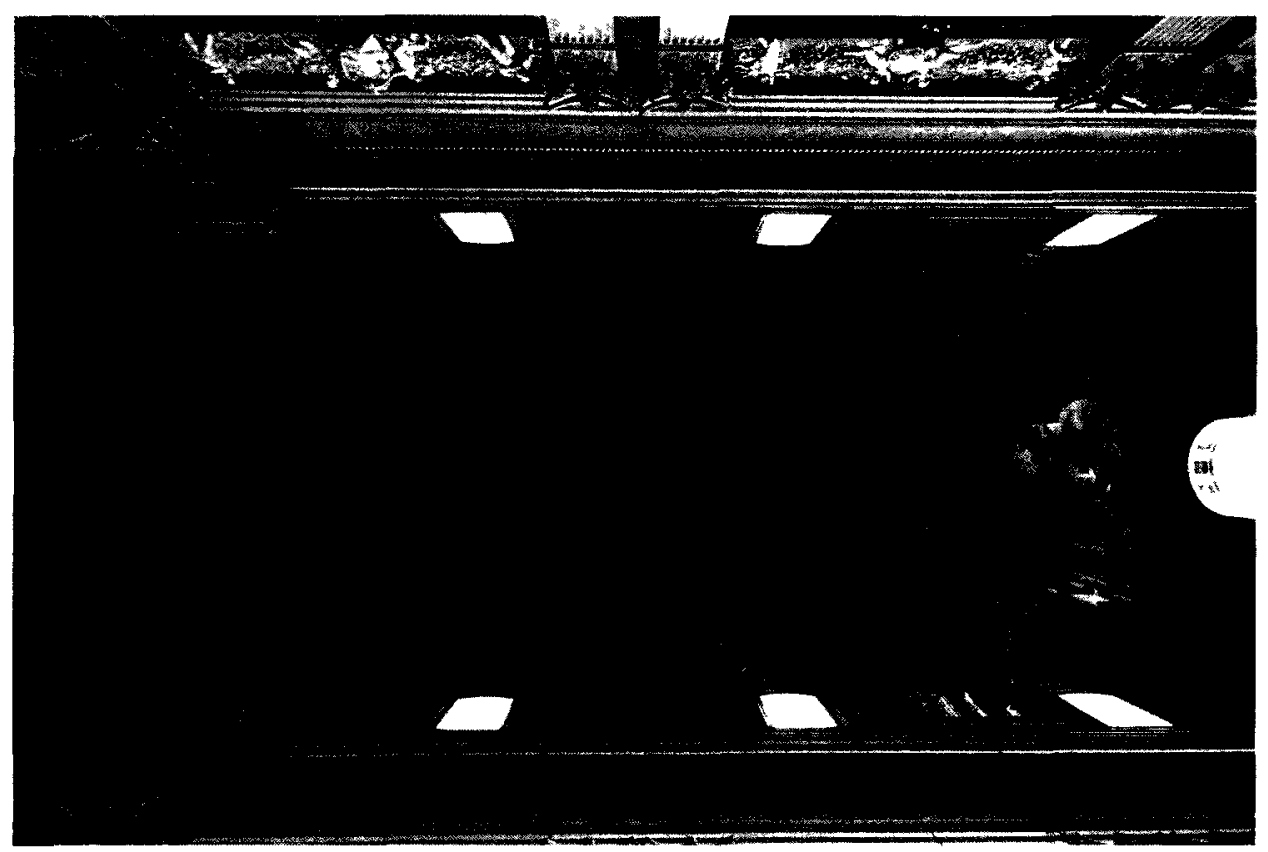

$3^{16}$ Sant'Ignazio Vault: The trompe l'oeil are paintings that pretended to extend real space into a new imaginary one. Their purpose is to create the illusion of impossible threedimensional constructions, such as depictions of heaven, or surpass the limitations forced upon the building through monetary or space constraints. In the case of Sant'Ignazio's vaulted ceiling, the ceiling is extended into a depiction of the story of the glorification of Saint Ignatius and the missionary work of the Jesuit Order with images of angels and other symbolic figures. The trompe l'oeil is used to extend the space into an imaginary one not physically possible. 


\section{Andorra's Pavilion for the Fourth Dimension}

The translation of the pavilion from the third to the fourth dimension begins with a web-based, digital model that simulates the pavilion for the third dimension. This model can be accessed from any computer with internet connectivity as well as from a control panel built into the balconies of the physical pavilion (figure $3^{17}$ ). The visitor to the web-based model interacts with the pavilion through the use of an interface (figure $3^{18}$ ) that allows them to move freely and easily in first or third person view, whichever the visitor prefers. While in first person view, they are restricted to artificial laws of gravity and collision and are unable to fly or pass through walls. The third person uses an avatar that has the same restrictions; however the camera may orbit around them freely, allowing the pavilion to be viewed, rather than inhabited.

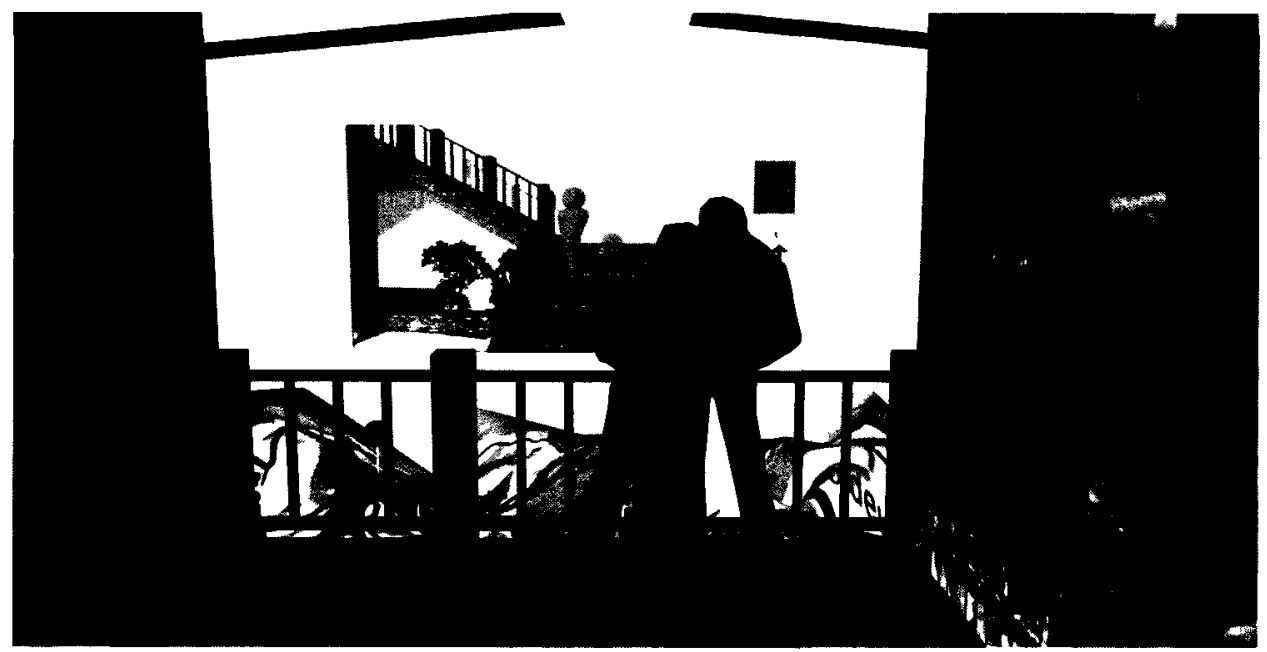

$3^{17}$ Physical Pavilion access to 4D Pavilion: From the balconies of the physical pavilion, a visitor can use a control panel to access the four-dimensional pavilion, allowing them to explore the higher dimension while occupying the lower dimensional pavilion. 


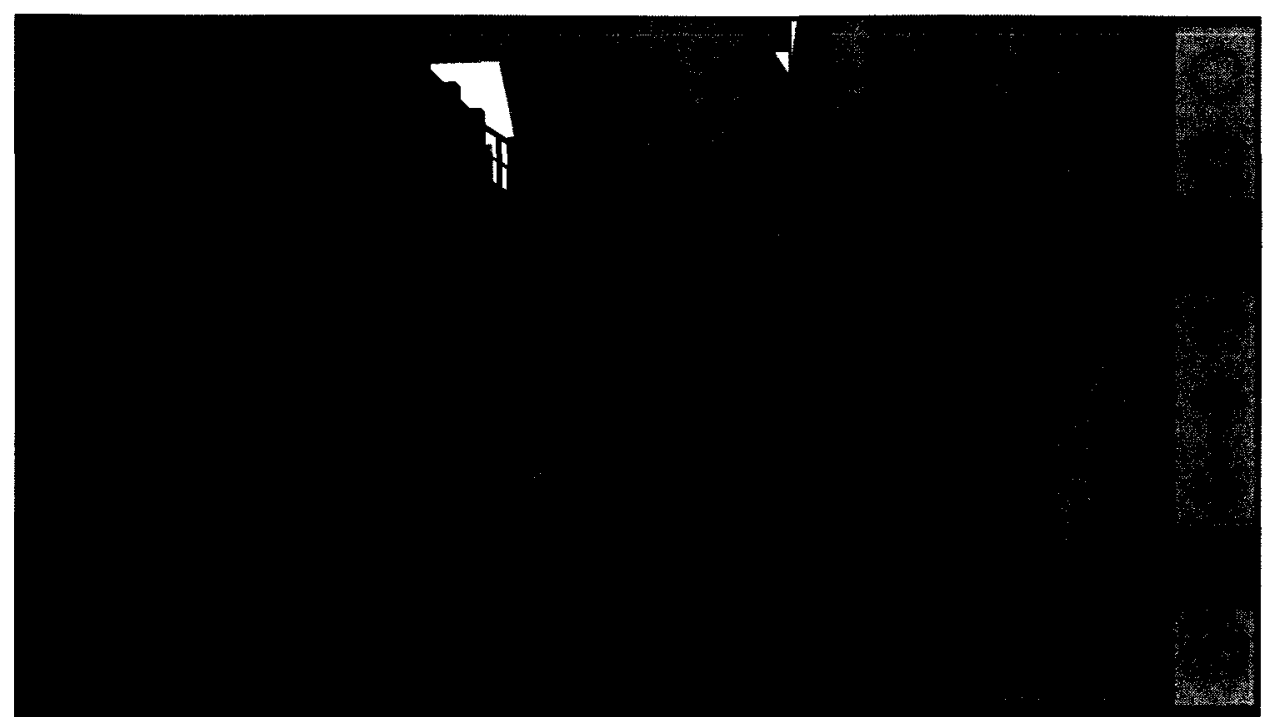

$3^{18}$ Online Pavilion Interface: The colors of blue, yellow, and red for the interface controls are chosen to reflect the colors of the Andorra flag. The control panel on the right if the Interface has eight commands: orbit, walk, third person, first person, next cross-section, previous cross-section, three-dimensional, and four-dimensional.

The difference between the two pavilions becomes evident when the visitor walks onto the balconies overlooking the main exhibit. The relief map from the physical pavilion is now reduced to a flat map of Andorra with only the roads outlined. The exhibit, defined as the virtual within the physical pavilion, is here viewed as a three-dimensional cross-section of a greater four-dimensional exhibit. Three-dimensional cross-sections, discussed previously in chapter one with the dimensional rules and the Beckman Institute, can best be understood when compared to two-dimensional cross-sections of a three-dimensional object. If a threedimensional object is sliced at key intervals, the whole object is understood by viewing the twodimensional cross-sections, such as in the case of a sphere being broken down into different size circles (as explained in chapter one). With cross-sections, there are unknown voids in the data between sections that can contain unexpected shapes. The circles may not construct a sphere but something entirely different as shown in figure $3^{19}$. A four-dimensional object can similarly be sliced to produce three-dimensional cross-sections with the area between them remaining a mystery until the object is viewed in its four-dimensional form. The exhibit space of the pavilion is therefore divided into five cross-sections. Contained to the right of the interface view on the visitors monitor is a control panel that contains the function to jump to the next or 


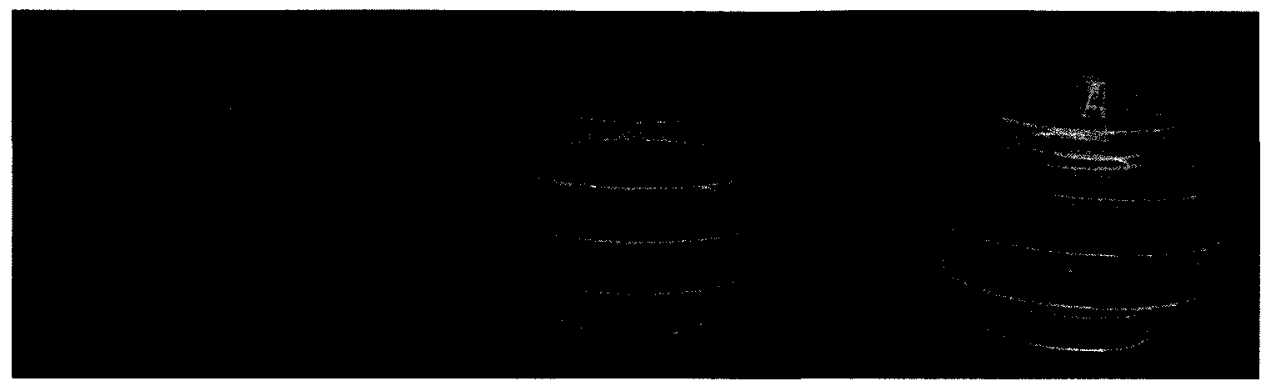

$3^{19}$ Two Dimensional Cross-Sections: The cross-sections of a sphere are not unique to its shape but may actually be the cross-sections of an irregular shape. The area between the cross-sections unknown until shown in the higher dimension.

previous cross-section, among other commands. The visitor first looks down from the balcony and views the first cross-section of the flat map with major roads outlined (figure $3^{20}$ ). They do not witness the height of the Andorran mountains and how they are used for skiing and hiking, nor do they see prominent architecture and art or learn about the Andorran cities. These are shown separately once the visitor jumps to the subsequent cross-sections. Within the three-dimensional pavilion, the distance in the $w$ direction that separates the cross-sections is removed; therefore creating a projection of the four-dimensional exhibit onto the three dimensional pavilion. All the cross-sections are viewed within the same space, appearing in the unified form.

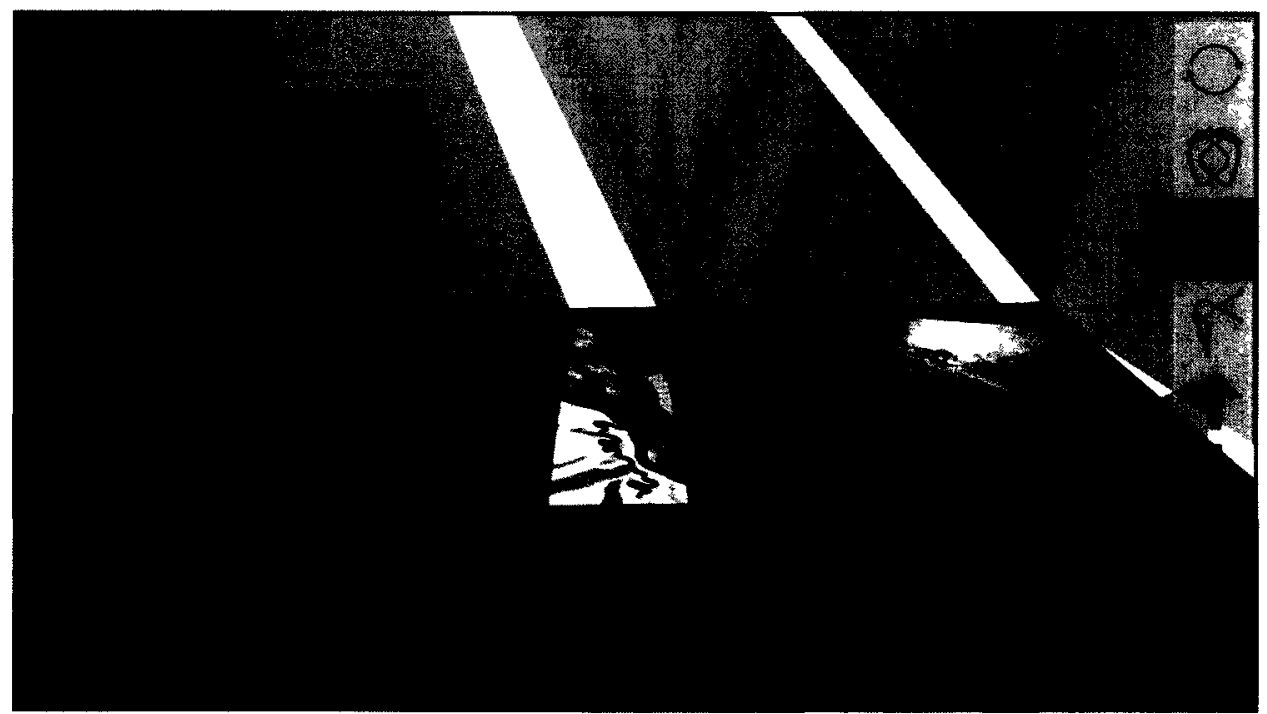

$3^{20}$ First Cross-Section from Main Balcony: Within third person view, the visitor views the first three-dimensional cross-section from the balconies. By using the control panel, the visitor can advance to the next or previous cross-section. 
The three-dimensional cross-sections that comprise the main Andorran exhibit do not show what is between them. Much like the circle cross-sections that do not belong to a sphere in the previous figure, the space between the different sections is a mystery at this point. To see this area, the visitor must change the view from three-dimensional to four by using a command found on the interface control panel. Once the command is activated, the scene rotates to reveal the fourth dimension, similar to the description of the axis rotation earlier in this chapter.

With the fourth dimension now visible, new elements appear while others have shifted to reveal what was not previously apparent. To maintain a level of simplicity so to not completely alienate the visitor, the new forms are comprised of the previously introduced planes of $x w, y w$, and $z w$ and are colour coded (figure $3^{21}$ ). The visitor, standing on the main balcony notices a shift in geometry to their side. The barn door that used to act as a barrier preventing them from falling has shifted along the new $w$ direction to reveal a staircase (figure $3^{22}$ ). The visitor, previously restricted to walking on the ground (or $x z$ ) plane, has the ability to

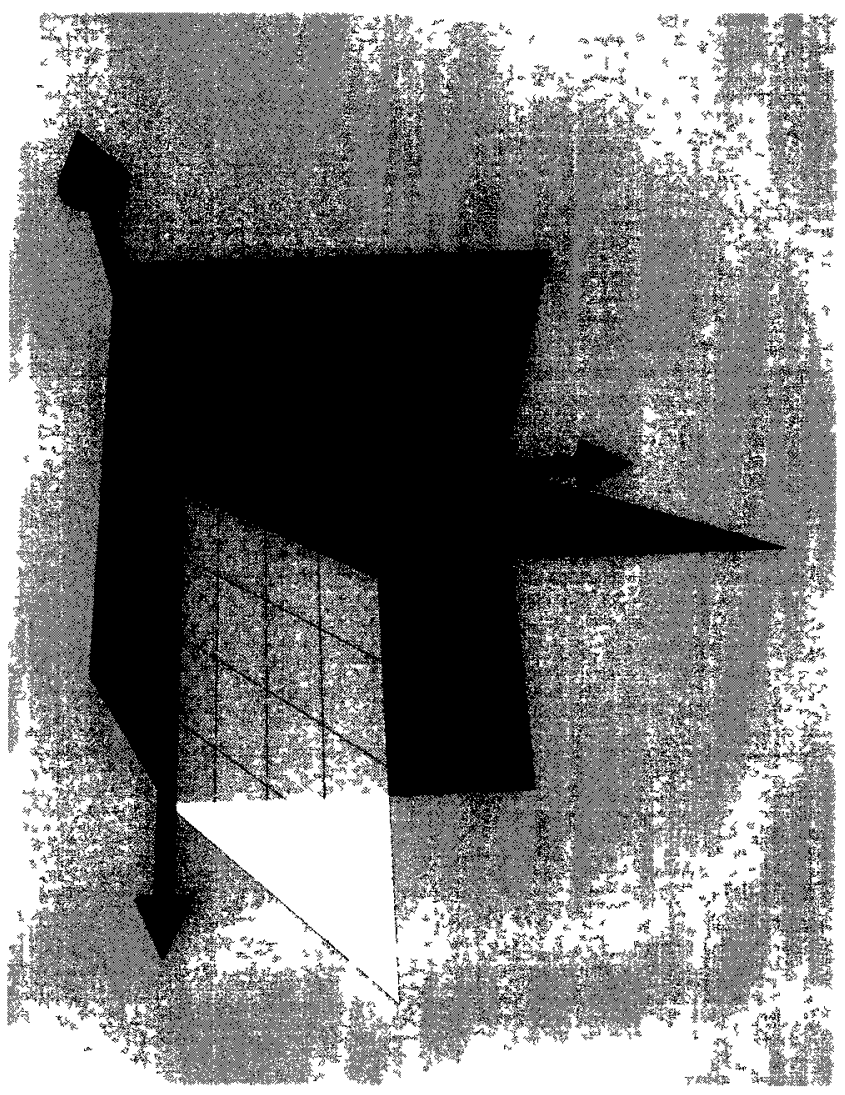




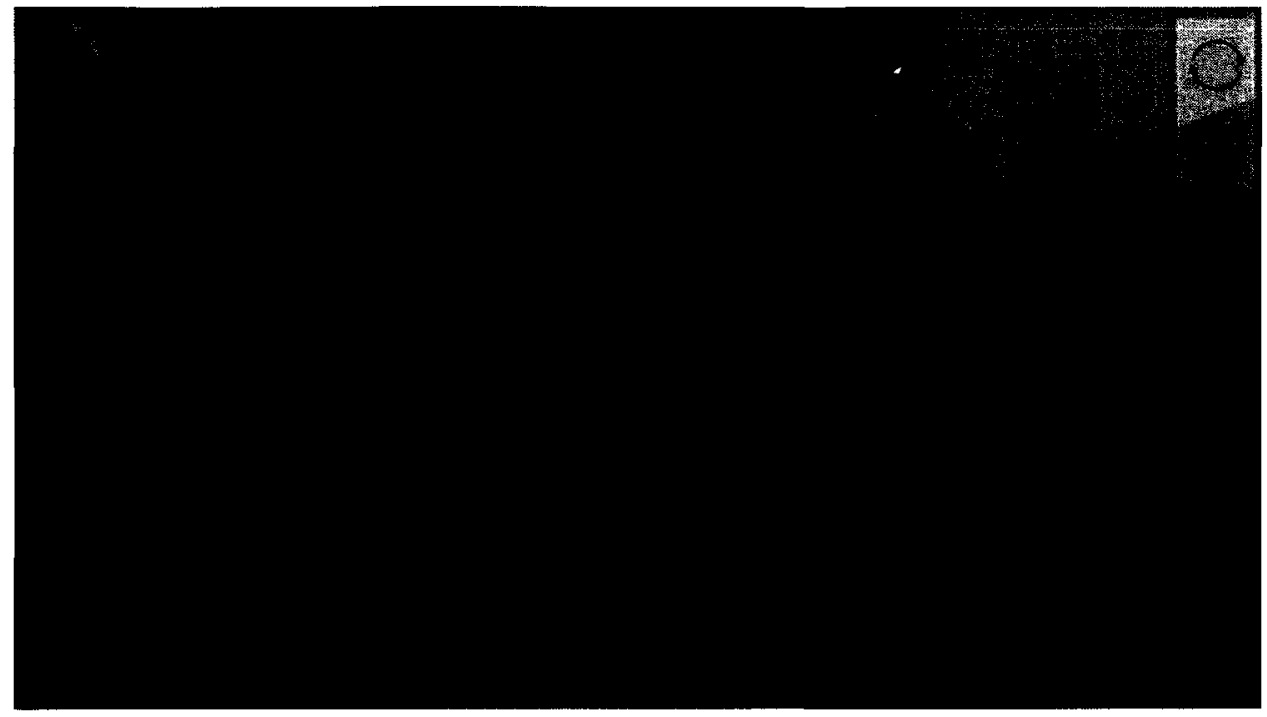

$3^{22}$ Four-Dimensional Staircase: After switching to the fourth dimension, the wall of the balcony is shifted along the $w$ axis and a staircase incorporating the $x w, y x$, and $z w$ planes is revealed.

walk along the new $\mathrm{xw}$ and $\mathrm{zW}$ planes. The visitor travels down the steps and for the first time, they have contact with the exhibit. They walk along the roads of the map, touch the artwork and architecture, or climb up and slide down the mountain slopes. Now that the visitor has fully embraced the fourth dimension, they are granted the privilege of interacting with the exhibit previously kept at " $w$ " length from them.

As the visitor looks up and down in the $w$ direction from the newly explored exhibit, they see in the distance the four other cross-sections. Joining them together are new volumes that follow the same construction method of the added staircase. The visitor steps onto the new $\mathrm{xW}$ and $\mathrm{zW}$ planes they provide and begin their walk to the next cross-section (figure $3^{23}$ ). While traveling, the new walls reveal videos and images that depict elements of Andorra not previously explored. The journey to the country and its rich mountain vistas, the history that helped form Andorra as a nation, the people that live in the country and that visit it for its nature, shopping, and mountain activities, and the cultural events and festivals that are celebrated appear in the different divisions between the cross-sections (figure $3^{24}$ ). It is the journey through these areas that reveal the full definition of Andorra. See Appendix B: Animation 2, Appendix C: Animation 3, and Appendix D: Animation 4 for further explanation on the four-dimensional pavilion experience. 


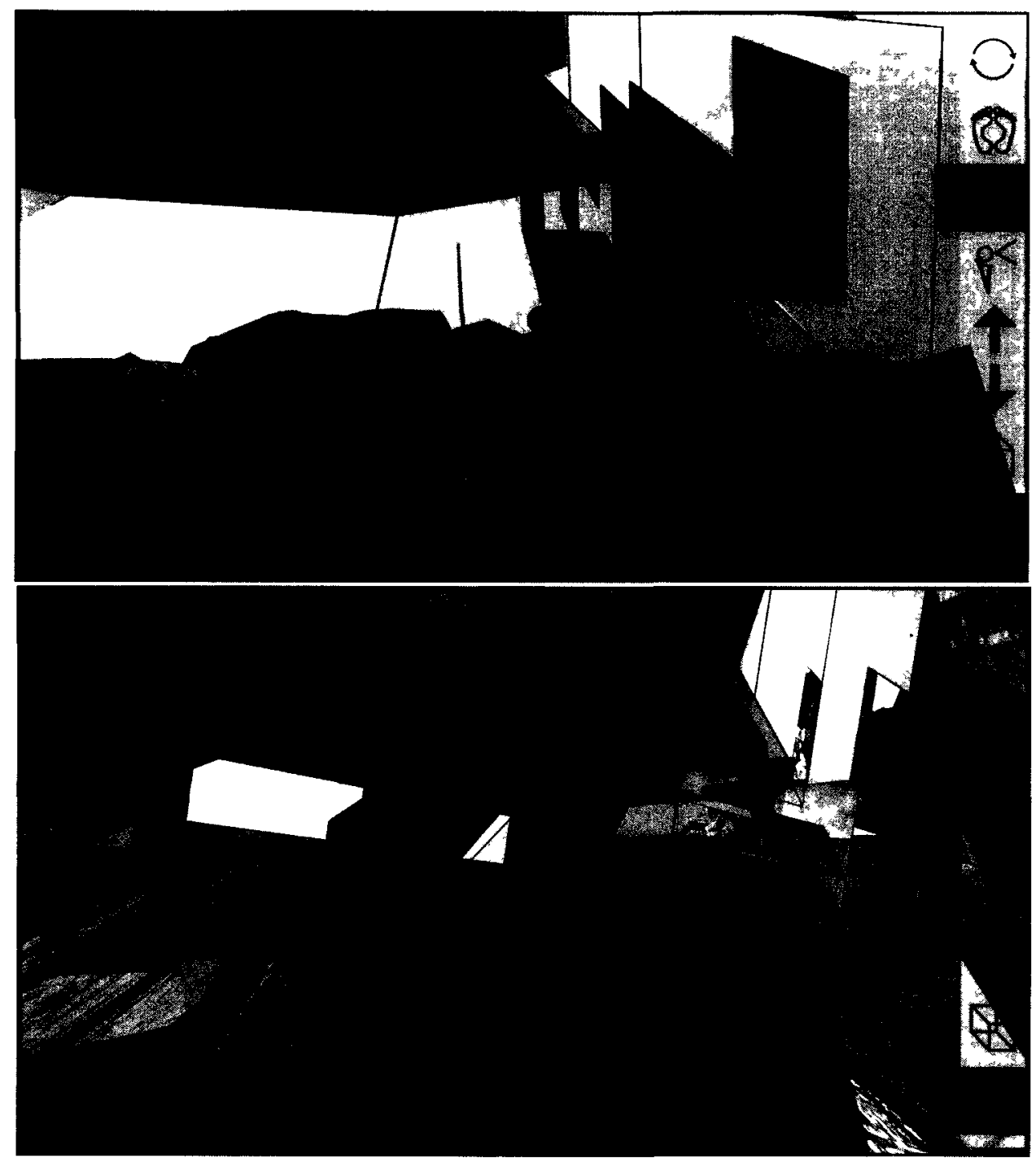

$3^{23}$ and $3^{24}$ Four-Dimensional Exhibit: Represented in the first image with the same colours as previously, the $x w, y w$, and zw planes join the three-dimensional cross-sections together and create exhibit space. The $x w$ and zw planes are walkable while the $y w$ plane is vertical exhibit space. As illustrated in the second image, videos and images of Andorra's culture, people, and landscape will be displayed on all three new planes.

\section{Reflection Back onto the Three Dimensional}

After the creation and exploration of the four-dimensional exhibit space, it becomes evident that this process needs to reflect back onto the three-dimensional pavilion. The fourdimensional exhibit and the three-dimensional pavilion space are divided by a stone wall. This wall segregates the two spaces and allows the three-dimensional physical space to be unaffected 
by the higher dimensional expansion; however, the wall itself should not be unaffected. Using the analogy of an explosion, the wall may protect the area beyond it from any disturbance, but it will do so by absorbing the blast. The stone wall will absorb the four-dimensional expansion's affects, revealing them to the three-dimensional pavilion space.

To have the wall altered by the four-dimensional expansion the wall is viewed in relation to the new four-dimensional pavilion space constructed of $x w, y w$, and $z w$ planes. The $z$ value is removed from the planes, allowing them to overlap with the wall since they are no longer separated by the $z$ value (figure $3^{25}$ ). The wall and planes are now seen as the three-dimensional space known as $x y w$. The $w$ value replaces the $z$ and acts as depth, allowing the planes to create protrusions into the walls $w$ value that are then translated to be equal to the walls $z$ value.

This creates distortions in the three-dimensional stone wall that reflect the four-dimensional expansion that occurs on the one side of it. While a visitor is in the three-dimensional pavilion, they are provided with a glimpse of the four-dimensional expansion through the protrusions in the wall, as shown in figure $3^{26}$. A glimpse of what is to come is revealed, causing anticipation in the visitor for the subsequent journey to the fourth dimension to rise.

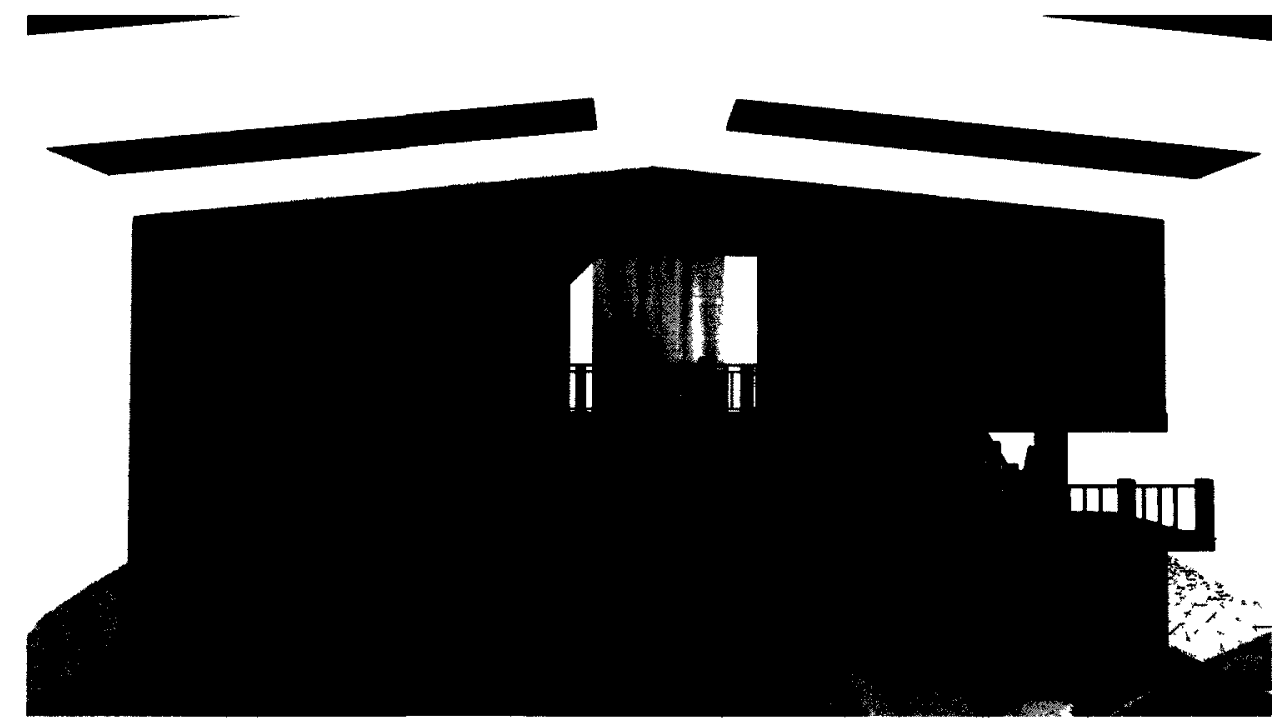

$3^{25}$ Projection of $4 D$ Onto Stone Wall: The four-dimensional exhibit space is projected back onto the stone wall. 


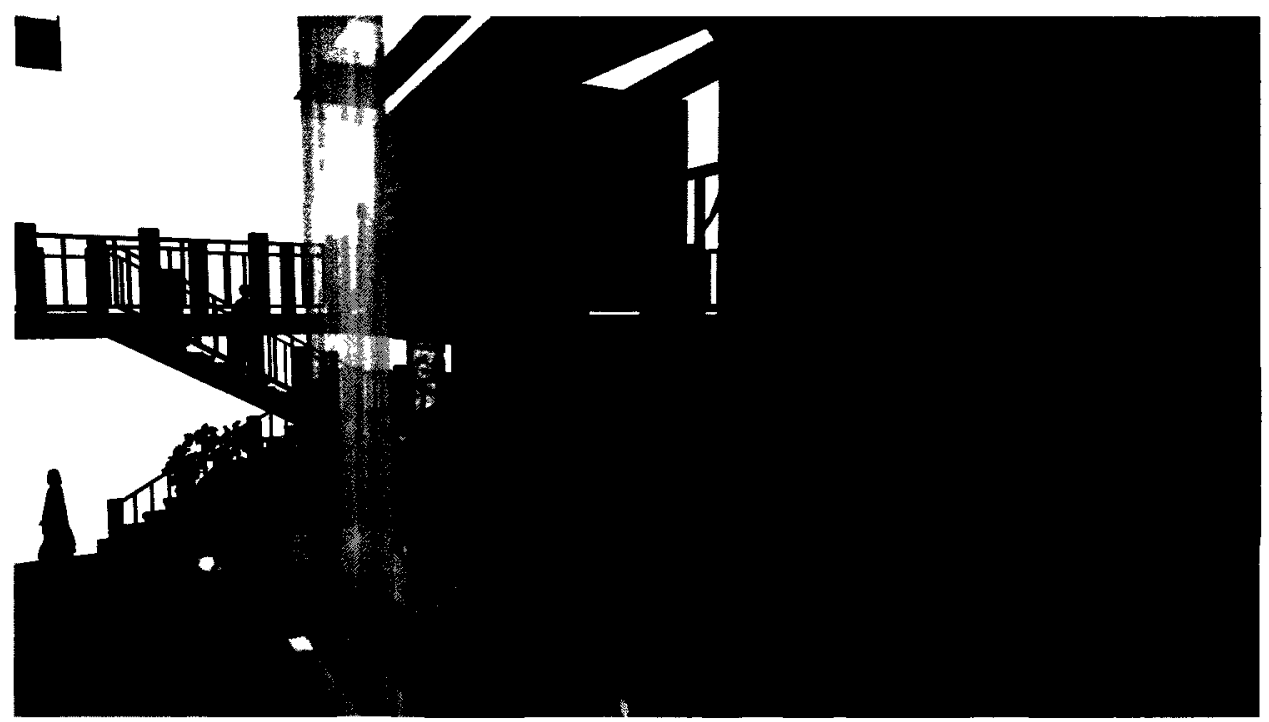

$3^{26}$ Stone Wall in Physical with 4D Influence: The stone wall shows evidence of the fourdimensional end result within the physical pavilion.

iv Trompe l'oeils, a French term meaning to "fool the eye", are successful ways to continue the architectural process above and beyond the built form and bring it into the virtual where a greater understanding of the work can be perceived. Trompe l'oeils were popular perspective paintings decorating $16^{\text {th }}$ and $17^{\text {th }}$ Century architecture, especially churches that pretended to extend real space into a new imaginary one. Their purpose was to create the illusion of impossible three-dimensional constructions, such as depictions of heaven, or surpass the limitations forced upon the building through monetary or space constraints. For example, a ceiling painted to appear taller or more elegantly decorated than it actually is. The Church of Sant'ignazio is a perfect example of how trompe l'oeils can be used to surpass the limitations the physical world forces upon architecture by expanding into a new physically impossible imaginary space.

$<$ Wheeler, Katherine. "Fictive and Real Architecture: a Preliminary Drawing for Andrea Pozzo's Vault Fresco at Sant'Ignazio, Rome." Thresholds. 2005 Winter, n.28, p100-106. Pg 100.> 


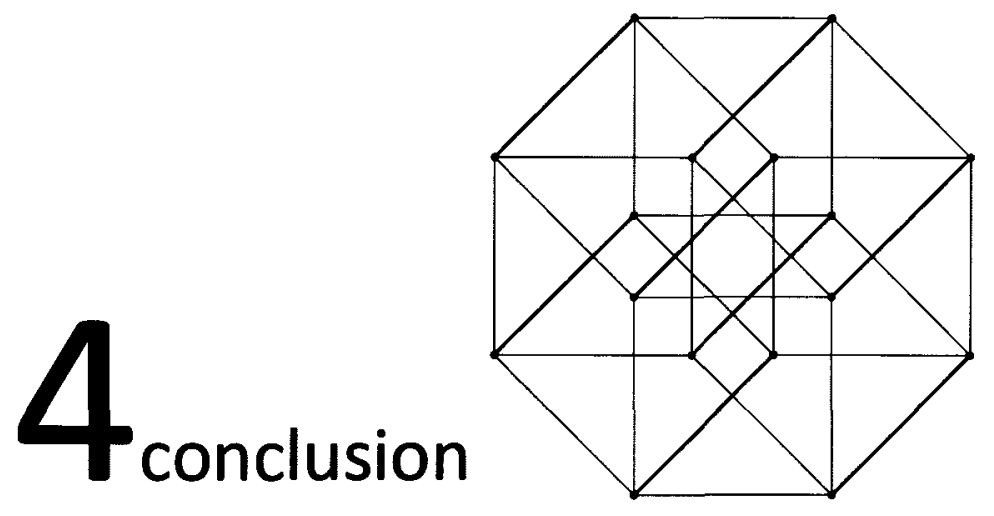

"There, before my ravished eye, a Cube, moving in some altogether new direction, but strictly according to Analogy, so as to make every particle of his interior pass through a new kind of Space, with a wake of its own - shall create a still more perfect perfection than himself, with sixteen terminal Extra-solid angles, and Eight solid Cubes for his Perimeter. And once there, shall we stay our upward course? In that blessed region of Four Dimensions, shall we linger on the threshold of the Fifth, and not enter therin? Ah, no! Let us rather resolve that our ambition shall soar with our corporal ascent. Then, yielding to our intellectual onset, the gates of the Sixth Dimension shall fly open; after that a Seventh, and then an Eighth -" $i$

The four-dimensional Andorran pavilion for Expo Shanghai Online begins with a threedimensional architecture that is then extended, selectively, into higher space. Similar to the game Super Paper Mario discussed in chapter one, not all elements expand into the fourth dimension. Some objects, for example Andorran artifacts, remain as lower dimensional objects, allowing a juxtaposition to occur between them and those identified as virtual representations of Andorra that do expand into higher space. The representation of Andorra remains anchored to the physical elements of the Andorran countryside, allowing the journey through the fourdimensional to be more accessible for an online visitor. . Those viewing the four-dimensional pavilion within the Andorran pavilion at the Expo 2010 Shanghai's site have the opportunity to see the contrast between the physical three-dimensional and the virtual four-dimensional spaces simultaneously.

To demonstrate the fourth dimension, several methods of higher dimensional representation are used in both the physical and virtual pavilion. The main exhibit of the Andorran virtual pavilion is first displayed as three-dimensional cross-sections, a method used to visualize the higher dimension by the Beckman Institute in chapter one. The four-dimensional 
page | 60

exhibit is sliced to reveal five three-dimensional cross-sections, each showing a moment of the overall higher dimensional space. The next method of four-dimensional representation presents the higher dimension through the four-dimensional grid and axis. Here, the area between the cross-sections is revealed. The higher dimension is shown through planes representing the new $x w, y w$, and $z w$ surfaces. Continuing the four-dimensional representation back onto the physical pavilion, the physical exhibit is a projection, where the five cross-sections are collapsed onto each other with the removal of the $w$ value. This is reminiscent of the discussion in chapter one about three-dimensional shadows and projections of four-dimensional objects. This was further demonstrated through the series of studies on four-dimensional spatial cognition conducted at the University of Illinois by the Beckman Institute.

While the translation of the third dimension into the fourth dimension is essential to developing this thesis, equally important is the representation of the fourth dimension in the lower dimensions. To achieve this, the four-dimensional exhibit space, comprised of the newly defined planes $x w, y w$, and $z w$, is projected back onto the stone wall that separates the fourdimensional exhibit and three-dimensional pavilion space. The wall projects and distorts as the higher dimensional space interacts with it. Within the three-dimensional pavilion, evidence of what is to come is shown through the permutations of the wall.

For the online visitor, the pavilion can be entered and explored through threedimensional cross-sections and the space can be expanded into the four-dimensional experience. Here, the visitor is able to see the exhibit in its entirety. The visitor can walk along the traditional $x z$ plane as well as the newly introduced $x w$ and $z w$ planes. By reducing the expansion into the fourth dimension to planes it allows for an easier comprehension of the newly identified surfaces. The diversity of four-dimensional representation and the navigation of the visitor through the virtual pavilion ensures that the overall impression of a journey is achieved. Once explored entirely, the visitor understands that the journey and seclusion of Andorra is central to the identity of the nation. Although people may travel or move to Andorra for a multitude of reasons, be it the shopping, winter sports, hiking, spa resorts, or its seclusion, they all share in a similar experience to reach the Andorran border. By traveling to a higher dimension within the virtual pavilion, the visitor's journey to the exhibit is analogous to a journey to Andorra. 
In conclusion, this thesis considers the platform of the Internet, and specifically Expo Shanghai Online, as a space for the exploration of a four-dimensional architecture $i$. A three and four-dimensional pavilion for the country of Andorra demonstrates how the physical can transform within the virtual when a dimensional expansion occurs. The Internet provides a space that is not limited by the laws of physics and can therefore do the impossible, such as expand to the fourth dimension. Although still viewed as a three-dimensional space, it is possible to imagine that the virtual pavilion could provide pa three-dimensional viewport into the fourth-dimension. This allows for the higher dimension to be both represented and occupied. An architecture that recognizes the fourth dimension is not limited to Expo Shanghai 2010. Increasingly, physical buildings are being duplicated online to provide a way for those from all areas of the world to visit them virtually. Museums, art galleries, and concert halls are just a few types of building that are becoming prominent as online destinations. For these spaces to be a mere duplication of a physical counterpart is doing them an injustice. With the removal of many real world limitations, an architecture of the fourth dimension has the opportunity to transcend our current understanding of inter-dimensional architecture.

Abbott, Edwin Abbott. Flatland, a Romance of Many Dimensions. New York: Penguin Books, 1998. Pg 105. 


\section{Bibliography}

Abbott, Edwin Abbott. Flatland, a Romance of Many Dimensions. New York: Penguin Books, 1998.

Ambinder, Michael S; Wang, Ranxiao Frances; et al. "Human four-dimensional spatial intuition in virtual reality." Psychonomic Bulletin \& Review. Vol. 16 No. 5, October 2009. Pg 818-823.

Collier, Basil. "Over the Pass: a Visit to the Co-Principality of the Valleys of Andorra ", Architectural Review. 1940, Aug., v.88, P 47-50.

Expo Shanghai Organizers. Expo 2010 Shanghai China. <http://en.expo2010.cn/> Unknown Date. Visited October 10, 2010.

Expo Shanghai Organizers. Expo Shanghai Online. <http://en.expo.cn/> Unknown Date. Visited October 22, 2010.

Expo Shanghai Organizers. World Exhibition Shanghai China 2010 Expo Shanghai Online: Guide For Development and Construction or the Experiencing Pavilion. Third Edition. Shanghai: August 2009.

Expo Shanghai Organizers. World Exhibition Shanghai China 2010 Participation Guide (For Official Participants). Shanghai: 2007.

Harvey, Penelope. Hybrids of Modernity: Anthropology, the Nation State and the Universal Exposition. [electronic resource]. London : Taylor \& Francis e-Library, 2003.

Henderson, Linda Dalrymple,. The Fourth Dimension and Non-Euclidean Geometry in Modern Art. Princeton, N.J.: Princeton University Press, 1983.

Innovatif. Shanghai Expo 2010: Slovenian Pavilion. <http://www.expo2010.si/en/> Unknown Date. Visited October $9,2010$.

Jackson, Anna. Expo: International Expositions 1851-2010. New York: V\&A Publishing, 2008.

Latvia Pavilion Organizers. Latvia Expo 2010. <http://www.latvijaexpo2010.Iv/en/> Unknown Date. Visited October 10, 2010.

Massicotte, Isabelle. The Architecture of Expo 67: National Identities and the Signs of Time. Ottawa: Carleton University, 2003.

Peter, Zellner. Hybrid Space: New Forms in Digital Architecture. New York: Rizzoli, 1999

Republic of Slovenia. Slovenia.si: Your Gatewat to Information on Slovenia. <www.slovenia.si/ spotlights/201007/201007211051467> Unknown Date. Visited October 9, 2010.

Schofield, A. T. (Alfred Taylor). Another World Or, the Fourth Dimension. Mt. View, Calif.: Boulder, Colo.: Wiretap: NetLibrary, [199-?].

Scobie, Alexander. Hitler's State Architecture; the Impact of Classical Antiquity. University Park: Pennsylvania State U., 1990.

Spanish Pavilion Organizers. Pabellón de Espana. <http://www.pabellonshanghai.es/en/> Unknown Date. Visited October 10, 2010. 


\section{Bibliography cont'd}

Thomas, Lucas M. "Looksley's Line Up Review: Could this be a glimpse at the 3D future of the DS?" IGN Entertainment Games. <http://ds.ign.com/articles/109/1091081p1.html> May 20, 2010. Visited July 24, 2010.

Union College, Department of Mathematics. "Hypercube Basics." Some Notes On The Fourth Dimension. Union College. <http://www.math.union.edu/ dpvc/math/4D/basics-new/n-cubes-sweep.html> Nov 16, 2008. Visited April 26, 2010.

Unknown Author. Andorra Country Review [electronic resource]. Houston: CountryWatch Incorporated, 2010.

Unknown Author. "Comoros Pavilion." World Expo 2010 Shanghai. <http://expo2010shanghai. com/?s=comoros $>$ September 3, 2010. Visited October 20, 2010.

Wang, Ranxiao Francis. "A Case Study on Human Learning of Four-Dimensional Objects in Virtual Reality: Passive Exploration and Display Techniques." 2009 International Conference on Frontier of Computer Science and Technology. December 17-19, 2009, p 519 - 523.

Wheeler, Katherine. "Fictive and Real Architecture: a Preliminary Drawing for Andrea Pozzo's Vault Fresco at Sant'Ignazio, Rome." Thresholds. 2005 Winter, n.28, p100-106.

Zhenghua, Wang. "Number of Participants at 2010 Expo hits record." China Daily. <http://www.chinadaily. com.cn/china/2010expo/2010-04/29/content_9789076.htm> April 29, 2010. Visited October 10, 2010.

Zhongxiang, Zhang. "African Joint Pavilion - Shanghai Expo: Not to be missed." Forum on China-Africa Cooperation. <http://www.focac.org/eng/zfgx/t696790.htm> May 25, 2010. Visited October 19, 2010. 


\section{Illustration Sources}

$1^{1}$ Union College, Department of Mathematics. Building Higher Dimensions. Online Image. "Hypercube Basics." Some Notes On The Fourth Dimension. < http://www.math.union.edu/ dpvc/math/4D/ basics-new/n-cubes-sweep.html>. Nov 16, 2008. Visited April 26, 2010.

$1^{2}$ Union College, Department of Mathematics. The Cubical Faces of a Hypercube. Online Image. "Hypercube Basics." Some Notes On The Fourth Dimension. <http://www.math.union.edu/ dpvc/ math/4D/basics-new/ hcube-faces.html> Nov 16, 2008. Visited April 26, 2010.

$1^{3}$ Abbott, Edwin Abbott. My View of Lineland. Flatland, a Romance of Many Dimensions. New York: Penguin Books, 1998. Pg 66.

$1^{4}$ Dir. Jean Painlevé. Stills from Film. La Quatrième Dimension. L'institut de Cinématographie. 1936.

$1^{5}$ Abbott, Edwin Abbott. Sphere Passing Through Flatland. Flatland, a Romance of Many Dimensions. New York: Penguin Books, 1998. Pg 86.

$1^{6}$ wiivideowalktrhough. Stills from video. "Super Paper Mario Walkthrough - World 5-2." YouTube. < http://www.youtube.com/watch?v=aJO_7b5Q8jg> November 22, 2007. Visited November 19, 2010.

1' rombroad. Stills from video. "Crush-Gameplay." YouTube. <http://www.youtube.com/ watch?v=mYumyD7XNik> February 19, 2007. Visited November 19, 2010.

$1^{8}$ SImplyNintendo. Stills from video. "Lookley's Line Up." YouTube. < http://www.youtube.com/watch?v=IE MkgVnzvdE\&feature=related> April 23,2010. Visited November 19, 2010.

$1^{9}$ Author Made. 3D to 4D Environment. Created using the Computer Modeling Software Autodesk Maya. April 5, 2010.

$1^{10}$ Peter, Zellner. Paracube. Hybrid Space: New Forms in Digital Architecture. New York: Rizzoli, 1999. Pg. 135.

$1^{11}$ Michael S. Ambinder, Ranxiao Frances Wang, et al. Supplementary Materials: video stills. "Human four-dimensional spatial intuition in virtual reality." Psychonomic Bulletin \& Review. Vol 16 No. 5, October 2009. Pg 818-823. <http://pbr.psychonomic-journals.org/content/16/5/818/suppl/DC1> Visited November 19, 2010.

$2^{1}$ Wagner, Stefan. Kongresshalle Reichsparteitagsgelande. Online Image. ww2museums.com. <http:// www.ww2museums.com/article/8348/Congress-Hall-Nazi-Party-Rally-Grounds.htm > No Date. Visited November 11, 2010.

$2^{2}$ Unknown Author. Colosseum. Online Image. Destination 360. No Date. Visited November 11, 2010.

$2^{3}$ Author Taken. Andorran Architecture. Taken in Ordino, Andorra. December 5, 2009. 


\section{Illustration Sources cont'd}

$2^{4}$ Meyer, Lutz. Esglesia Sant Miquel d'Engolasters, Andorra. Online Image. locr: locate vour photos. <http://www.locr.com/photo-andorra-escaldes-engordany-iberian-peninsula-carretera-d\%26\%23 039\%3Bengolasters-13955126> February 5, 2010. Visited November 11, 2010.

$2^{5}$ Unknown Authór. World Expo Shanghai Render. Online Image. World Expo 2010. <http:// worldexpotour2010.com/> No Date. Visited July 10, 2010.

$2^{6}$ Unknown Author. Expo Site Planning-8. Online Image. "Expo Site Planning." ChinaHotelsReservation. com. <http://www.chinahotelsreservation.com/World_Expo_2010_Shanghai_China/Expo_Site_ Planning.html> No Date. Visited July 10, 2010.

27 Latvian Pavilion Organizers. Latvian Pavilion Exterior. Online Image. "Latvia Pavilion." Expo 2010 Shanghai China. <http://en.expo2010.cn/c/en_gj_zgfc_low_tpl_49.htm?id=1> No Date. Visited October 18, 2010.

$2^{8}$ Latvian Pavilion Organizers. Latvian Pavilion Interior. Online Image. Latvia Expo 2010. <http://www. latvijaexpo2010.Iv/en/photos/?aid=9\&pid=6> June 5, 2010. Visited October 18, 2010.

$2^{9}$ Spain Pavilion Organizers. Spain Pavilion Exterior. Online Image. "Spain Pavilion." Expo 2010 Shanghai China. <http://en.expo2010.cn/c/en_gj_2gfc_low_tpl_74.htm?id=2> No Date. Visited October 18, 2010.

$2^{10}$ Spain Pavilion Organizers. Spain Pavilion Interior. Online Image. "Spain Pavilion." Expo 2010 Shanghai China. $<$ http://en.expo2010.cn/c/en_gj_zgfc_low_tpl_74.htm?id=2> No Date. Visited October 18, 2010.

$2^{11}$ Podrecca, B., JAPTI. Slovenian Pavilion. Online Image. Shanghai Expo 2010: Slovenian Pavilion. <http:// www.expo2010.si/en/ slovenian-pavilion/presentation-of-the-pavilion/> Unknown Date. Visited October 9, 2010.

$2^{12}$ Podrecca, B., JAPTI. Slovenian Pavilion - inside. Online Image. Shanghai Expo 2010: Slovenian Pavilion. <http://www.expo2010.si/en/ slovenian-pavilion/presentation-of-the-pavilion/> Unknown Date. Visited October 19, 2010.

$2^{13}$ Unknown Author. Africa Joint Pavilion. Online Image. "Comoros Pavilion." World Expo 2010 Shanghai. <http://expo2010shanghai.com/?s=comoros> September 3, 2010. Visited October 20, 2010.

$2^{14}$ Unknown Author. Comoros Pavilion (Shih - Pei Chang). Online Image. "Comoros Pavilion." World Expo 2010 Shanghai. <http://expo2010shanghai.com/?s=comoros> September 3, 2010. Visited October 20, 2010.

$2^{15}$ Expo Shanghai Organizers. Screenshot of Opening Page. Online Image. Expo Shanghai Online. <http:// en.expo.cn/> Unknown Date. Visited October 22, 2010.

$2^{16}$ Expo Shanghai Organizers. Screenshot of Zone C Site Tour View. Online Image. Expo Shanghai Online. <http://en.expo.cn/indexn.html> Unknown Date. Visited October 22, 2010. 


\section{Illustration Sources cont'd}

$2^{17}$ Expo Shanghai Organizers. Screenshot of Latvian Virtual Pavilion Interior. Online Image. "Latvian Browsing Pavilion." Expo Shanghai Online. <http://en.expo.cn/indexn.html> Unknown Date. Visited October 22, 2010.

$2^{18}$ Slovenian Virtual Pavilion Organizers. Screenshot of Slovenian Virtual Pavilion Map. Online Image. "Slovenian Experiencing Pavilion." Expo Shanghai Online. <http://en.expo.cn/indexn.html> Unknown Date. Visited October 22, 2010.

$2^{19}$ Slovenian Virtual Pavilion Organizers. Screenshot of Slovenian Virtual Pavilion Interior. Online Image. "Slovenian Experiencing Pavilion." Expo Shanghai Online. <http://en.expo.cn/indexn.html> Unknown Date. Visited October 22, 2010.

$2^{20}$ Spanish Virtual Pavilion Organizers. Screenshot of Spanish Virtual Pavilion Interior. Online Image. "Spain Experiencing Pavilion." Expo Shanghai Online. <http://en.expo.cn/indexn.html> Unknown Date. Visited October 22, 2010.

$2^{21}$ Spanish Virtual Pavilion Organizers. Screenshot of Spanish Virtual Pavilion Extended Space Entrance. Online Image. "Spain Experiencing Pavilion." Expo Shanghai Online. <http://en.expo.cn/indexn. html Unknown Date. Visited October 22, 2010.

$2^{22}$ Spanish Virtual Pavilion Organizers. Screenshot of Spanish Virtual Extended Space. Online Image. "Spain Experiencing Pavilion." Expo Shanghai Online. <http://en.expo.cn/indexn.html> Unknown Date. Visited October 22, 2010.

$3^{1}$ Author Made. Three Dimensional and Four Dimensional Grid. Ink and the Computer Modeling Software Autodesk Maya. November 22, 2010.

$3^{3}$ Author Made. Three Dimensional and Four Dimensional Axis Rotation. Created using the Computer Modeling Software Autodesk Maya. November 18, 2010.

$3^{3}$ Author Made. Unit Square, Cube, and Hypercube. Created using the Computer Modeling Software Autodesk Maya. November 18, 2010.

$3^{4}$ Author Made. Four-Dimensional Building Blocks. Created using the Computer Modeling Software Autodesk Maya. November 18, 2010.

$3^{5}$ Author Made. Andorran Pavilion Prototype. Created using the Computer Modeling Software Autodesk Maya. December 1, 2009.

$3^{6}$ Meyer, Lutz. Andorra City Views: Sant Julia de Loria, Andorra, Pyrenees. Online Image. flickr. <http:// www.flickr.com/photos/lutzmeyer/4528690004/> April 16, 2010. Visited November 27, 2010.

$3^{7}$ Meyer, Lutz. Old Houses in Andorra. Online Image. flickr. <http://www.flickr.com/photos/ lutzmeyer/4166285593/> June 28, 2008. Visited November 27, 2010. 


\section{Illustration Sources cont'd}

$3^{8}$ Author Made. Andorran Pavilion Shell. Created using the the Computer Modeling Software Autodesk Maya. October 20, 2010.

$3^{9}$ Author Made. Andorran Pavilion Site Map. Created using Adobe Photoshop. November 1, 2010.

$3^{10}$ Author Made. Andorran Pavilion Exterior. Created using the Computer Modeling Software Autodesk Maya and Adobe Photoshop. January 8, 2011.

$3^{11}$ Author Made. Andorran Pavilion Interior. Created using the Computer Modeling Software Autodesk Maya. December 8, 2010.

$3^{12}$ Author Made. Andorran Pavilion Interior. Created using the Computer Modeling Software Autodesk Maya. December 8, 2010.

$3^{13}$ Author Made. View of Main Exhibit From Main Balcony. Created using the Computer Modeling Software Autodesk Maya. December 8, 2010.

$3^{14}$ Author Made. Andorran Physical Pavilion Sections. Created using the Computer Modeling Software Autodesk Maya. November 24, 2010.

$3^{15}$ Author Made. Andorran Physical Pavilion Plans. Created using the Computer Modeling Software Autodesk Maya. December 13, 2010.

$3^{16}$ McAdam, Bruce. Sant'Ignazio. Online Image. Flickr. <http://www.www.flickr.com/photos/24049533@ NO0/3211754443> January 14, 2009. Visited November 24, 2010.

$3^{17}$ Author Made. Physical Pavilion Access to 4D Pavilion. Created using the Computer Modeling Software Autodesk Maya. January 8, 2011.

$3^{18}$ Author Made. Online Pavilion Interface. Created using Adobe Photoshop and the Computer Modeling Software Autodesk Maya. December 13, 2010.

$3^{19}$ Author Made. Two Dimensional Cross-Sections. Created using the Computer Modeling Software Google Sketchup. November 26, 2010.

$3^{20}$ Author Made. First Cross-Section From Main Balcony. Created using the Computer Modeling Software Autodesk Maya. December 8, 2010.

$3^{21}$ Author Made. Four Dimensional Colour Coded Grid. Created using the Computer Modeling Software Autodesk Maya. December 13, 2010.

$3^{22}$ Author Made. Four-Dimensional Staircase. Created using the Computer Modeling Software Autodesk Maya. December 10, 2010.

$3^{23}$ Author Made. Four Dimensional Exhibit. Created using the Computer Modeling Software Autodesk Maya. December 10, 2010. 


\section{page | 68}

$3^{24}$ Author Made. Four Dimensional Exhibit. Created using the Computer Modeling Software Autodesk Maya. December 10, 2010.

$3^{25}$ Author Made. Projection of $4 D$ Onto Stone Wall. Created using the Computer Modeling Software Autodesk Maya. January 11, 2011.

$3^{26}$ Author Made. Stone Wall in Physical with $4 D$ Influence. Created using the Computer Modeling Software Autodesk Maya. January 11, 2011. 


\section{Appendix A: Animation 1}

Animation 1, strongly influenced by the video game studies, examines how the three and fourdimensional can relate. The focus is on how three-dimensional space can be expanded into the fourth dimension to reveal unforeseen architectural elements. A figure has come to a dead end within a three-dimensional world. Once the scene is rotated to reveal a fourth-dimension, an opening appears and the figure is able to proceed. Animation can be seen at http://www.ktresearch-design.ca/masters-thesis. Storyboard can be read below.
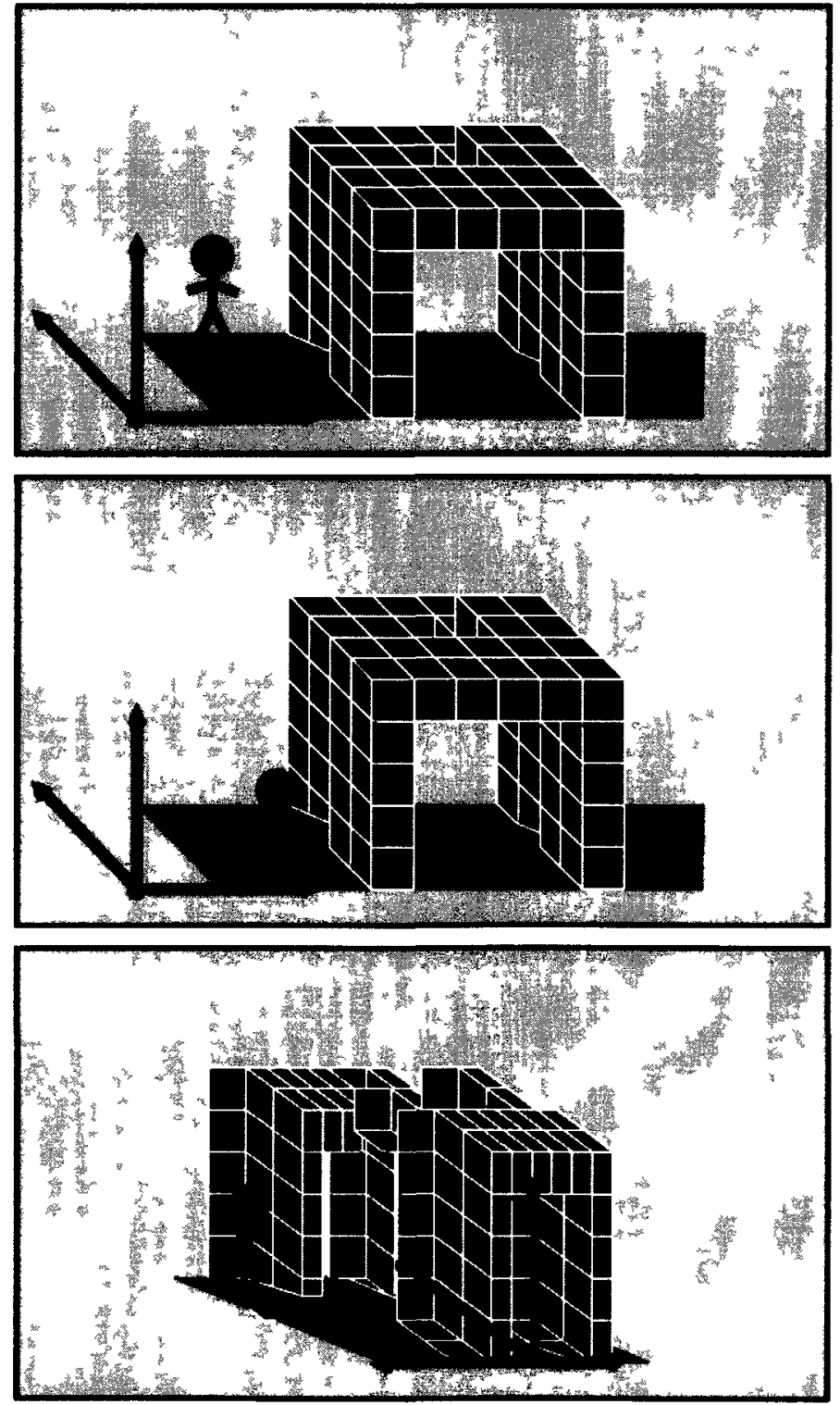

The scene opens to a figure standing next to a threedimensional structure that has no visible openings for him to pass through. At the bottom left corner is an axis that reveals a three dimensional axis.

The figure moves up, down and left, right but cannot find a way to continue forward. Within the three-dimensional scene, there is no possible continuation.

The scene rotates to reveal a fourth dimensional axis as well as fourth dimension to the scene. An opening appears within the now fourdimensional structure. 


\section{Appendix A: Animation 1 cont'd}
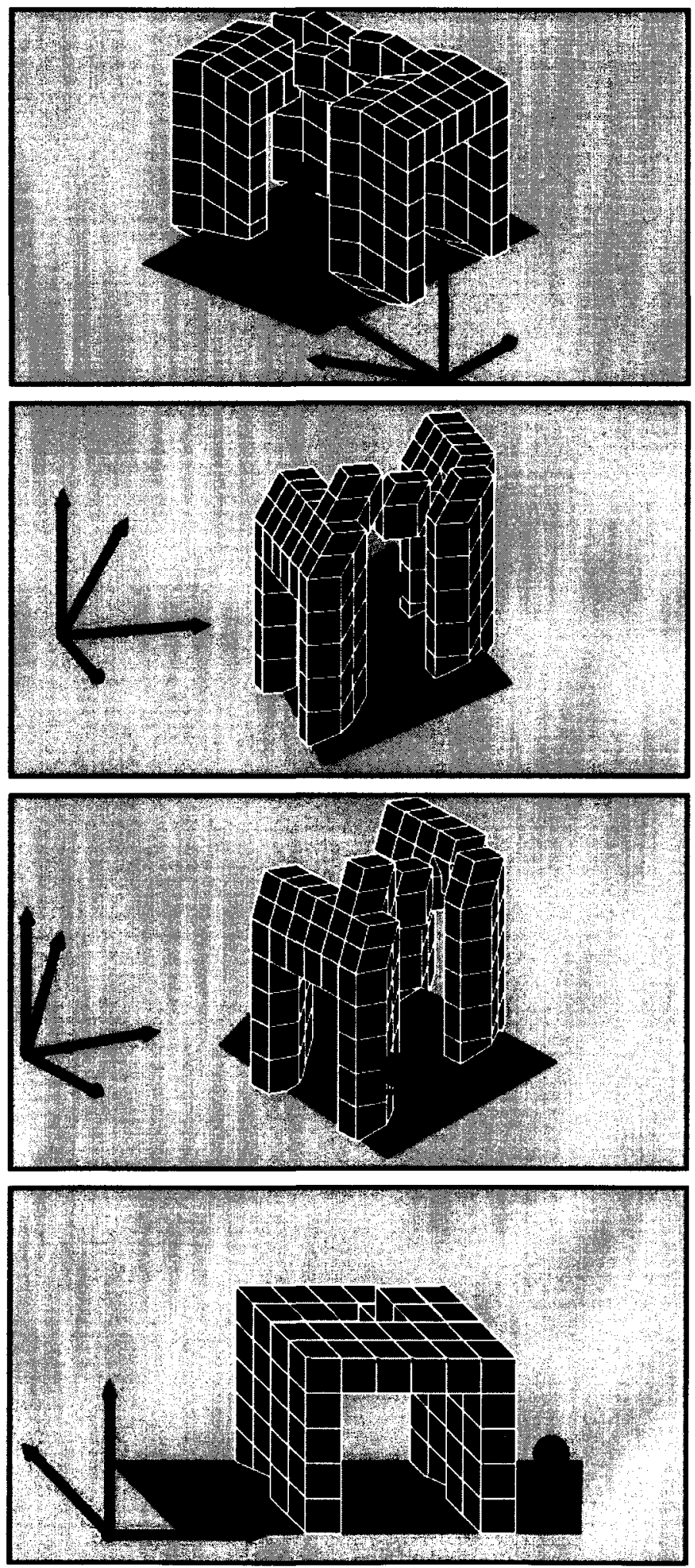

The figure moves through the four-dimensional opening.

The scene is rotated to allow for better visibility as the figure moves through the four -dimensional structure.

The figure has passed through the four-dimensional structure.

The scene is rotated back to hide the fourth dimension. The figure now stands at the other side of the threedimensional structure that could not be passed within this dimension. 


\section{Appendix B: Animation 2}

Animation 2 depicts the first narrative of the online pavilion. The focus is on the interface, control panel, and exploring the area of the virtual pavilion that is a duplication of the physical pavilion. On the left of the screen, the tool currently being used will be shown. On the right is the control panel with the active tools highlighted. Animation can be seen at http://www.ktresearch-design.ca/masters-thesis. Storyboard can be read below.

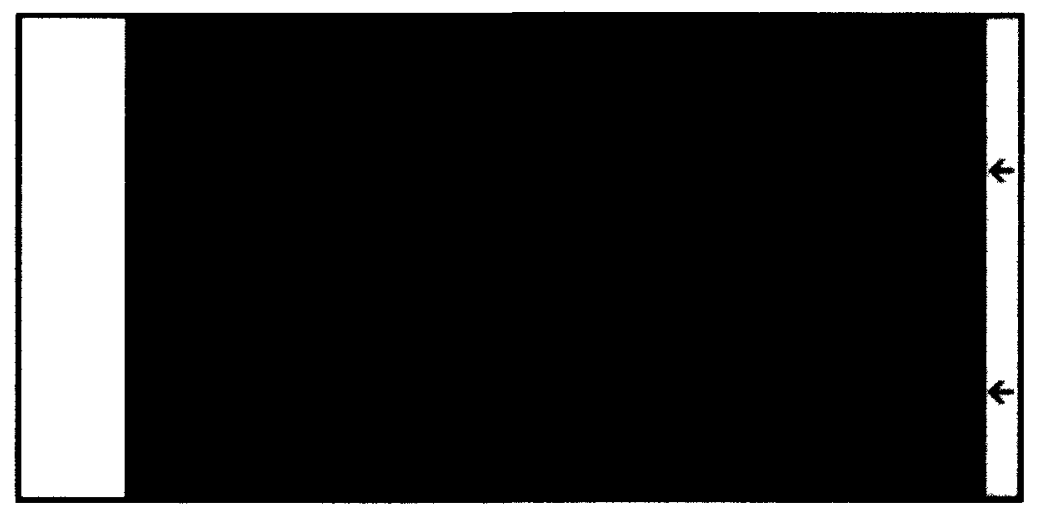

The scene opens to a third person view looking from the front door of the pavilion. This is where the online visitor will enter the virtual pavilion. Two commands are active, the third person and third dimension command. No command is in use.

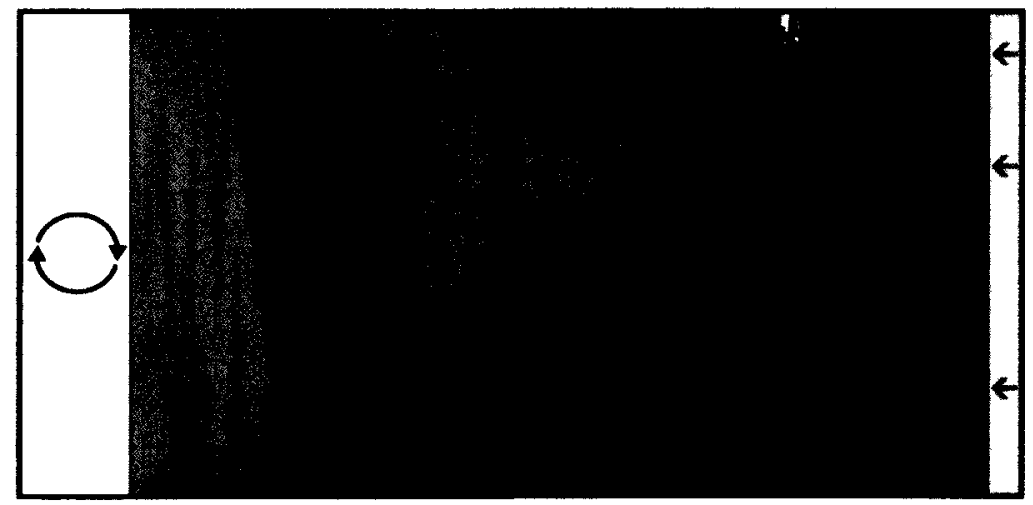

The orbit command becomes activated and is used to orbit the scene around the figure.

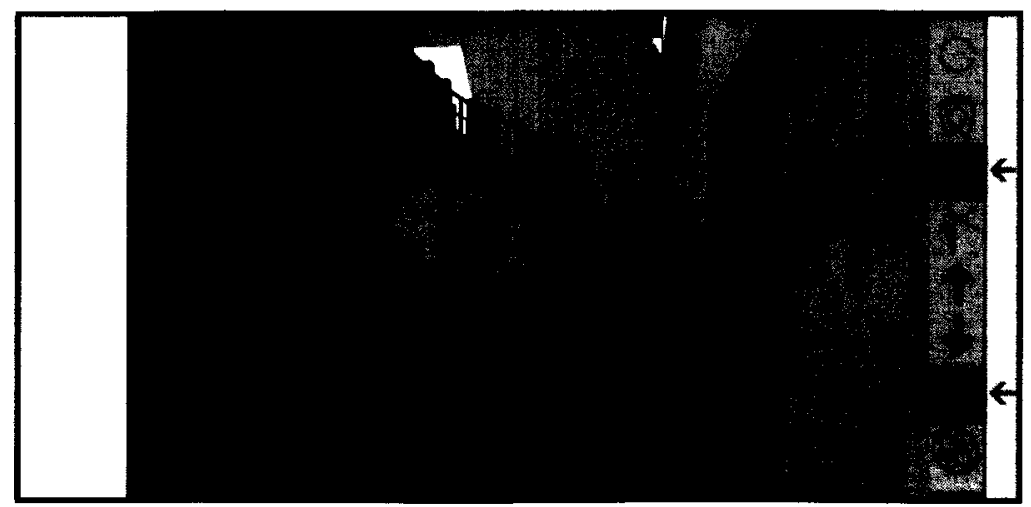

The orbit ends with the view positioned to see the staircase on the right of the figure. 


\section{Appendix B: Animation 2 cont'd}

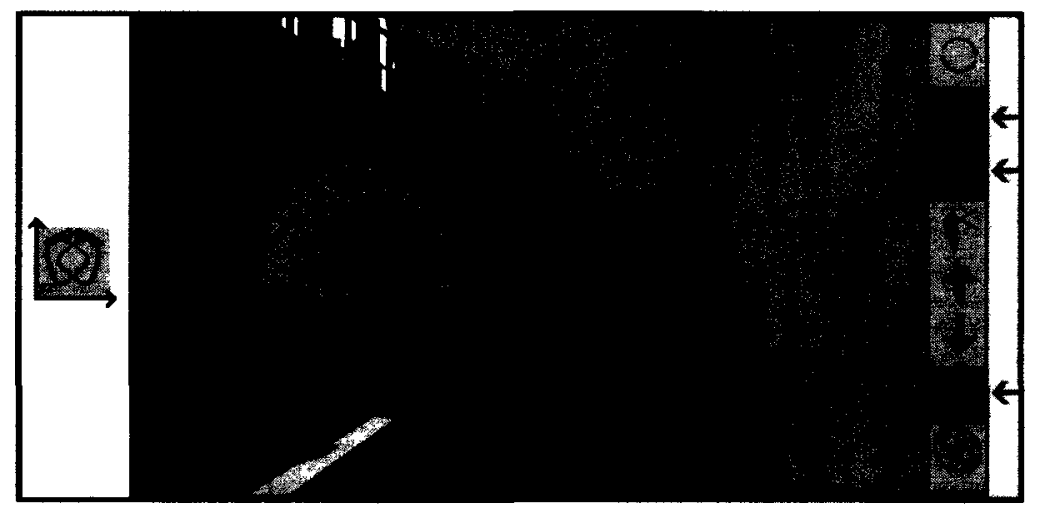

The walking command is activated and the figure walks up the staircase. On the left, the symbol for walking on the $x z$ plane is seen. Within the current three-dimensional view this is the only plane that can be walked on. Once the fourth dimension is introduced, two new walking planes exist.

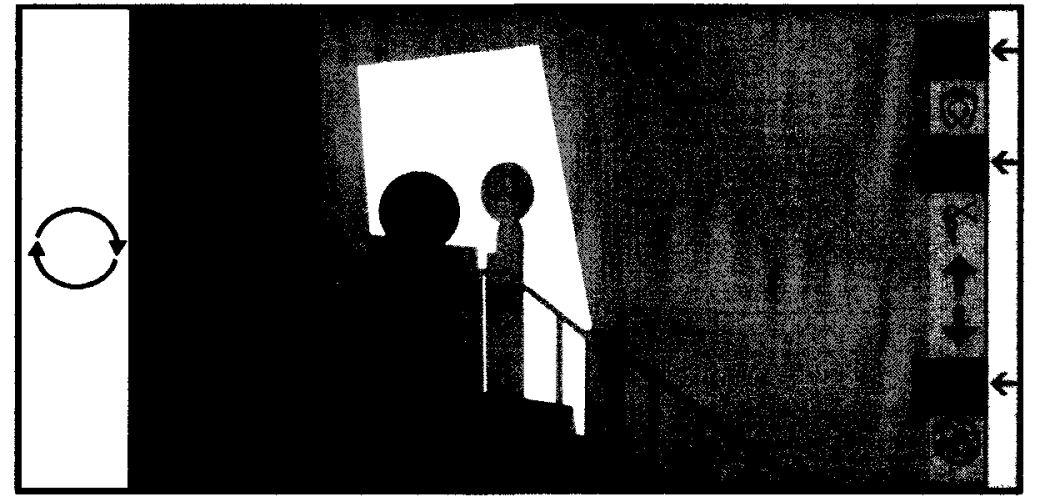

The figure stops at the top of the stairs and the orbit command is used to orbit around to have a better view of the second level.

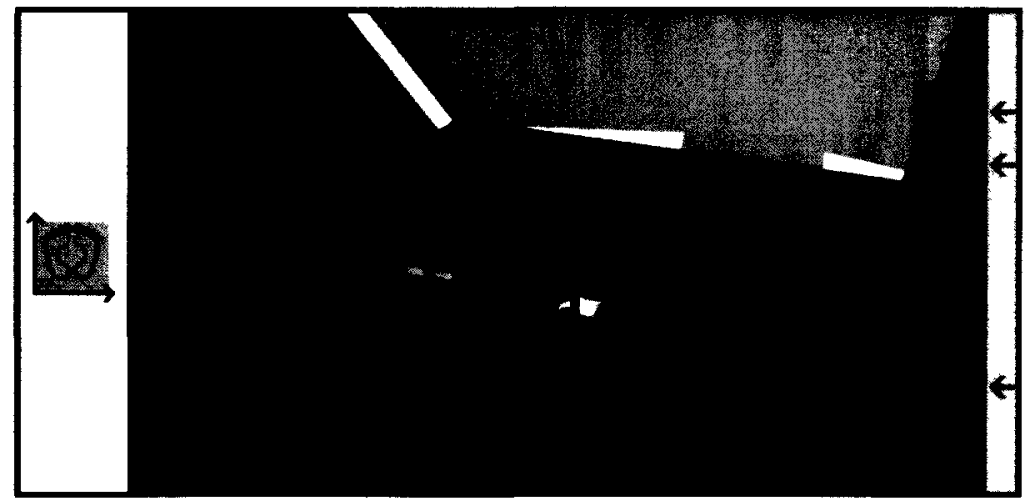

The figure walks along the second level and stops once they have arrived on the balcony that overlooks the main exhibit space, currently viewed as three-dimensional cross-sections of a greater four-dimensional exhibit.

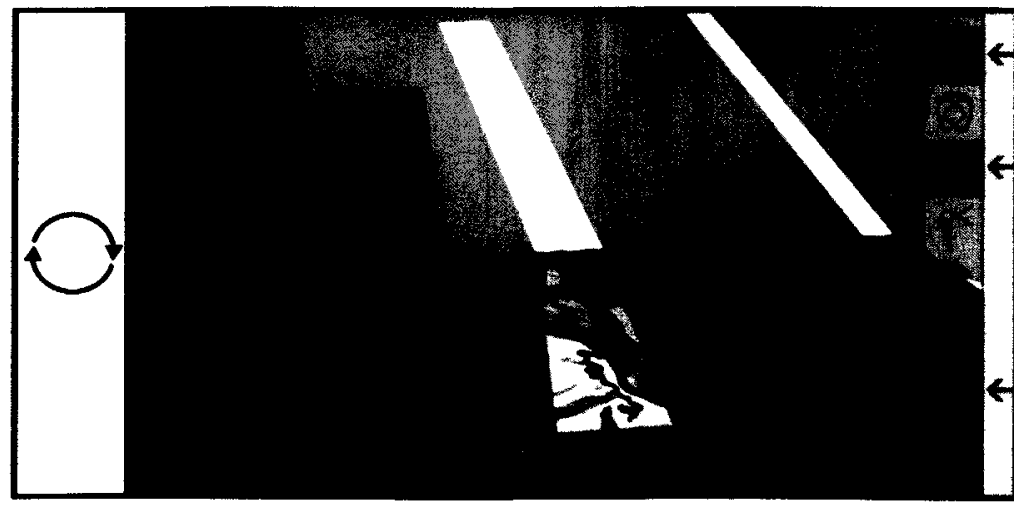

The scene is orbited and ends on a view from the side of the cross-section with the figure standing on the balcony above it. 


\section{Appendix C: Animation 3}

As a continuation from Animation 2, Animation 3 begins with where the previous scene left off. The viewer is taken through the many three-dimensional cross-sections once the next and previous cross-section commands are activated via the control panel on the online interface. Animation can be seen at http://www.kt-research-design.ca/masters-thesis. Storyboard can be read below.

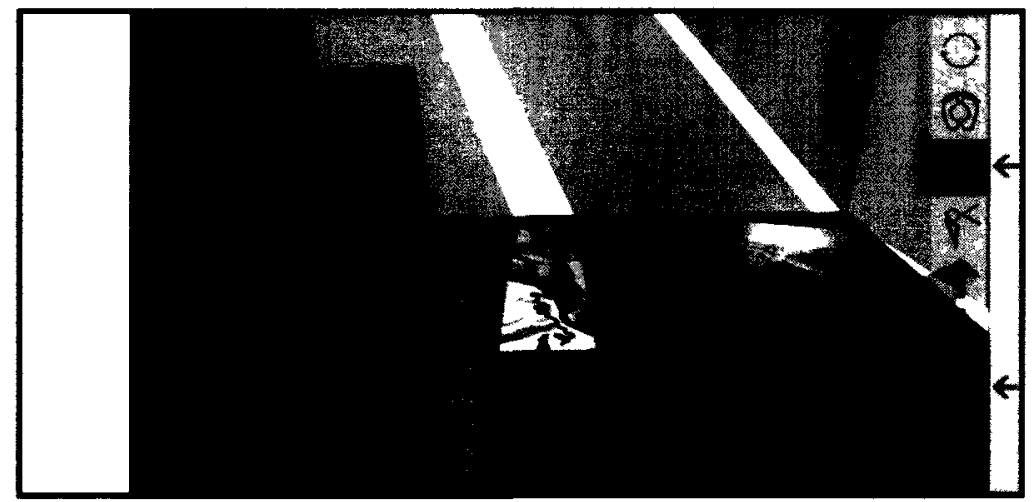

The first cross-section depicts the major roads of Andorra. A marker that can be moved or hidden by the online visitor shows an image of the view from a particular road. These images will help the visitor picture what it is like to travel within Andorra.

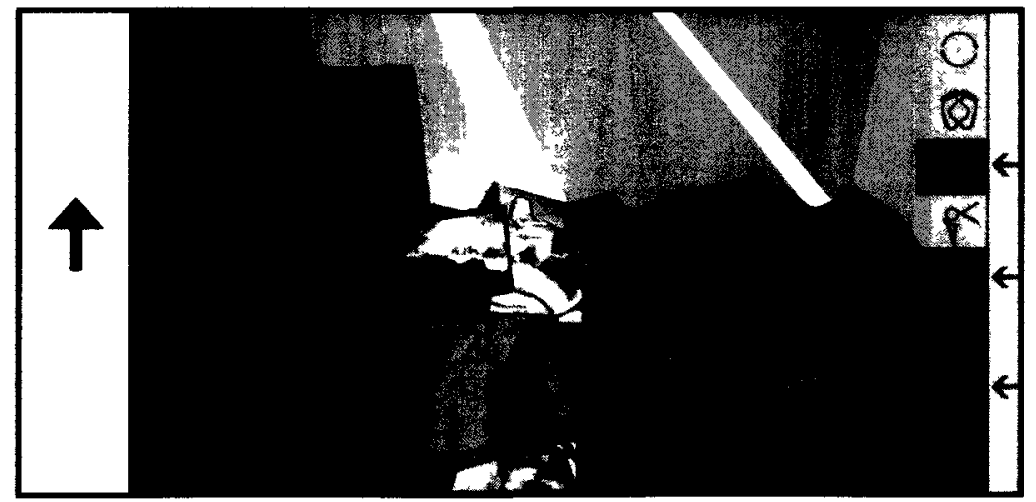

As indicated on the left hand side, the next cross-section command is activated, shifting the exhibit to reveal a new cross-section. Here, the once flat map has a medium relief and the prominent hiking trails and ski hills are shown.

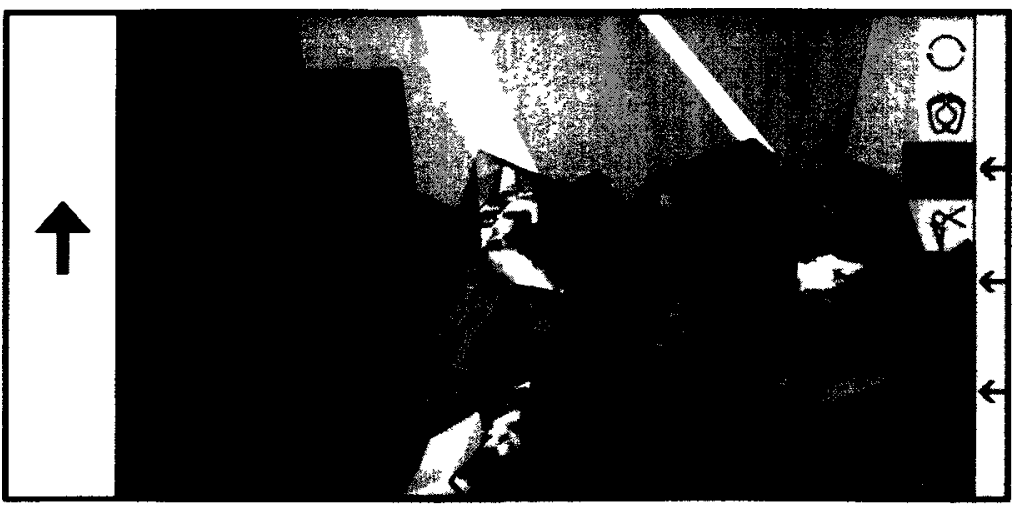

Once moving to the next cross-section, the relief of the map is increased and the major pieces of architecture within Andorra are identified. 


\section{Appendix C: Animation 3 cont'd}

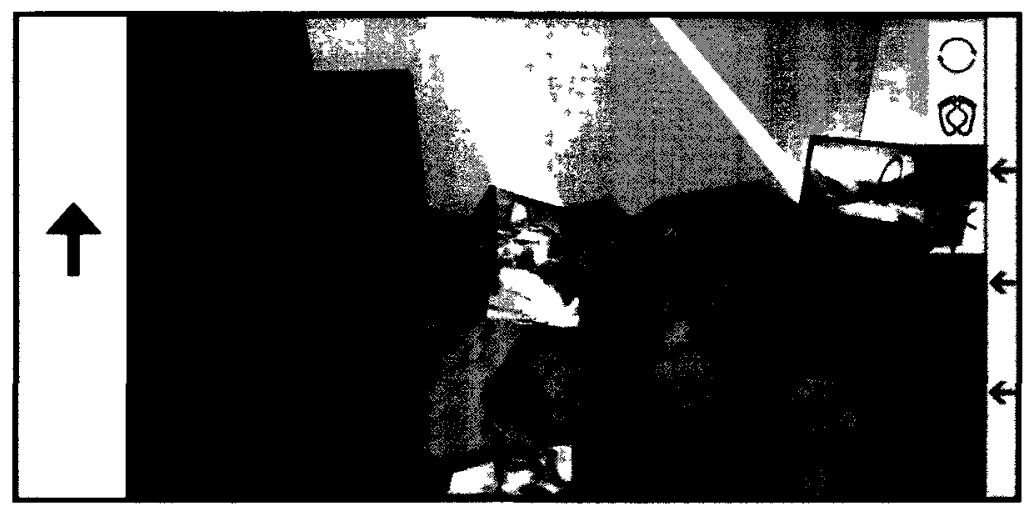

The fourth three-dimensional cross-section reveals a medium relief with the prominent Andorran art, such as sculptures, shown.

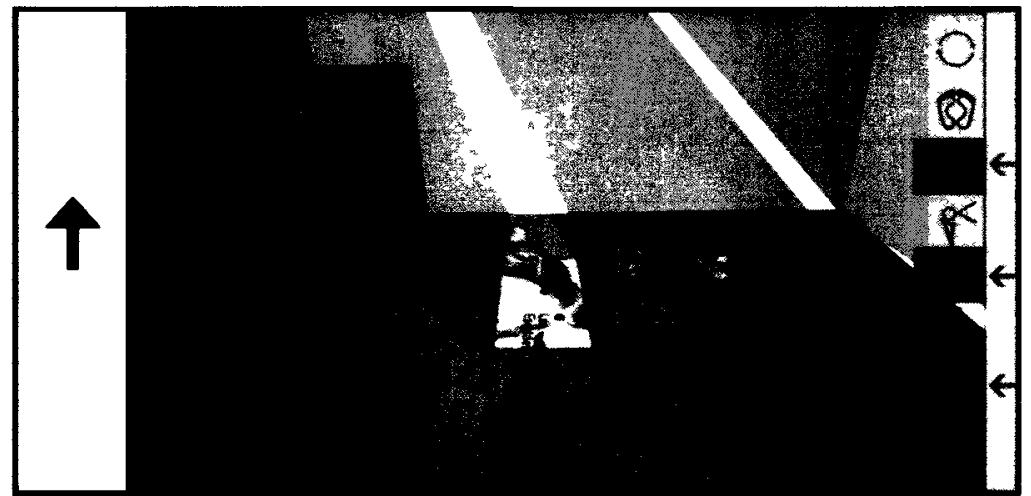

The fifth cross-section is a flat map once again with the major Andorran cities marked. At this point, the view cannot move forward to additional cross-sections but may move backwards.

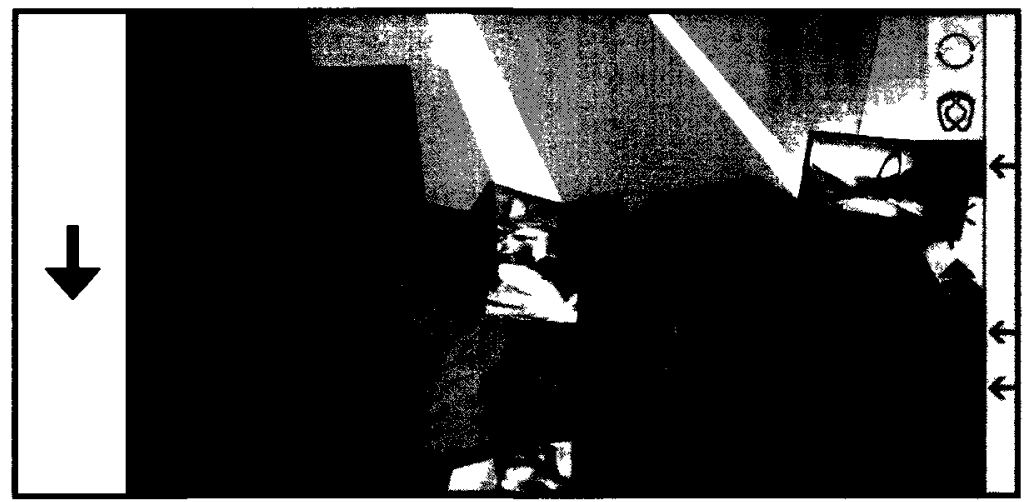

Using the previous crosssection command, the view moves backwards to view the fourth cross-section revealing the Andorran art.

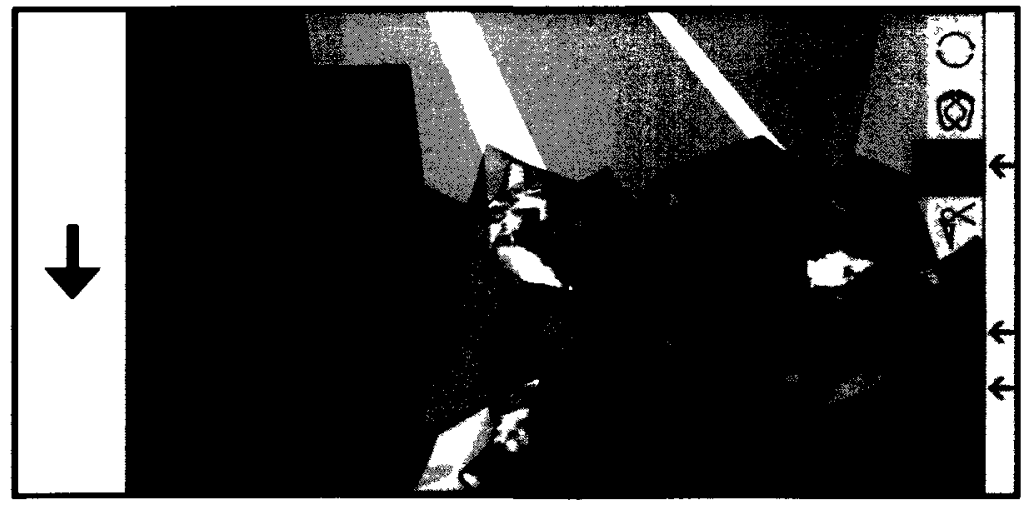

A final previous cross-section command is used to have the scene end on third crosssection. Here, the greatest map relief is viewed with the prominent Andorran architecture displayed. 


\section{Appendix D: Animation 4}

The final animation, Animation 4, continues from the third. Here, the fourth dimension function on the online interface's control panel is activated to reveal the four-dimensional exhibit space. The figure is able to walk down a newly discovered four-dimensional staircase and explore the new exhibit space not visible in the lower dimension or the three-dimensional cross-sections. Animation can be seen at http://www.kt-research-design.ca/masters-thesis. Storyboard can be read below.

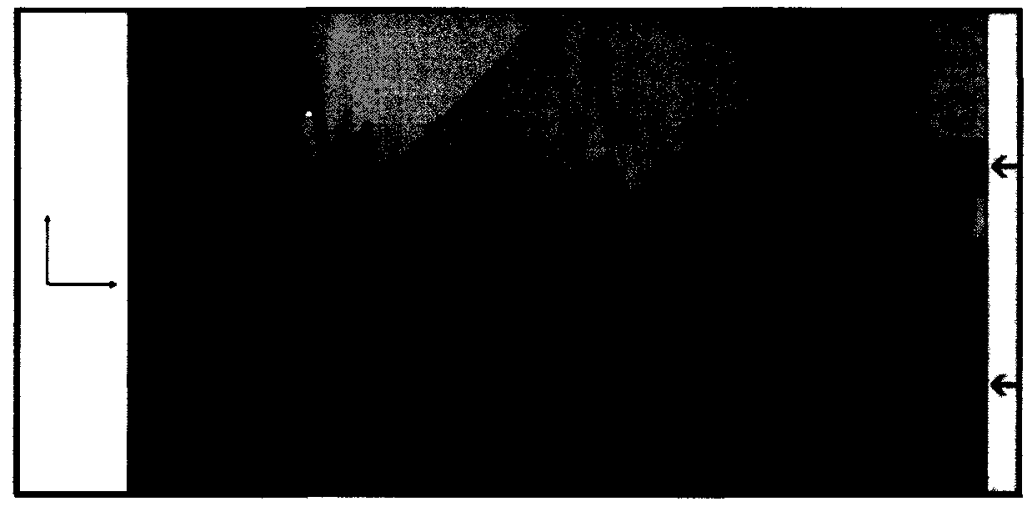

The scene opens to the same view that animation 3 occurred at. On the left, an axis can now be seen that shows a three -dimensional view.

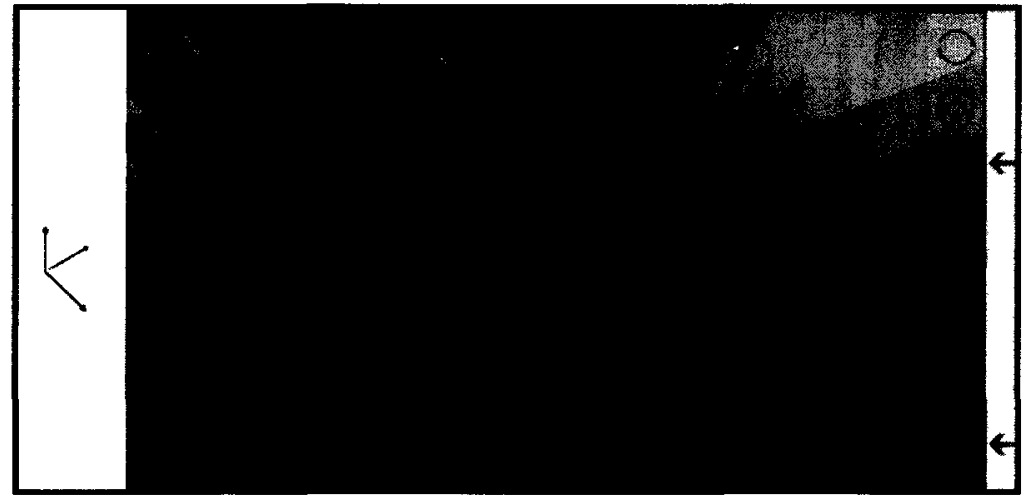

The four-dimensional function on the control panel is activated and, as seen within the axis on the left, the scene is expanded into the fourth dimension. The scene rotates to frame the balcony where the figure stands and staircase comprised of the newly added four-dimensional planes appears beside the balcony.

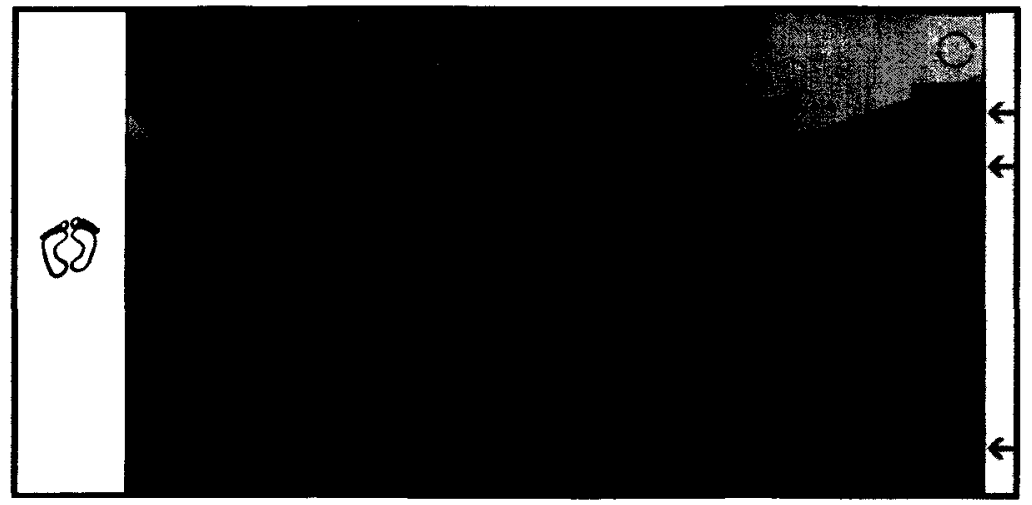

The figure walks onto the staircase. As they move onto the first plane, indicated in yellow, a new walking symbol appears on the left. The figure is walking on the newly introduced $z w$ plane. 


\section{Appendix D: Animation 4 cont'd}

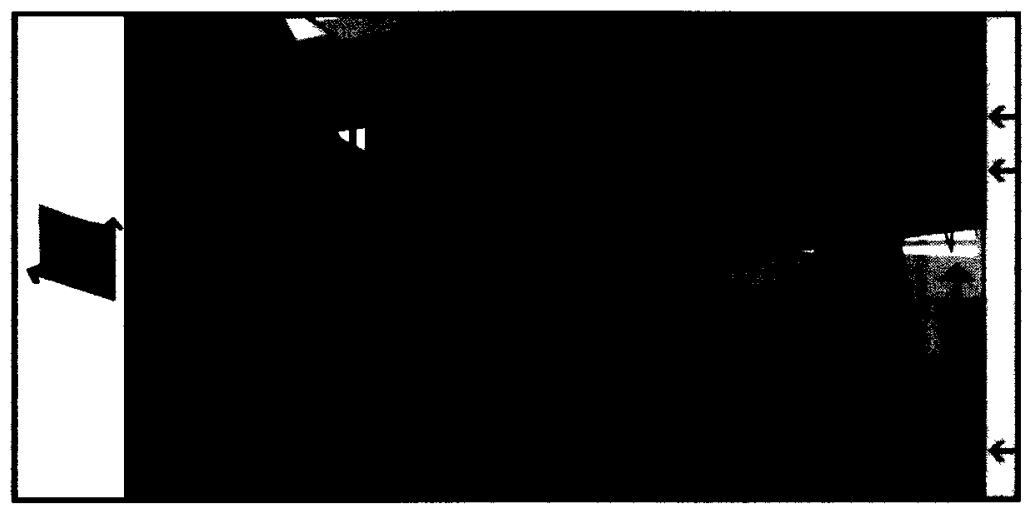

The figure continues down the stairs and as they rotate the figure begins walking on the $x w$ plane indicated in red. The yw plane, shown in green, is not a walkable plane.

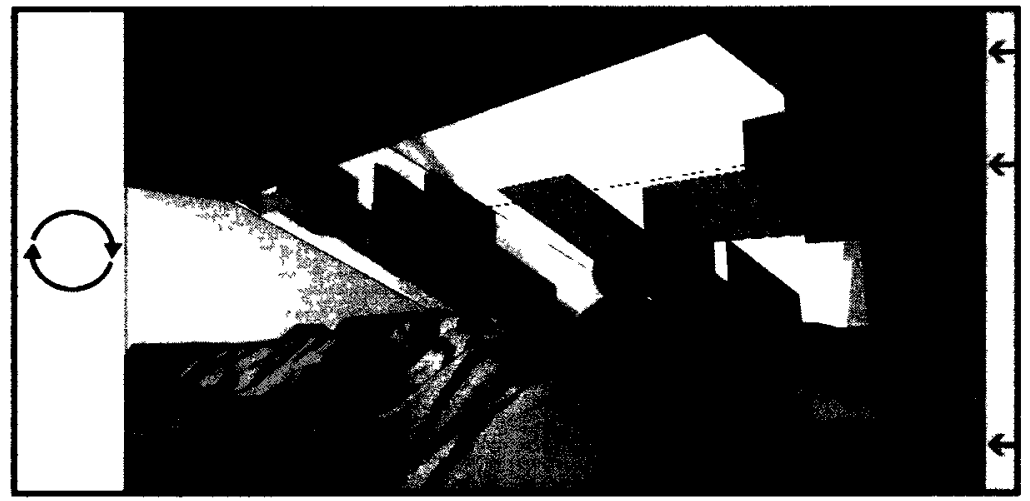

Once the figure is on the exhibit floor, a feet not possible until the four-dimensional staircase appeared, the orbit command is used to position the camera to reveal the four-dimensional exhibit space seen in the distance.

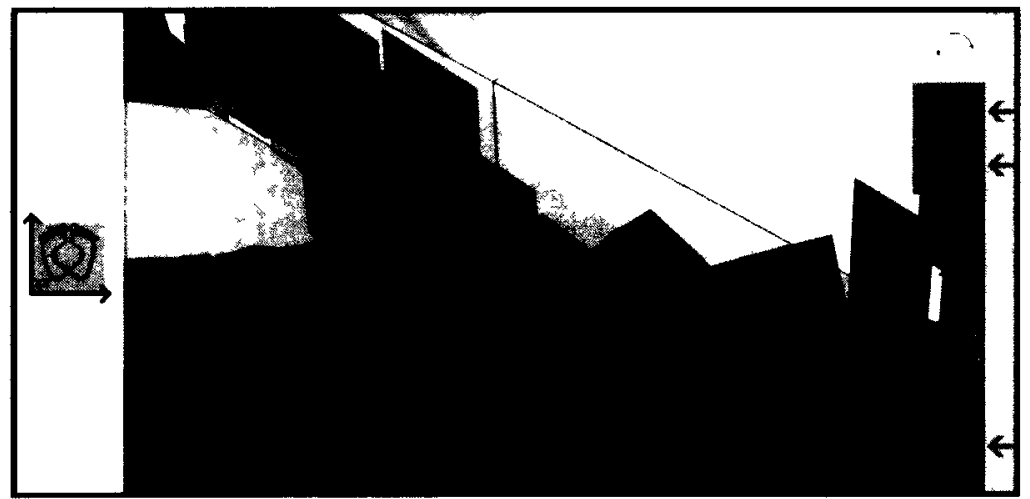

The figure walks along the exhibit floor towards the new exhibit space. The exhibit spaces divides the five crosssections.

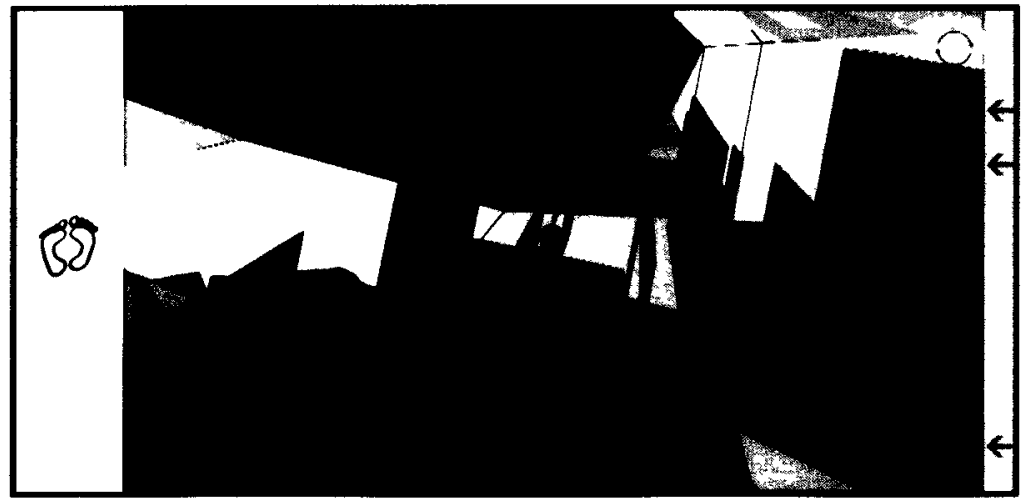

The figure walks up the exhibit space towards the next crosssection, changing between the $x w$ and $z w$ planes. The $y w$ plane is vertical exhibit space. 


\section{Appendix D: Animation 4 cont'd}

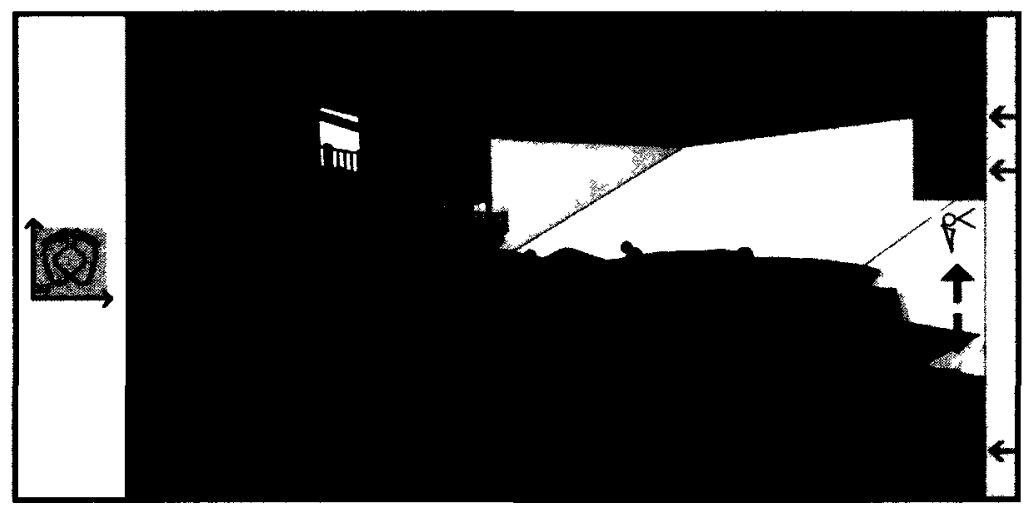

Once reached the next crosssection, the figure walks along the $x z$ exhibit space towards the four-dimensional stairs off of the three-dimensional balcony.

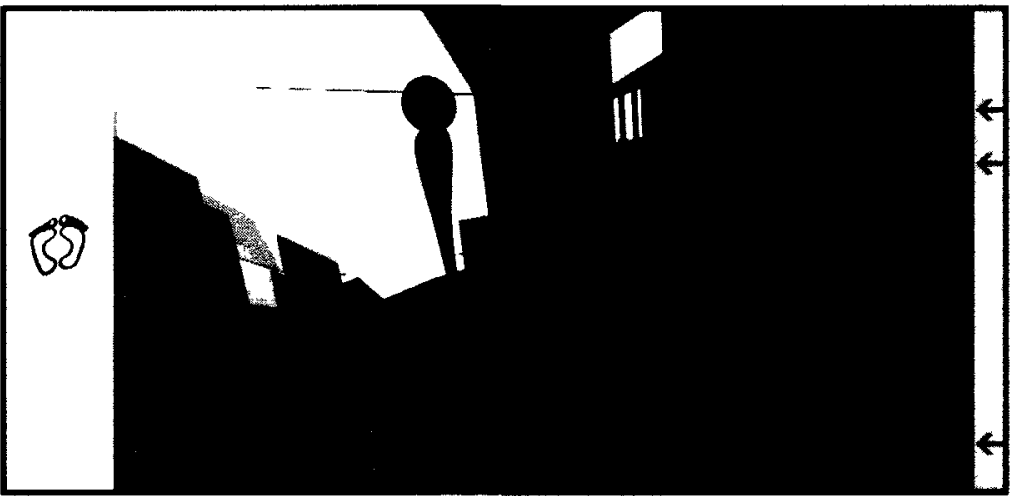

The figure walks up the staircase, changing between the $x w$ and $z w$ planes.

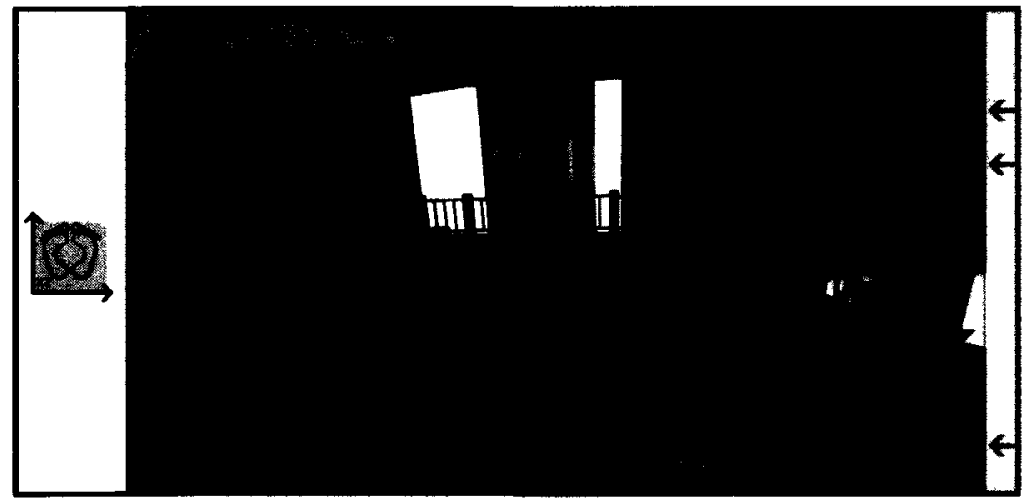

The figure moves to position themselves on the centre of the balcony.

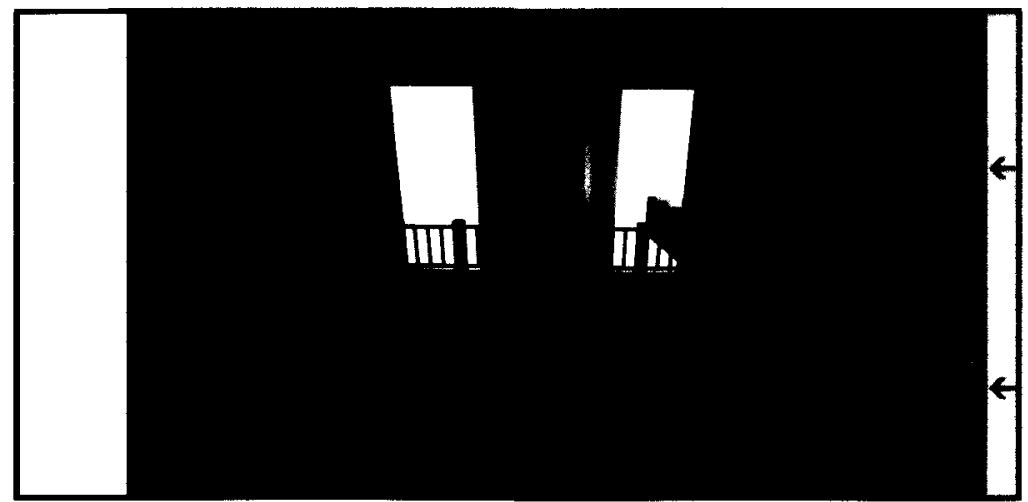

The scene transitions back to the three-dimensional and the four-dimensional staircase and exhibit space disappears. 